\title{
Operating charts for continuous sedimentation II: step responses
}

\author{
STEFAN DIEHL \\ Centre for Mathematical Sciences, Lund University, P.O. Box 118, SE-221 00 Lund, Sweden (e-mail: \\ diehl@maths.lth.se)
}

\begin{abstract}
The process of continuous sedimentation of particles in a liquid has often been predicted by means of operating charts and mass-balance considerations, where the underlying constitutive assumption is the one by Kynch. Much more complex operating charts (concentration-flux diagrams) can be obtained from a onedimensional model of an ideal continuous clarifier-thickener unit. The engineering concept of 'optimal operation' is defined generally as a special type of solution of the model equation, which is a conservation law with a source term and a space-discontinuous flux function. All qualitatively different step responses (with the unit initially in optimal operation in steady state) are presented and classified in terms of operating charts. Quantitative information relating several interesting variables are also presented concerning, for example, the time until overflow occurs as a function of the feed concentration and flux.
\end{abstract}

Keywords: operating charts, continuous sedimentation, step response, settling, thickener

Received $x x x x x$

\section{Introduction}

Continuous sedimentation is an industrial process of separating solid particles from a liquid under the influence of gravity. It is performed in a clarifier-thickener unit (or thickener, secondary clarifier, settler etc.) under a continuous inflow of a mixture at an intermediate height. Under normal and optimal operating conditions the effluent at the top is clear liquid and the underflow at the bottom has a high concentration of solids. There is an urgent need for mathematical models because of the difficulties in predicting and controlling the non-linear process. Even a one-dimensional model with a fairly simple constitutive assumption shows a non-linear behaviour with discontinuities in the concentration profile. As in the first paper in this series, [1], we consider such an 'ideal clarifier-thickener unit'. The mixture is assumed to be 'ideal' if it obeys the Kynch [2] constitutive assumption, in which the flux of particles depends only on the local concentration. This is the basis of the 'solids-flux theory', related to graphical constructions, operating charts, operating points, optimal operation etc., which has been obtained by mass balances under different assumptions. Several references within the engineering literature relating to these concepts are given in [1]. Most of these deal only with the thickening zone (below the feed inlet) and steady-state situations. The modelling when the clarification zone (above the feed level) is also taken into account were addressed in [3-10].

Kynch's assumption fails to take into account the compressible behaviour that many real suspensions show. In particular this applies for the flocculent materials in secondary settlers in wastewater treatment plants. Nonetheless, the solids-flux theory is still used today with some success, see e.g. [11-16]. All consequences of Kynch's assumption are not yet examined. In [1], it was shown that the notion of operating chart is useful for giving an overview of all possible steady-state solutions of the partial differential equation that arise from the model. Most of the operating charts we refer to are concentration-flux diagrams in which the location of the feed point (input concentration and flux) yields qualitative and quantitative information 
of the process. In the present paper all possible qualitatively different step responses are constructed and classified by means of operating charts. The concept of optimal operation is defined for a general dynamic solution.

The Kynch assumption combined with conservation of mass yields a hyperbolic partial differential equation (conservation law), which was solved by the method of characteristics in the 1950's. Constructions by the method of characteristics of solutions describing sedimentation in the thickening zone (below the feed level) or in batch mode (sedimentation in a closed vessel) can be found in [17, Ch. 8.5], [18], [19, Ch. 6.7], [20-23]. The problem of giving a satisfactory treatment of the behaviour around the inlet and outlets, respectively, was not solved until the 1990's, see [24-27]. A different approach with a smoothed source term was presented by Chancelier et al. [28-30]. These difficulties partly explain all the different approaches that have been presented in the engineering literature during the last century to describe the non-linear process. The construction of solutions for the whole clarifier-thickener unit, see [26], makes it possible to provide answers to many issues raised in the engineering literature. In [26], existence and uniqueness of solutions were established only locally in time in the class of piecewise differentiable functions and with some further assumptions on piecewise monotonicity. It is only lately that global existence and uniqueness have been established by Bürger et al. [31, 32] and Karlsen and Towers [33]. In [31], the front-tracking method was utilized and approximate solutions were constructed as in [26]. Global existence was then established by proving convergence of the numerical front-tracking method. In [32], a well-posed entropy solution framework was established and uniqueness was shown. Existence of an entropy solution was proved with the aim of an upwind finite difference scheme of Engquist-Osher type. These results have been established for a constant source term and constant volume flows, which is the case of the step responses considered in the present paper. The general case when the source term and volume flows are allowed to vary with time, also discontinuously, is contained in [33]. They used the Lax-Friedrich finite difference scheme and a Kružkov-type notion of entropy solution to prove existence and uniqueness, respectively. Some further recent references on the modelling and simulation of the entire clarificationthickening process (with varying theoretical support) are [34-42]. In particular, the important contribution by Bürger et al. [42], which relies on the analyses by Karlsen et al. [43, 44], contains a generalization of the previous results for the hyperbolic equation to the case when also compression at high concentrations is modelled, which leads to a hyperbolic-parabolic partial differential equation.

When modelling a physical process mathematically there are several aspects to consider. Existence and uniqueness of solutions are of course the fundamental factors for well-posedness. Another issue is stability: the solution chosen by the criterion for uniqueness should be the natural and relevant one. In other words, a discontinuity chosen by the uniqueness condition should be stable under small disturbances (a small diffusion term is added to the equation), see [45, 46] and [42, Section 4.3]. Based on analytical solutions, reliable numerical algorithms can be obtained, see [31, 38, 39, 41, 47]. Although simulation programs using such numerical methods are of great value, they may not be sufficient if the process is non-linear and difficult to control, which is the case for continuous sedimentation. Sufficient conditions for maintaining the process in optimal operation involve information on the present concentration distribution, the values of the input variables and the control variable. To obtain such conditions, one must chart the dynamic behaviour. The overall aim of the present series of articles is to give a deeper knowledge of the process for all possible input data and to demonstrate how the process can be controlled. 
Section 2 contains the problem formulation and notation used for constructing global solutions. In the previous paper [1], reviewed in Section 3.1, all qualitatively different steadystate solutions and several relations between the different variables were presented by means of operating charts. In Section 3.2, the concept of optimal operation is defined generally. Section 4.1 contains the main operating chart for step responses when the settler is in optimal operation in steady state initially. Analytical solutions and numerical simulations of the different step responses can be found in Sections 4.2-4.10. By means of these constructed solutions, quantitative information is presented in several operating charts in Section 4.11.

Of the few experiments with step responses reported in the literature, those by Maljian and Howell [48] are particularly interesting with respect to the present paper. We comment upon these experiments briefly in the Conclusions.

\section{A model of continuous sedimentation}

The one-dimensional model was introduced in [26]. The notation necessary for describing the steady-state solutions was given in the previous paper [1]. Here we review the full notation for constructing global dynamic solutions.

\subsection{THE CLARIFIER-THICKENER UNIT}

Continuous sedimentation of solid particles in a liquid takes place in a clarifier-thickener unit or settler, see Figure 1 (left). Let $u(x, t)$ denote the concentration (mass per unit volume) at depth $x$ and time $t$. The height of the clarification zone is denoted by $H$ and the depth of the thickening zone by $D$. At $x=0$ the settler is fed with suspended solids at a known concentration $u_{\mathrm{f}}(t)$ and at a known constant flow rate $Q_{\mathrm{f}}>0$ (volume per unit time). A high concentration of solids is removed at the underflow, at $x=D$, at a flow rate $Q_{\mathrm{u}}$. This is the control variable that has the natural restriction $0<Q_{\mathrm{u}} \leq Q_{\mathrm{f}}$. The effluent flow $Q_{\mathrm{e}}$, at $x=-H$, is consequently defined by the flow condition $Q_{\mathrm{e}}=Q_{\mathrm{f}}-Q_{\mathrm{u}} \geq 0$. The crosssectional area $A$ of the settler is assumed to be constant and the concentration $u$ is assumed to be constant on each cross-section. The effluent and underflow concentrations, $u_{\mathrm{e}}(t)$ and $u_{\mathrm{u}}(t)$, are unknown. We define the bulk velocities in the thickening and clarification zone as

$$
q_{\mathrm{u}}=\frac{Q_{\mathrm{u}}}{A}, \quad q_{\mathrm{e}}=\frac{Q_{\mathrm{e}}}{A},
$$

respectively, hence $q_{\mathrm{e}}$ is positive upwards. The volume flow $Q_{\mathrm{u}}$ is the control variable of the process, and we assume that this flow can be adjusted by a pump.

\subsection{KYNCH'S ASSUMPTION AND CHARACTERISTIC CONCENTRATIONS}

According to the constitutive assumption by Kynch [2] the settling velocity of the solids due to gravity in a batch-settling column is a function of the local concentration only; $v_{\text {settl }}(u)$. The maximum packing concentration is denoted by $u_{\max }$. The batch settling flux (mass per unit time and unit area) is denoted by $f_{\mathrm{b}}(u)=v_{\text {settl }}(u) u$ and is assumed to satisfy

$$
\begin{array}{ll}
f_{\mathrm{b}} \in C^{2}\left[0, u_{\max }\right], & f_{\mathrm{b}}(u)>0, \quad 0<u<u_{\max }, \\
f_{\mathrm{b}}(0)=f_{\mathrm{b}}\left(u_{\max }\right)=0, & f_{\mathrm{b}} \text { has an inflection point } u_{\text {infl }} \in\left(0, u_{\max }\right), \\
f_{\mathrm{b}}^{\prime \prime}(u)<0, \quad u \in\left(0, u_{\text {infl }}\right), & f_{\mathrm{b}}^{\prime \prime}(u)>0, \quad u \in\left(u_{\text {infl }}, u_{\max }\right) .
\end{array}
$$



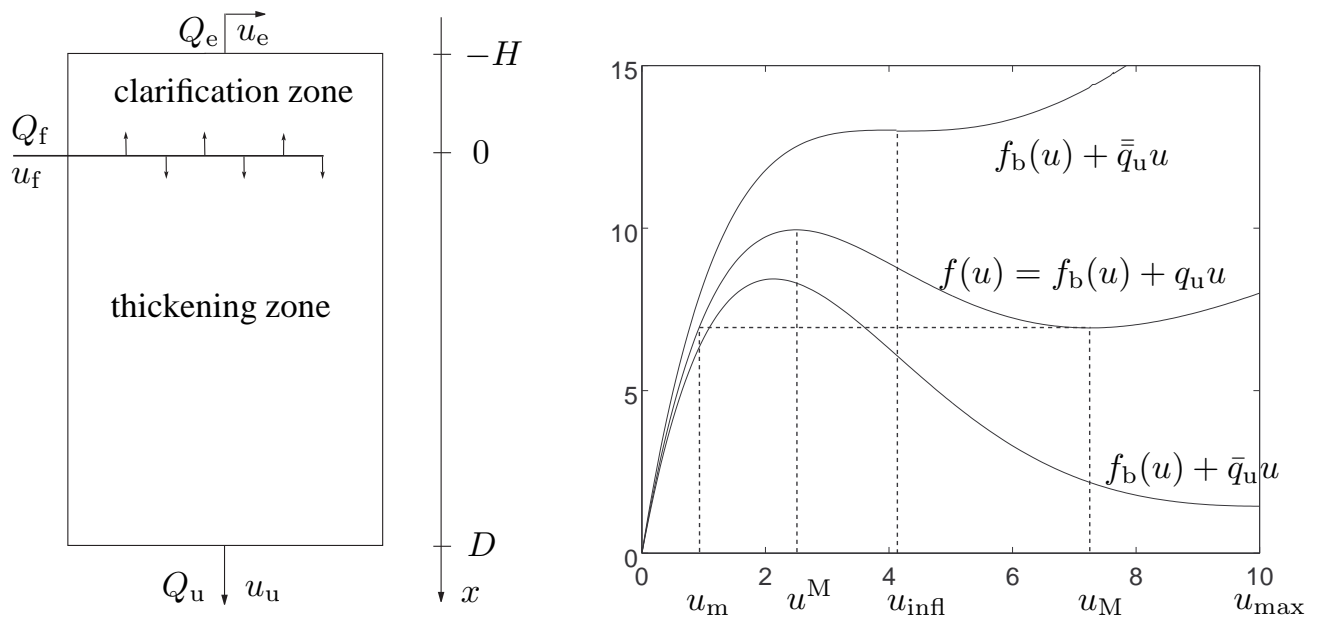

Figure 1. Left: Schematic picture of an ideal one-dimensional clarifier-thickener unit. Right: Flux curves and characteristic concentrations. The batch-settling flux used for the numerical simulations in this paper is $f_{\mathrm{b}}(u)=10 u\left(\left(1-0.64 u / u_{\max }\right)^{6.55}-0.36^{6.55}\right)\left[\mathrm{kg} /\left(\mathrm{m}^{2} \mathrm{~h}\right)\right]$.

In continuous sedimentation the volume flows $Q_{\mathrm{u}}$ and $Q_{\mathrm{e}}$ give rise to the flux terms $q_{\mathrm{u}} u$ and $-q_{\mathrm{e}} u$, respectively, which are superimposed on the batch settling flux to yield

$$
\begin{aligned}
& g(u)=f_{\mathrm{b}}(u)-q_{\mathrm{e}} u, \quad-H<x<0, \\
& f(u)=f_{\mathrm{b}}(u)+q_{\mathrm{u}} u, \quad 0<x<D .
\end{aligned}
$$

The form of the batch settling flux function $f_{\mathrm{b}}$ and the two volume flows $Q_{\mathrm{u}}$ and $Q_{\mathrm{e}}$ imply that there are particular characteristic concentrations that appear in the solutions. Let $u_{\mathrm{z}}>0$ be the unique (cf. Lemma 2.2) positive zero of $g$, i.e., $g\left(u_{z}\right)=0$. (If $g(u)<0$ for all $u>0$, we define $u_{\mathrm{z}}=0$. This corresponds to an extreme case, which is probably not of interest in this application.) Define

$$
\begin{array}{ll}
\bar{q}_{\mathrm{u}}=-f_{\mathrm{b}}^{\prime}\left(u_{\max }\right), & \bar{Q}_{\mathrm{u}}=\bar{q}_{\mathrm{u}} A, \\
\overline{\bar{q}}_{\mathrm{u}}=-f_{\mathrm{b}}^{\prime}\left(u_{\mathrm{infl}}\right), & \overline{\bar{Q}}_{\mathrm{u}}=\overline{\bar{q}}_{\mathrm{u}} A,
\end{array}
$$

which are the bulk velocities such that the slope of $f$ is zero at $u_{\max }$ and $u_{\text {infl }}$, respectively, see Figure 1 (right). The local minimizer, denoted $u_{\mathrm{M}}$, on the right of $u_{\text {infl }}$ plays an important role in the behaviour of the process. For intermediate values of $q_{\mathrm{u}}$, i.e., $\bar{q}_{\mathrm{u}}<q_{\mathrm{u}}<\overline{\bar{q}}_{\mathrm{u}}$, we have $0=f^{\prime}\left(u_{\mathrm{M}}\right)=f_{\mathrm{b}}^{\prime}\left(u_{\mathrm{M}}\right)+q_{\mathrm{u}}$. To obtain a definition for all values of $q_{\mathrm{u}}$ we define the restriction $\tilde{f}_{\mathrm{b}}=\left.f_{\mathrm{b}}\right|_{\left(u_{\text {inf }}, u_{\max }\right)}$. Then $\tilde{f}_{\mathrm{b}}^{\prime}$ is increasing and we define

$$
u_{\mathrm{M}}= \begin{cases}u_{\max }, & 0 \leq q_{\mathrm{u}} \leq \bar{q}_{\mathrm{u}}, \\ \left(\tilde{f}_{\mathrm{b}}^{\prime}\right)^{-1}\left(-q_{\mathrm{u}}\right), & \bar{q}_{\mathrm{u}}<q_{\mathrm{u}}<\overline{\bar{q}}_{\mathrm{u}}, \\ u_{\mathrm{infl}}, & q_{\mathrm{u}} \geq \overline{\bar{q}}_{\mathrm{u}} .\end{cases}
$$

Given $u_{\mathrm{M}}$ we define $u_{\mathrm{m}}$ as the unique concentration satisfying

$$
f\left(u_{\mathrm{m}}\right)=f\left(u_{\mathrm{M}}\right), \quad 0 \leq u_{\mathrm{m}} \leq u_{\mathrm{infl}} .
$$


The concentration of the local maximum of the flux function $f(u)$ is denoted by $u^{\mathrm{M}}$. It depends on $Q_{\mathrm{u}}$ and is well defined for $0 \leq Q_{\mathrm{u}}<\overline{\bar{Q}}_{\mathrm{u}}$. For $Q_{\mathrm{u}} \geq \overline{\bar{Q}}_{\mathrm{u}}$ we may define $u^{\mathrm{M}} \equiv u_{\text {infl. }}$.

\subsection{The MATHEMATiCAL MODEL}

We extend the space variable to the whole real line by assuming that the particles outside the settler have the same speed as the liquid. The total flux function is defined as

$$
F(u, x)= \begin{cases}-q_{\mathrm{e}} u, & x<-H \\ g(u)=f_{\mathrm{b}}(u)-q_{\mathrm{e}} u, & -H<x<0 \\ f(u)=f_{\mathrm{b}}(u)+q_{\mathrm{u}} u, & 0<x<D \\ q_{\mathrm{u}} u, & x>D .\end{cases}
$$

The conservation law (preservation of mass) can be written as the partial differential equation

$$
u_{t}+(F(u, x))_{x}=s(t) \delta(x),
$$

where $\delta$ is the Dirac measure and the source function

$$
s(t)=\frac{Q_{\mathrm{f}}}{A} u_{\mathrm{f}}(t)=\frac{Q_{\mathrm{u}}+Q_{\mathrm{e}}}{A} u_{\mathrm{f}}(t)=\left(q_{\mathrm{u}}+q_{\mathrm{e}}\right) u_{\mathrm{f}}(t)
$$

describes the feed flux, i.e., the mass per unit time and unit settler area entering the settler. Equation (1) should be interpreted in the weak sense yielding a solution for $t>0$ given initial data $u_{0}(x), x \in \mathbb{R}$.

We are interested in constructing piecewise smooth solutions $u(x, t)$, i.e., which are defined to be bounded and $C^{1}$ except along a finite number of $C^{1}$-curves, along which the left and right limits (with respect to the $x$-axis) of $u$ exist. The initial-value function $u_{0}$ is assumed to be piecewise monotone, by which we mean that there are at most a finite number of points where a shift of monotonicity occurs. The feed concentration $u_{\mathrm{f}}$ is assumed to be piecewise smooth with bounded derivatives, piecewise monotone and continuous from the right. This regularity assumption is also imposed as the volume flows $Q_{\mathrm{u}}$ etc. vary with time.

Within the thickening zone the conservation law (1) reduces to $u_{t}+f(u)_{x}=0$. The jump condition for a discontinuity $x=x(t)$, with the concentrations $u^{ \pm x} \equiv u(x(t) \pm 0, t)$, is

$$
x^{\prime}(t)=S_{f}\left(u^{x+}, u^{x-}\right) \equiv \frac{f\left(u^{x+}\right)-f\left(u^{x-}\right)}{u^{x+}-u^{x-}}
$$

and the entropy condition by Oleinik [49] is

$$
S_{f}\left(\alpha, u^{x-}\right) \geq S_{f}\left(u^{x+}, u^{x-}\right) \quad \text { for all } \alpha \text { between } u^{x-} \text { and } u^{x+} .
$$

The analogous situation is valid in the clarification zone with $g$ replacing $f$ in the formulae (3) and (4).

At boundary discontinuities the situation is more complicated and we need the notation

$$
\begin{aligned}
u_{ \pm}(t) & =\lim _{\varepsilon \searrow 0} u( \pm \varepsilon, t), & u^{ \pm}(t) & =\lim _{\varepsilon \searrow 0} u_{ \pm}(t+\varepsilon), \\
u_{H}(t) & =\lim _{\varepsilon \searrow 0} u(-H+\varepsilon, t), & u^{H}(t) & =\lim _{\varepsilon \searrow 0} u_{H}(t+\varepsilon), \\
u_{D}(t) & =\lim _{\varepsilon \searrow 0} u(D-\varepsilon, t), & u^{D}(t) & =\lim _{\varepsilon \searrow 0} u_{D}(t+\varepsilon) .
\end{aligned}
$$


At the feed inlet, $x=0$, the jump condition is

$$
f\left(u^{+}(t)\right)=g\left(u^{-}(t)\right)+s(t) .
$$

This equation is not sufficient to determine the two boundary concentrations uniquely. Therefore, we use the entropy condition introduced in [25] and named Condition $\Gamma$. It is a generalization of Oleinik's entropy condition and we refer to [26,27] for its use in the construction of unique solutions in the class of piecewise smooth functions $u(x, t)$ for which $u^{ \pm}, u^{H}$, and $u^{D}$ are piecewise monotone. For given $u_{-}$and $u_{+}$we define the monotone auxiliary functions

$$
\begin{aligned}
& \hat{f}\left(u ; u_{+}\right)= \begin{cases}\min _{u \leq \alpha \leq u_{+}} f(\alpha), & 0 \leq u \leq u_{+} \\
\max _{u+\leq \alpha \leq u} f(\alpha), & u_{+}<u \leq u_{\max }\end{cases} \\
& \check{g}\left(u ; u_{-}\right)= \begin{cases}\max _{u \leq \alpha \leq u_{-}} g(\alpha), & 0 \leq u \leq u_{-} \\
\min _{u_{-} \leq \alpha \leq u} g(\alpha), & u_{-}<u \leq u_{\max } .\end{cases}
\end{aligned}
$$

Condition $\Gamma$ states that, for every fixed $t$, the flux at $x=0$ is the flux value (ordinate) $\gamma(t)$ of the intersection of the graphs of $\check{g}\left(\cdot ; u_{-}(t)\right)+s(t)$ and $\hat{f}\left(\cdot ; u_{+}(t)\right)$, and that the boundary concentrations satisfy

$$
f\left(u^{+}(t)\right)=\gamma(t)=g\left(u^{-}(t)\right)+s(t) .
$$

For the boundary concentrations at $x=-H$ and $x=D$ Condition $\Gamma$ actually yields the following explicit formulae (here we use the regularity assumption that $u(\cdot, t)$ is piecewise monotone):

$$
\begin{aligned}
& u^{D}(t)= \begin{cases}u_{D}(t), & u_{D}(t) \in\left[0, u_{\mathrm{m}}\right) \cup\left(u_{\mathrm{M}}, u_{\max }\right] \\
u_{D}(t), & u_{D}(t)=u_{\mathrm{m}} \text { and } u(x, t) \leq u_{\mathrm{m}} \text { for small } D-x>0 \\
u_{\mathrm{M}}, & u_{D}(t)=u_{\mathrm{m}} \text { and } u(x, t)>u_{\mathrm{m}} \text { for small } D-x>0 \\
u_{\mathrm{M}}, & u_{D}(t) \in\left(u_{\mathrm{m}}, u_{\mathrm{M}}\right) \\
u_{\mathrm{M}}, & u_{D}(t)=u_{\mathrm{M}} \text { and } u(x, t) \leq u_{\mathrm{M}} \text { for small } D-x>0 \\
u_{D}(t), & u_{D}(t)=u_{\mathrm{M}} \text { and } u(x, t)>u_{\mathrm{M}} \text { for small } D-x>0\end{cases} \\
& u^{H}(t)= \begin{cases}0, & u_{H}(t) \in\left[0, u_{\mathrm{z}}\right) \\
0, & u_{H}(t)=0 \text { and } u(x, t)<u_{\mathrm{z}} \text { for small } x+H>0 \\
u_{H}(t), & u_{H}(t)=u_{\mathrm{z}} \text { and } u(x, t) \geq u_{\mathrm{z}} \text { for small } x+H>0 \\
u_{H}(t), & u_{H}(t) \in\left(u_{\mathrm{z}}, u_{\max }\right] .\end{cases}
\end{aligned}
$$

The underflow and effluent concentrations are then obtained from the conservation law at the outlets:

$$
\begin{aligned}
& u_{\mathrm{u}}(t)=\frac{f\left(u^{D}(t)\right)}{q_{\mathrm{u}}}=u^{D}(t)+\frac{A f_{\mathrm{b}}\left(u^{D}(t)\right)}{Q_{\mathrm{u}}}, \\
& u_{\mathrm{e}}(t)=-\frac{g\left(u^{H}(t)\right)}{q_{\mathrm{e}}}=u^{H}(t)-\frac{A f_{\mathrm{b}}\left(u^{H}(t)\right)}{Q_{\mathrm{e}}} .
\end{aligned}
$$

Since $f_{\mathrm{b}}$ is non-convex we need the following operations, see Ballou [50], to construct solutions in the thickening zone. Given the flux function $f$ and $u \in\left[0, u_{\text {inf }}\right]$ define

$$
u^{*}=\max \left\{\alpha \in\left[u_{\text {infl }}, u_{\text {max }}\right]: S_{f}(u, \alpha) \leq S_{f}(u, \beta) \forall \beta \in\left[u, u_{\text {max }}\right]\right\} .
$$


For $u \in\left[u_{\text {infl }}, u_{\max }\right]$ define

$$
u_{*}=\min \left\{\alpha \in\left[0, u_{\text {inf }}\right]: S_{f}(u, \alpha) \leq S_{f}(u, \beta) \forall \beta \in[0, u]\right\} .
$$

LEMMA 2.1. For $0<u<u^{*}<u_{\max }$ the operation ${ }^{*}$ is continuously differentiable and satisfies

Proof. See Ballou [50].

$$
\begin{gathered}
\frac{d u^{*}}{d u}=\frac{f^{\prime}(u)-f^{\prime}\left(u^{*}\right)}{f^{\prime \prime}\left(u^{*}\right)\left(u-u^{*}\right)}<0, \\
f^{\prime}(u)>f^{\prime}\left(u^{*}\right)=S_{f}\left(u, u^{*}\right) .
\end{gathered}
$$

LEMMA 2.2. Let $h(u)=f_{\mathrm{b}}(u)+\alpha u$ for $0 \leq u \leq u_{\max }$ with $\alpha \in \mathbb{R}$. Then

- $h^{\prime}(u) u-h(u)<0,0<u<u_{\max }$,

- the straight line $y=\beta u$ with $\alpha<\beta<h^{\prime}(0)$ intersects the graph of $h$ at precisely one point in $\left(0, u_{\max }\right)$,

- the operation * is independent of $\alpha$.

Proof. The first two statements are proved in [1]. For $u \in\left[0, u_{\mathrm{infl}}\right]$ the definition of $u^{*}$ is equivalent to

$$
\begin{gathered}
h\left(u^{*}\right)-h(u)=\left(u^{*}-u\right) h^{\prime}\left(u^{*}\right) \quad \Longleftrightarrow \\
f_{\mathrm{b}}\left(u^{*}\right)+\alpha u^{*}-f_{\mathrm{b}}(u)-\alpha u=\left(u^{*}-u\right)\left(f_{\mathrm{b}}^{\prime}\left(u^{*}\right)+\alpha\right) \quad \Longleftrightarrow \\
f_{\mathrm{b}}\left(u^{*}\right)-f_{\mathrm{b}}(u)=\left(u^{*}-u\right) f_{\mathrm{b}}^{\prime}\left(u^{*}\right),
\end{gathered}
$$

which does not depend on $\alpha$. Hence, the third statement is proved.

\section{Steady states and optimal operation}

We review some of the more important concepts from [1] concerning the steady state solutions and present a general definition of optimal operation during dynamic operation.

\subsection{THE STEADY STATES}

All steady-state solutions can be classified in terms of the steady-state chart shown in Figure 2. The regions in the chart are

$$
\begin{aligned}
\mathcal{U}_{1} & =\left\{(u, y): 0<q_{\mathrm{u}} u \leq y<\min \left(f\left(u_{\mathrm{M}}\right), f(u)\right)\right\} \\
\mathcal{U}_{2} & =\left\{(u, y): u_{\mathrm{M}}<u \leq u_{\max }, f\left(u_{\mathrm{M}}\right)<y<f(u), y \geq q_{\mathrm{u}} u\right\} \\
\ell_{1} & =\left\{(u, f(u)): 0<u<u_{\mathrm{m}}\right\} \\
p & =\left(u_{\mathrm{m}}, f\left(u_{\mathrm{m}}\right)\right) \\
\ell_{2} & =\left\{\left(u, f\left(u_{\mathrm{M}}\right)\right): u_{\mathrm{m}}<u \leq u_{\mathrm{M}}\right\} \\
\ell_{3} & =\left\{\left(u, f\left(u_{\mathrm{M}}\right)\right): u_{\mathrm{M}}<u \leq \frac{f\left(u_{\mathrm{M}}\right)}{q_{\mathrm{u}}}\right\}
\end{aligned}
$$




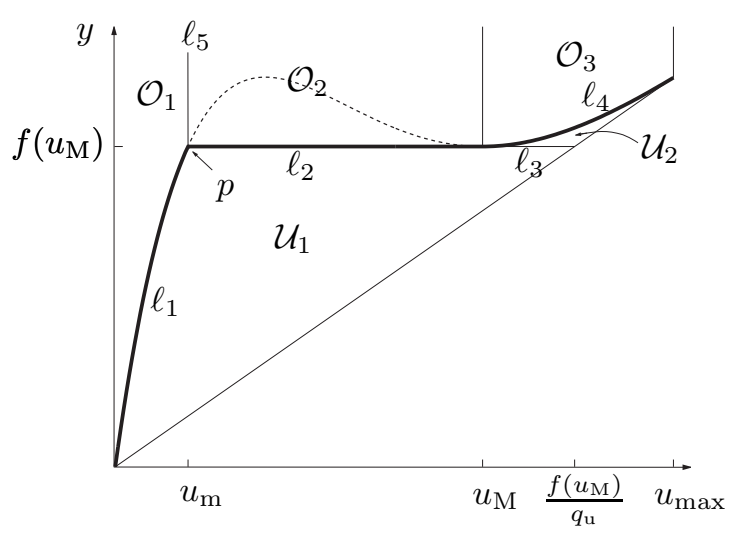

Figure 2. The steady-state chart. The thick graph is the limiting flux.

$$
\begin{aligned}
\ell_{4} & =\left\{(u, f(u)): u_{\mathrm{M}}<u \leq u_{\max }\right\} \\
\ell_{5} & =\left\{\left(u_{\mathrm{m}}, y\right): y>f\left(u_{\mathrm{M}}\right)\right\} \\
\mathcal{O}_{1} & =\left\{(u, y): 0<u<u_{\mathrm{m}}, y>f(u)\right\} \\
\mathcal{O}_{2} & =\left\{(u, y): u_{\mathrm{m}}<u \leq u_{\mathrm{M}}, y>f\left(u_{\mathrm{M}}\right)\right\} \\
\mathcal{O}_{3} & =\left\{(u, y): u_{\mathrm{M}}<u \leq u_{\max }, y>f(u)\right\} .
\end{aligned}
$$

Depending on the location of the feed point $\left(u_{\mathrm{f}}, s\right)$ in the steady-state chart there are different possible steady-state solutions, which are all piecewise constant and non-decreasing with depth, see [1] for a complete table. The limiting flux (Chancelier et al. [28]), see Figure 2, and the excess flux are defined as:

$$
\begin{aligned}
& f_{\lim }(u)=\min _{u \leq \alpha \leq u_{\max }} f(\alpha)= \begin{cases}f(u), & u \in\left[0, u_{\mathrm{m}}\right] \cup\left[u_{\mathrm{M}}, u_{\max }\right], \\
f\left(u_{\mathrm{M}}\right), & u \in\left(u_{\mathrm{m}}, u_{\mathrm{M}}\right),\end{cases} \\
& \mathcal{E}\left(u_{\mathrm{f}}, s\right)=s-f_{\lim }\left(u_{\mathrm{f}}\right) .
\end{aligned}
$$

Let $f_{\text {thick }}$ denote the flux in the thickening zone in steady state. The following formulae hold in steady state:

$$
\begin{array}{ll}
f_{\text {thick }}\left(u_{\mathrm{f}}, s\right)=\min \left(s, f_{\text {lim }}\left(u_{\mathrm{f}}\right)\right), & u_{\mathrm{u}}\left(u_{\mathrm{f}}, s\right)=\frac{A f_{\text {thick }}\left(u_{\mathrm{f}}, s\right)}{Q_{\mathrm{u}}}, \\
Q_{\mathrm{e}}\left(u_{\mathrm{f}}, s\right)=\frac{A s}{u_{\mathrm{f}}}-Q_{\mathrm{u}}, & u_{\mathrm{e}}\left(u_{\mathrm{f}}, s\right)=\frac{A \max \left(0, \mathcal{E}\left(u_{\mathrm{f}}, s\right)\right)}{Q_{\mathrm{e}}} \quad\left(Q_{\mathrm{e}}>0\right) .
\end{array}
$$

The total mass in the settler as a function of the feed point is given in [1]. If the feed point $\left(u_{\mathrm{f}}, s\right)$ lies below the graph of the limiting flux $\left(\mathcal{E}\left(u_{\mathrm{f}}, s\right)<0\right)$, then the effluent concentration is zero and the settler is said to be underloaded since it can handle more feed flux with still zero effluent concentration. If the feed point lies above the graph of the limiting flux $(\mathcal{E}>0)$, then $u_{\mathrm{e}}>0$ and the settler is said to be overloaded. The intermediate case is when the feed point is located on the graph of the limiting flux. Then $\mathcal{E}=0$ and the settler is said to be critically loaded. If $\left(u_{\mathrm{f}}, s\right) \in \mathcal{U}_{1} \cup \mathcal{U}_{2} \cup \mathcal{O}_{1} \cup \mathcal{O}_{2} \cup \mathcal{O}_{3}$ there exists a unique steady-state solution. If $\left(u_{\mathrm{f}}, s\right) \in \bigcup_{i=1}^{5} \ell_{i}$ there exists a steady-state solution, which is uniquely determined except for the location of a discontinuity. The point $p$ is exceptional in the sense that $\left(u_{\mathrm{f}}, s\right)=p$ implies 
that there may exist three discontinuities within the settler; one at the feed level and in one the clarification and thickening zone, respectively. Otherwise, $\left(u_{\mathrm{f}}, s\right) \neq p$ and there is at most two discontinuities.

\subsection{OPTIMAL OPERATION}

The most wanted situation is when the concentration is zero in the clarification zone and there is a discontinuity at $x=x_{\mathrm{sb}} \in(0, D)$ within the thickening zone. The settler is then said to be in optimal operation in steady state. Disregarding the exceptional point $p$, this is equivalent to

$$
\left(u_{\mathrm{f}}, s\right) \in \ell_{2}\left(Q_{\mathrm{u}}\right) \cup \ell_{3}\left(Q_{\mathrm{u}}\right) \quad \text { and } \quad u_{\mathrm{m}}\left(Q_{\mathrm{u}}\right)<m\left(x_{\mathrm{sb}}, Q_{\mathrm{u}}\right) /(A D)<u_{\mathrm{M}}\left(Q_{\mathrm{u}}\right),
$$

where the total mass in the settler satisfies

$$
m\left(x_{\mathrm{sb}}, Q_{\mathrm{u}}\right)=A\left(x_{\mathrm{sb}} u_{\mathrm{m}}\left(Q_{\mathrm{u}}\right)+\left(D-x_{\mathrm{sb}}\right) u_{\mathrm{M}}\left(Q_{\mathrm{u}}\right)\right), \quad 0<x_{\mathrm{sb}}<D, 0<Q_{\mathrm{u}}<\overline{\bar{Q}}_{\mathrm{u}} .
$$

If $\left(u_{\mathrm{f}}, s\right)=p$, then optimal operation may also occur. Note that (11) holds only in optimal operation in steady state. This connection between $m, x_{\mathrm{sb}}$ and $Q_{\mathrm{u}}$ can be shown in an operating chart; see [1]. The discontinuity at $x=x_{\mathrm{sb}}$ is called the sludge blanket in wastewater treatment and it is important to be able control it. We write SBL for the sludge blanket level and a rising SBL refers to reality, although the $x$-coordinate decreases, because of the downward-pointing $x$-axis. A general definition of optimal operation in a dynamic situation is the following. Let $u_{\mathrm{cl}}$ denote the restriction of the solution $u$ to the clarification zone.

DEFINITION 3.1. The settler is said to be in optimal operation at time tif $Q_{\mathrm{u}}(t)<\overline{\bar{Q}}_{\mathrm{u}}$ and the solution of (1) satisfies:

- $u_{\mathrm{cl}}(x, t)=0 \Leftrightarrow u(x, t)=0,-H<x<0$,

- there exists a level $x_{\mathrm{sb}}(t) \in(0, D)$ such that

$$
u(x, t) \in \begin{cases}{\left[0, u_{\text {infl }}\right),} & 0<x<x_{\mathrm{sb}}(t) \\ {\left[u_{\text {infl }}, u_{\text {max }}\right],} & x_{\mathrm{sb}}(t)<x<D .\end{cases}
$$

Hence, we have a natural definition of the SBL for a settler in optimal operation: it is the discontinuity at the level $x=x_{\mathrm{sb}}(t)$ in the thickening zone, such that the jump in the concentration passes the characteristic concentration $u_{\text {infl }}$.

\section{Step responses from optimal operation}

\subsection{OPERATING CHART FOR STEP RESPONSES}

All the qualitatively different steady-state solutions can be classified by the steady-state chart in Figure 2 above together with [1, Table 1]. From an operational point of view, however, this is not sufficient to answer questions such as: If the feed point makes a jump, how does the transient look like? How long does it take to reach the new steady state? Given an increase in the feed flux, how long does it take until there will be an overflow, i.e., $u_{\mathrm{e}}>0$ ? How is the speed of the moving sludge blanket related to the input variables? In this section we 
shall answer such questions by constructing transient solutions when the settler is in optimal operation in steady state initially and the feed point makes a jump in the steady-state chart. After investigating such step responses it turns out that they can be classified in terms of an operating chart, which is a refinement of the steady-state chart in Figure 2. For the sake of presentation and to obtain an overview of the qualitatively different step responses, we therefore show this chart now and refer to Section 4.11 for a summary of the properties of the transients. To this end, divide the steady-state chart in Figure 2 into further subregions (see Figure 3):

$$
\begin{array}{lll}
\mathcal{O}_{2 \mathrm{a}}=\mathcal{O}_{2} \cap\left\{(u, y): y \leq \hat{f}\left(u ; u_{\mathrm{m}}\right)\right\}, & & \mathcal{O}_{3 \mathrm{c}}=\mathcal{O}_{3} \cap\left\{(u, y): f(u) \leq f\left(u^{\mathrm{M}}\right)<y\right\}, \\
\mathcal{O}_{2 \mathrm{~b}}=\mathcal{O}_{2} \cap\left\{(u, y): u<u^{\mathrm{M}}, y>f(u)\right\}, & & \mathcal{U}_{2 \mathrm{a}}=\mathcal{U}_{2} \cap\left\{(u, y): y \leq f\left(u^{\mathrm{M}}\right)\right\}, \\
\mathcal{O}_{2 \mathrm{c}}=\mathcal{O}_{2} \cap\left\{(u, y): u \geq u^{\mathrm{M}}, y>f\left(u^{\mathrm{M}}\right)\right\}, & & \mathcal{U}_{2 \mathrm{~b}}=\mathcal{U}_{2} \cap\left\{(u, y): y>f\left(u^{\mathrm{M}}\right)\right\}, \\
\mathcal{O}_{3 \mathrm{a}}=\mathcal{O}_{3} \cap\left\{(u, y): y \leq f\left(u^{\mathrm{M}}\right)\right\}, & & \ell_{4 \mathrm{a}}=\ell_{4} \cap\left\{(u, y): y \leq u^{\mathrm{M}}\right\}, \\
\mathcal{O}_{3 \mathrm{~b}}=\mathcal{O}_{3} \cap\left\{(u, y): f(u)>f\left(u^{\mathrm{M}}\right)\right\}, & & \ell_{4 \mathrm{~b}}=\ell_{4} \cap\left\{(u, y): y>u^{\mathrm{M}}\right\} .
\end{array}
$$

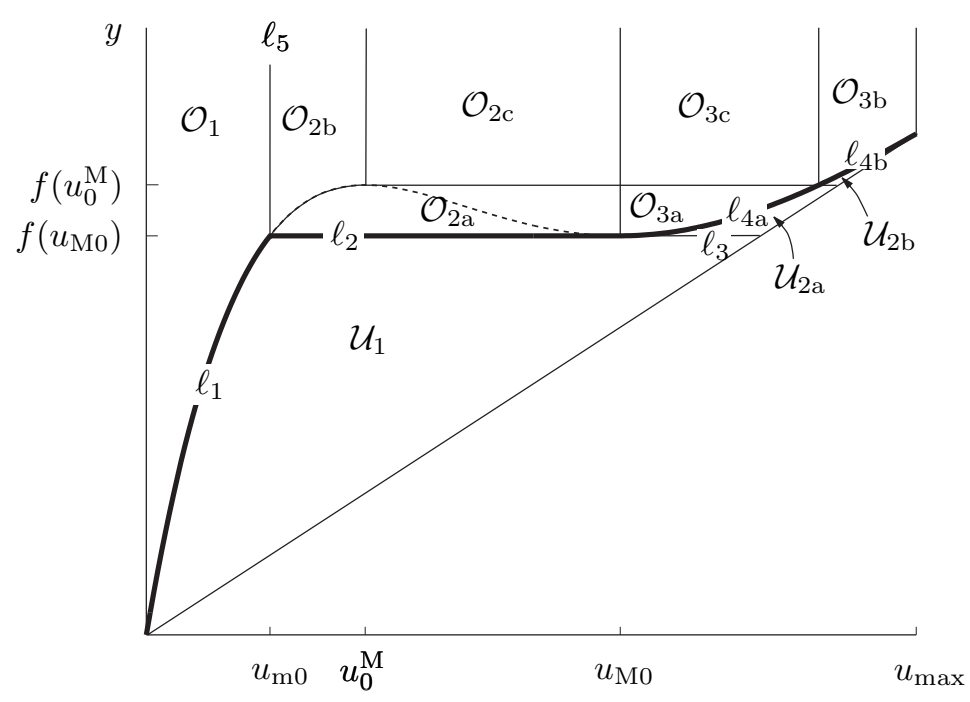

Figure 3. Operating chart for step responses from optimal operation.

Notation: The index ${ }_{0}$ denotes the value of a variable at $t=0-$. Recall that the time dependent variables are defined to be continuous from the right, for example, $u_{\mathrm{f} 0}=u_{\mathrm{f}}(0-) \neq$ $u_{\mathrm{f}}(0+)=u_{\mathrm{f}}(0)$. Variables written without the zero index correspond to the new steady state, which may arise after a finite or infinite time. The control parameter is in this paper fixed; $Q_{\mathrm{u} 0}=Q_{\mathrm{u}}$. Hence $f_{0}=f$ and we prefer to write $f$; and likewise for $\hat{f}$. However, to be able to compare the solutions with those in the subsequent paper [51], we write out the zero index for the characteristic concentrations $u_{\mathrm{m} 0}, u_{\mathrm{M} 0}$ and $\left(u^{\mathrm{M}}\right)_{0}$. The latter cumbersome notation is replaced by $u_{0}^{\mathrm{M}}$. For variables that vary continuously during the transient period, or some part of it, the time dependence is written out, for example, $m(t)$ or $u_{\mathrm{e}}(t)$. Their values in the new steady state are then written out explicitly, for example, $m\left(t_{5}\right)$ is the constant mass for $t \geq t_{5}$, and we write $u_{\mathrm{e} \infty}$ for an asymptotic value. 
Initial conditions: The settler is initially in optimal operation in steady state, i.e., the feed point $\left(u_{\mathrm{f} 0}, s_{0}\right) \in p \cup \ell_{2} \cup \ell_{3}$, there is zero concentration in the clarification zone and a sludge blanket in the thickening zone at the depth $x_{\mathrm{sb} 0}$ with the concentration $u_{\mathrm{m} 0}$ above and $u_{\mathrm{M} 0}$ below it. The total mass in the settler is

$$
m_{0}=A\left(x_{\mathrm{sb} 0} u_{\mathrm{m} 0}+\left(D-x_{\mathrm{sb} 0}\right) u_{\mathrm{M} 0}\right) .
$$

Numerical data and simulations: In order to put data into the formulae and to show graphs of numerical simulations the following numerical data are used throughout the paper:

$$
\begin{array}{ll}
H=1 \mathrm{~m}, & u_{\max }=10 \mathrm{~kg} / \mathrm{m}^{3}, \\
D=4 \mathrm{~m}, & u_{\text {inf }}=4.15 \mathrm{~kg} / \mathrm{m}^{3}, \\
A=\pi(30 \mathrm{~m})^{2}=2827 \mathrm{~m}^{2}, & x_{\mathrm{sb} 0}=2 \mathrm{~m} \text { (unless otherwise stated) } .
\end{array}
$$

Note that the initial mass depends on the values of $u_{\mathrm{m} 0}$ and $u_{\mathrm{M} 0}$, which depend on $Q_{\mathrm{u} 0}=Q_{\mathrm{u}}$. The latter variable is, for clarity, set to different values in the different cases below, which means that the initial mass is different, too. We only show the interesting cases when $Q_{\mathrm{u}}<$ $\overline{\bar{Q}}_{\mathrm{u}}=5161 \mathrm{~m}^{3} / \mathrm{h}$. The batch settling flux $f_{\mathrm{b}}(u)$ used is shown in Figure 1 (right), and its representation is given in that figure caption, although it is of minor interest as long as it satisfies (1). The three-dimensional graphs are obtained by the numerical method described in [47]. It is based on Godunov's [52] method, in which the concentration related to each grid point along the $x$-axis at a given time point is the average of an analytical solution originating from piecewise constant initial data at the preceding time point. It is a conservative method, which means that although discontinuities are smoothed (by numerical diffusion), they are located correctly, that is, they move with the correct speed.

Note that a change in the feed flux, i.e. $\Delta s \equiv s-s_{0} \neq 0$, may be caused by a change in the feed concentration $u_{\mathrm{f}}$ and/or $Q_{\mathrm{f}}$. A change in $Q_{\mathrm{f}}$ causes a change in $Q_{\mathrm{e}}$, as we assume that the control parameter $Q_{\mathrm{u} 0}$ is kept fixed.

\subsection{SteP RESPONSE AS $\left(u_{\mathrm{f}}, s\right) \in \mathcal{U}_{1}$}

The feed point has moved downwards in the operating chart in Figure 3. The feed flux is decreased, $\Delta s=s-s_{0}<0$, and the settler will become underloaded. We shall see that the new steady state arises after a finite time. First we determine the new boundary concentrations above and below the feed level at $t=0$ by using Condition $\Gamma$, see Figure 4 (left). The intersection of $\hat{f}\left(u ; u_{\mathrm{m}}\right)$ and $\check{g}(u ; 0)+s$ occurs at the flux level $\gamma=s$. This defines the boundary concentrations $u^{-}(0)=0$ and $u^{+}(0)=u_{1}$. Hence, $u_{1}$ is uniquely defined by $f\left(u_{1}\right)=s$. Note that it is impossible to construct a solution with the concentration $u_{\mathrm{z}}$ (see Figure 4, left) as a boundary limit concentration. The unique solution is shown in Figure 5. According to the jump condition (3) the shock wave $x_{1}$ has the constant speed $x_{1}^{\prime}(t)=S_{f}\left(u_{1}, u_{\mathrm{m} 0}\right) \approx$ $f^{\prime}\left(u_{1}\right) \approx f^{\prime}\left(u_{\mathrm{m} 0}\right)>0$, which is a large velocity downwards. At $t=t_{1}$ this shock wave meets the SBL and a new shock wave $x_{2}$ with the (much lower) speed $S_{f}\left(u_{1}, u_{\mathrm{M} 0}\right)$ is created. This one reaches the bottom at $t=t_{2}$. Noting that $S_{f}\left(u_{1}, u_{\mathrm{m} 0}\right)=\frac{f\left(u_{1}\right)-f\left(u_{\mathrm{m} 0}\right)}{u_{1}-u_{\mathrm{m} 0}}=\frac{-\Delta s}{u_{\mathrm{m} 0}-u_{1}}$ we get the following expressions for the time points:

$$
\begin{aligned}
& t_{1}=\frac{x_{\mathrm{sb} 0}\left(u_{\mathrm{m} 0}-u_{1}\right)}{-\Delta s}, \\
& t_{2}=t_{1}+\frac{\left(D-x_{\mathrm{sb} 0}\right)\left(u_{\mathrm{M} 0}-u_{1}\right)}{-\Delta s}=\frac{m_{0}-A D u_{1}}{-A \Delta s} .
\end{aligned}
$$



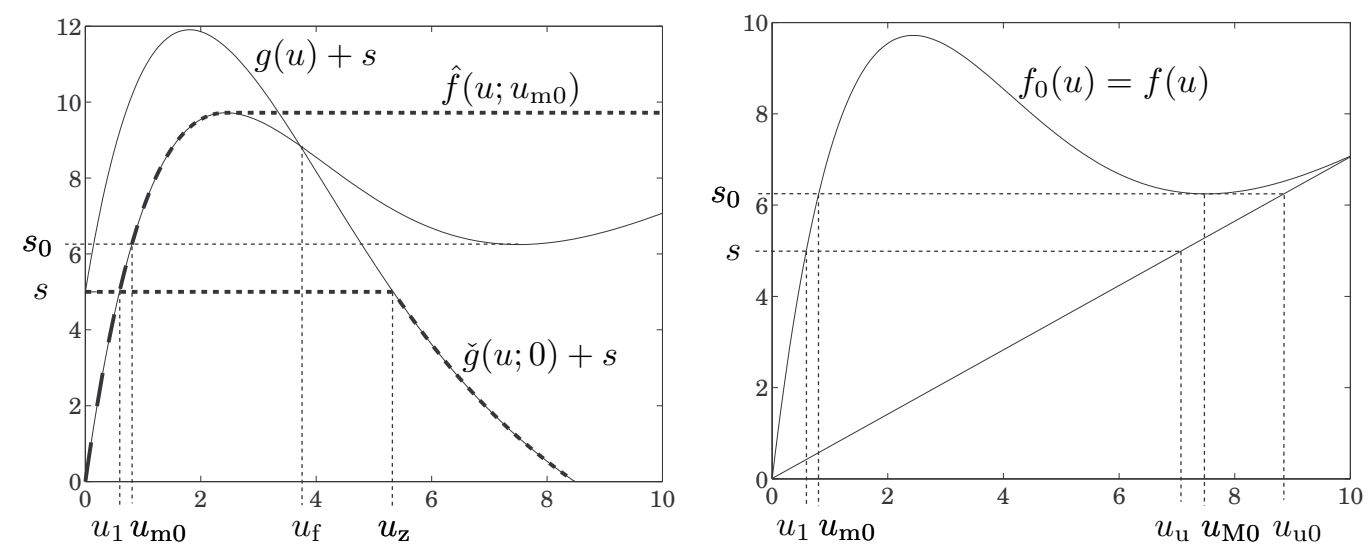

Figure 4. $\left(u_{\mathrm{f}}, s\right) \in \mathcal{U}_{1}$. Left: Construction of new boundary concentrations at $x=0$ and $t=0+$. Note that $u_{\mathrm{f}}$ is (always) the intersection of $f$ and $g(\cdot)+s$ (see [26]). Right: Concentrations appearing in the solution shown in Figure 5.

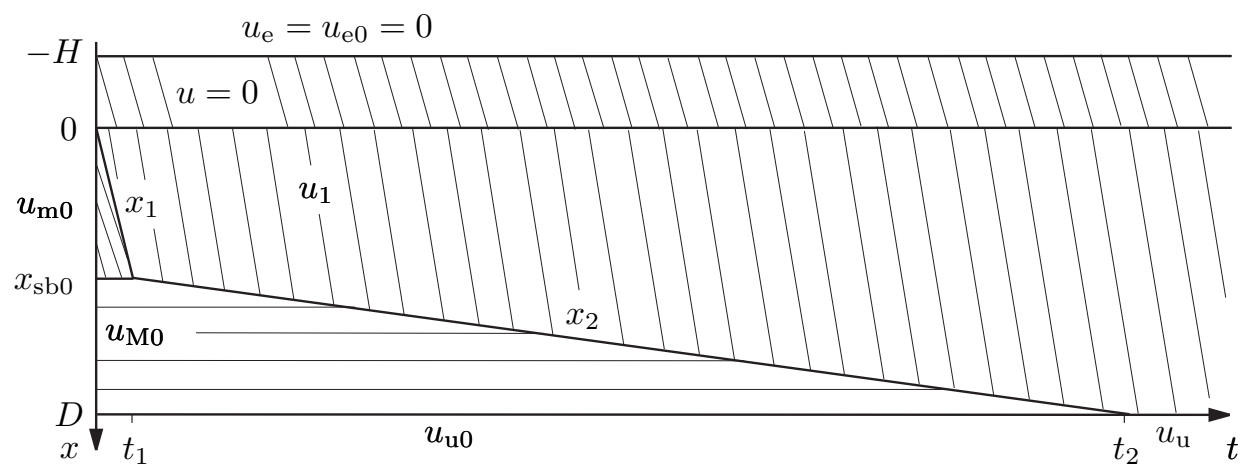

Figure 5. Step response as $\left(u_{\mathrm{f}}, s\right) \in \mathcal{U}_{1}$. The new steady state comes into effect after the finite time $t_{2}$. Thick lines are boundaries or discontinuities. Thin lines are characteristics. The settler is in optimal operation till $t_{2}$.

Note that the numerator of the last expression is the difference in mass between the two steady states and the denominator the difference between the feed mass fluxes. Hence, the time for the transition between the two steady states is in inverse proportion to $|\Delta s|$. The mass in the settler decreases linearly till $t_{2}$ and is then constant:

$$
m(t)= \begin{cases}m_{0}+t\left(A s-Q_{\mathrm{u} 0} u_{\mathrm{u} 0}\right)=m_{0}+t\left(A s-A s_{0}\right)=m_{0}+t A \Delta s, & 0<t \leq t_{2} \\ m_{0}+t_{2} A \Delta s=A D u_{1}, & t \geq t_{2}\end{cases}
$$

Numerical values corresponding to Figure 4 and obtained by the formulae are

$$
\begin{array}{lll}
u_{\mathrm{f}}=3.72 \mathrm{~kg} / \mathrm{m}^{3} & u_{\mathrm{m} 0}=0.80 \mathrm{~kg} / \mathrm{m}^{3} & t_{1}=21 \mathrm{~min} \\
s_{0}=6.25 \mathrm{~kg} /\left(\mathrm{m}^{2} \mathrm{~h}\right) & u_{\mathrm{M} 0}=7.50 \mathrm{~kg} / \mathrm{m}^{3} & t_{2}=11.4 \mathrm{~h} \\
s=5 \mathrm{~kg} /\left(\mathrm{m}^{2} \mathrm{~h}\right) & u_{1}=0.59 \mathrm{~kg} / \mathrm{m}^{3} & m\left(t_{2}\right)=6.7 \text { tonnes } \\
Q_{\mathrm{f}}=3800 \mathrm{~m}^{3} / \mathrm{h} & u_{\mathrm{u} 0}=8.83 \mathrm{~kg} / \mathrm{m}^{3} & \\
Q_{\mathrm{u} 0}=2000 \mathrm{~m}^{3} / \mathrm{h} & u_{\mathrm{u}}=7.07 \mathrm{~kg} / \mathrm{m}^{3} & \\
Q_{\mathrm{e}}=1800 \mathrm{~m}^{3} / \mathrm{h} & m_{0}=47.0 \text { tonnes } &
\end{array}
$$



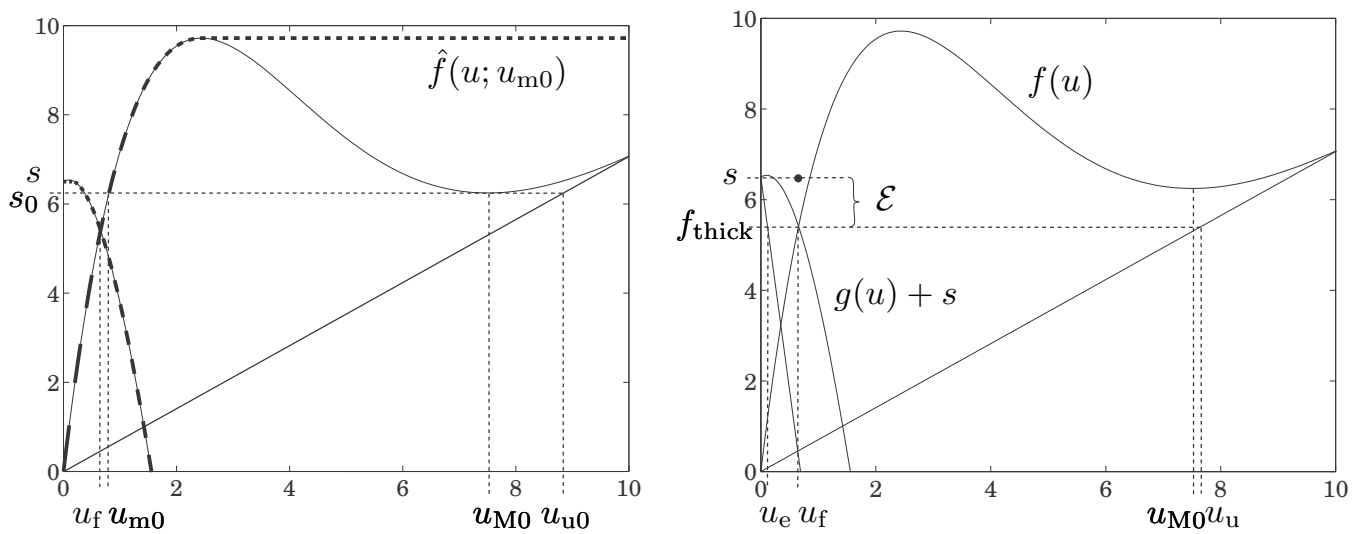

Figure 6. $\left(u_{\mathrm{f}}, s\right) \in \mathcal{O}_{1}$ with $\Delta s>0$. Left: $Q_{\mathrm{e}}$ is high, which implies that $\check{g}(u ; 0)+s$ intersects $\hat{f}\left(u ; u_{\mathrm{m} 0}\right)$ at the low concentration $u_{\mathrm{f}}$ at $t=0$. This defines the boundary concentrations $u^{-}(0)=u^{+}(0)=u_{\mathrm{f}}$. Right: Concentrations and fluxes of the new steady-state solution, cf. (10).

\subsection{STEP RESPONSE AS $\left(u_{\mathrm{f}}, s\right) \in p \cup \ell_{2} \cup \ell_{3}$}

In this case the feed point stays on the piece of line in the operating chart that permits an optimal operation in steady state. $\Delta s=s-s_{0}=0$ and this can be seen as a limit case of the previous one $\left(\mathcal{U}_{1}\right)$ with $u_{1}=u_{\mathrm{m} 0}$, cf. Figure 4 . This implies that the initial steady-state solution is not affected at all. Note that this is the case despite $u_{\mathrm{f}} \neq u_{\mathrm{f} 0}$, and hence $Q_{\mathrm{f}} \neq Q_{\mathrm{f} 0}$ and $Q_{\mathrm{e}} \neq Q_{\mathrm{e} 0}$.

\subsection{STEP RESPONSE AS $\left(u_{\mathrm{f}}, s\right) \in \ell_{1}$}

As in the case $\mathcal{U}_{1}, \Delta s<0$ holds. There is no mass in the clarification zone at $t=0$ and this will be the case in the new steady state, too. Actually, the solution and the formulae are the same as in the case of a jump to $\mathcal{U}_{1}$. This can be seen by considering Figure 4 (left) with the difference that $u_{\mathrm{f}}=u_{1}$, which means that the graph of $g(u)+s$ intersects $f(u)$ at this concentration. $Q_{\mathrm{e}}$ is thus very high. The intersection of $\hat{f}\left(u ; u_{\mathrm{m} 0}\right)$ and $\check{g}(u ; 0)+s$ also occurs at $u_{\mathrm{f}}=u_{1}$, which implies that the boundary concentrations and the solution are the same as in the case $\mathcal{U}_{1}$. (It can be seen that the boundary concentration $u^{-}(0)=u_{\mathrm{f}}$ cannot be used to obtain a solution.)

\subsection{SteP RESPONSE AS $\left(u_{\mathrm{f}}, s\right) \in \mathcal{O}_{1}$}

Necessarily, $\Delta u_{\mathrm{f}}=u_{\mathrm{f}}-u_{\mathrm{f} 0}<0$ holds, however, $\Delta s$ could be of any sign and size. Figure 6 shows a case with $\Delta s>0$ and the corresponding solution is shown in Figure 7. In the clarification zone a discontinuity is created at $t=0$. It moves with the velocity $x_{3}^{\prime}(t)=S_{g}\left(u_{\mathrm{f}}, 0\right)=g\left(u_{\mathrm{f}}\right) / u_{\mathrm{f}}<0$ and reaches the effluent level at time $\tau_{1}$. In the thickening zone the behaviour is the same as in the case $\mathcal{U}_{1}$ (Section 4.2). The time points are

$$
\begin{aligned}
& \tau_{1}=\frac{H u_{\mathrm{f}}}{-g\left(u_{\mathrm{f}}\right)}=\frac{H u_{\mathrm{f}}}{s-f\left(u_{\mathrm{f}}\right)}, \quad t_{1}=\frac{x_{\mathrm{sb} 0}\left(u_{\mathrm{m} 0}-u_{\mathrm{f}}\right)}{s_{0}-f\left(u_{\mathrm{f}}\right)}, \\
& t_{2}=t_{1}+\frac{\left(D-x_{\mathrm{sb} 0}\right)\left(u_{\mathrm{M} 0}-u_{\mathrm{f}}\right)}{s_{0}-f\left(u_{\mathrm{f}}\right)}=\frac{m_{0}-A D u_{\mathrm{f}}}{A\left(s_{0}-f\left(u_{\mathrm{f}}\right)\right)} .
\end{aligned}
$$




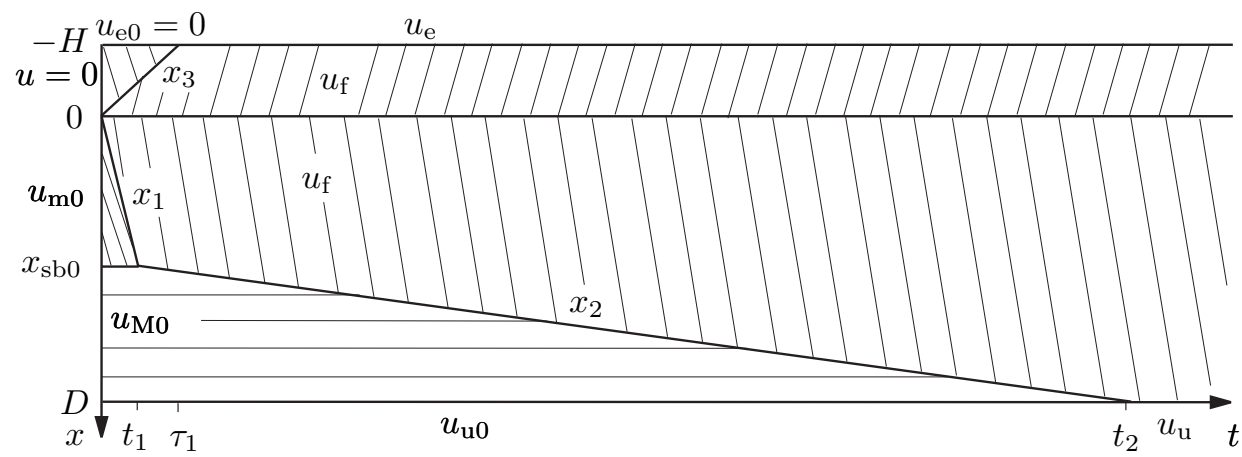

Figure 7. Step response as $\left(u_{\mathrm{f}}, s\right) \in \mathcal{O}_{1}$. The settler leaves the state of optimal operation at $t=0$.

The total mass varies piecewise linearly with time because of the piecewise constant solution and input data. At $t=0$ the mass balance gives $A s_{0}=Q_{\mathrm{u} 0} u_{\mathrm{u} 0}$ and for $t>\max \left(\tau_{1}, t_{2}\right)$ (at the new steady state) it gives $A s=Q_{\mathrm{e}} u_{\mathrm{e}}+Q_{\mathrm{u} 0} u_{\mathrm{u}}=Q_{\mathrm{e}} u_{\mathrm{e}}+A f\left(u_{\mathrm{f}}\right)$. Using these relations the mass evolution can be written as follows. If $\underline{\tau_{1}<t_{2}}$ (as in Figure 7), then

$$
m(t)= \begin{cases}m_{0}+t\left(A s-Q_{\mathrm{u} 0} u_{\mathrm{u} 0}\right)=m_{0}+t A\left(s-s_{0}\right)=m_{0}+t A \Delta s, & 0 \leq t<\tau_{1} \\ m_{0}+t A \Delta s-\left(t-\tau_{1}\right) Q_{\mathrm{e}} u_{\mathrm{e}}, & \tau_{1} \leq t<t_{2} \\ m_{0}+t_{2} A \Delta s-\left(t_{2}-\tau_{1}\right) Q_{\mathrm{e}} u_{\mathrm{e}} & t \geq t_{2} .\end{cases}
$$

The mass balance $m\left(t_{2}\right)=A(H+D) u_{\mathrm{f}}$ gives another expression for the time when the new steady state begins:

$$
t_{2}=\frac{m_{0}-A(H+D) u_{\mathrm{f}}+\tau_{1} A\left(s-f\left(u_{\mathrm{f}}\right)\right)}{A\left(s_{0}-f\left(u_{\mathrm{f}}\right)\right)} .
$$

If $\underline{\tau_{1} \geq t_{2}}$, then

$$
m(t)= \begin{cases}m_{0}+t A \Delta s, & 0 \leq t<t_{2} \\ m_{0}+t_{2} A \Delta s+\left(t-t_{2}\right)\left(A s-Q_{\mathrm{u} 0} u_{\mathrm{u}}\right) & \\ \quad=m_{0}+t A\left(s-f\left(u_{\mathrm{f}}\right)\right)-t_{2} A\left(s_{0}-f\left(u_{\mathrm{f}}\right)\right), & t_{2} \leq t<\tau_{1} \\ m_{0}+\tau_{1} A\left(s-f\left(u_{\mathrm{f}}\right)\right)-t_{2} A\left(s_{0}-f\left(u_{\mathrm{f}}\right)\right), & t \geq \tau_{1} .\end{cases}
$$

As above, the mass balance $m\left(t_{2}\right)=A(H+D) u_{\mathrm{f}}$ gives another expression for the time when the new steady state begins:

$$
\tau_{1}=\frac{A(H+D) u_{\mathrm{f}}+t_{2} A\left(s_{0}-f\left(u_{\mathrm{f}}\right)\right)-m_{0}}{A\left(s-f\left(u_{\mathrm{f}}\right)\right)} .
$$

The numerical values corresponding to Figure 6 and obtained by the formulae are

$$
\begin{array}{lll}
u_{\mathrm{f}}=0.66 \mathrm{~kg} / \mathrm{m}^{3} & u_{\mathrm{m} 0}=0.80 \mathrm{~kg} / \mathrm{m}^{3} & m_{\infty}=9.3 \text { tonnes } \\
s_{0}=6.25 \mathrm{~kg} /\left(\mathrm{m}^{2} \mathrm{~h}\right) & u_{\mathrm{M} 0}=7.50 \mathrm{~kg} / \mathrm{m}^{3} & t_{1}=21 \mathrm{~min} \\
s=6.5 \mathrm{~kg} /\left(\mathrm{m}^{2} \mathrm{~h}\right) & u_{\mathrm{u} 0}=8.83 \mathrm{~kg} / \mathrm{m}^{3} & t_{2}=16.7 \mathrm{~h} \\
Q_{\mathrm{f}}=28000 \mathrm{~m}^{3} / \mathrm{h} & u_{\mathrm{u}}=7.65 \mathrm{~kg} / \mathrm{m}^{3} & \tau_{1}=36 \mathrm{~min} \\
Q_{\mathrm{u} 0}=2000 \mathrm{~m}^{3} / \mathrm{h} & u_{\mathrm{e}}=0.12 \mathrm{~kg} / \mathrm{m}^{3} & \\
Q_{\mathrm{e}}=26000 \mathrm{~m}^{3} / \mathrm{h} & m_{0}=47.0 \text { tonnes } &
\end{array}
$$




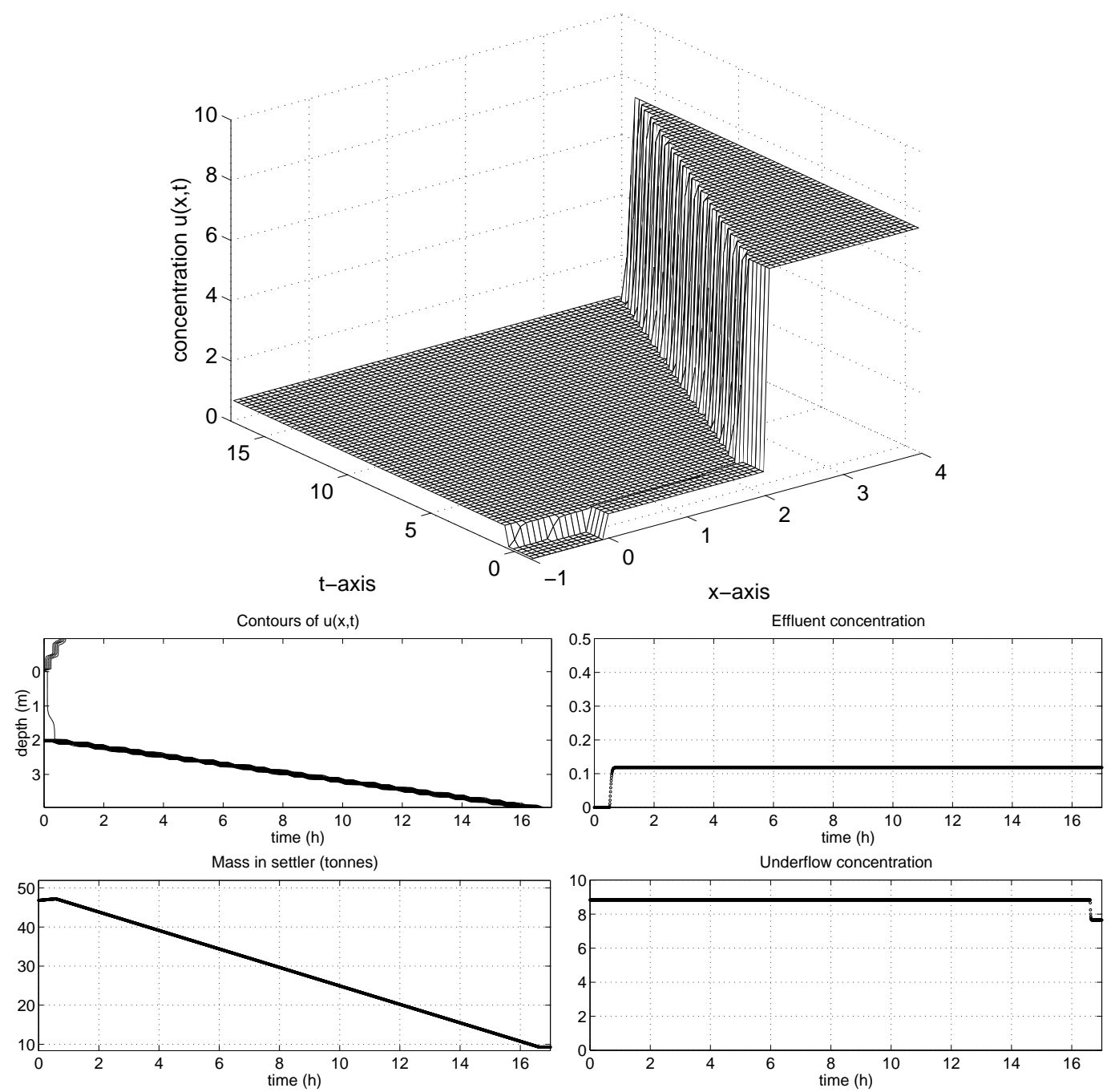

Figure 8. Step response as $\left(u_{\mathrm{f}}, s\right) \in \mathcal{O}_{1}$. Note that the three-dimensional graph shows the original steady-state solution during $-1 \mathrm{~h}<t<0 \mathrm{~h}$.

Note that, independently of whether $\tau_{1} \lessgtr t_{2}$, if $\Delta s>0$, the mass increases initially till $t=\min \left(\tau_{1}, t_{2}\right)$ and then decreases to the final value. A numerical simulation is shown in Figure 8 .

\subsection{STEP RESPONSE AS $\left(u_{\mathrm{f}}, s\right) \in \ell_{5}$}

In this case $u_{\mathrm{f}}=u_{\mathrm{m} 0}$ and $\Delta s>0$ hold. The solution can be seen as a limit case of $\mathcal{O}_{1}$. The discontinuity $x_{1}$ of Figure 7 does not exist in this case since $u_{\mathrm{f}}=u_{\mathrm{m} 0}$. This also implies that the sludge blanket remains constant at the level $x_{\mathrm{sb}}=x_{\mathrm{sb} 0}$; see Figure 9. The state of optimal operation is left immediately and the time point for the beginning of the new steady state is

$$
\tau_{1}=\frac{H u_{\mathrm{m} 0}}{-g\left(u_{\mathrm{m} 0}\right)}=\frac{H u_{\mathrm{m} 0}}{\Delta s}
$$




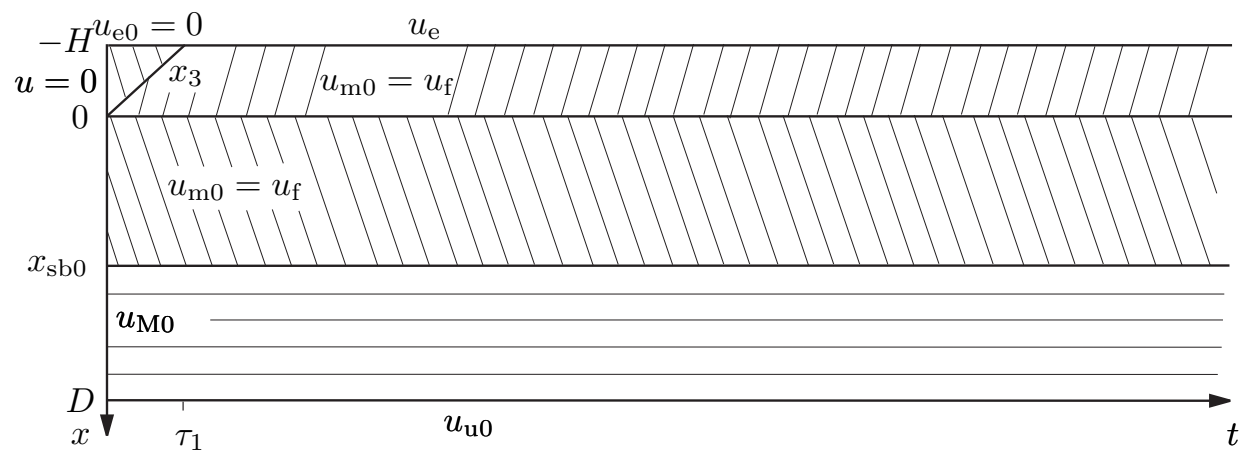

Figure 9. Step response as $\left(u_{\mathrm{f}}, s\right) \in \ell_{5}$. The settler leaves the state of optimal operation at $t=0$.

and the mass evolution is

$$
m(t)= \begin{cases}m_{0}+t A \Delta s, & 0 \leq t<\tau_{1} \\ m_{0}+\tau_{1} A \Delta s=m_{0}+A H u_{\mathrm{m} 0}, & t \geq \tau_{1} .\end{cases}
$$

\subsection{STEP RESPONSE AS $\left(u_{\mathrm{f}}, s\right) \in \mathcal{O}_{2}$}

In this case $\Delta s>0$. Depending on the size of $s$ and $u_{\mathrm{f}}$ there are qualitatively different intersections of $\hat{f}\left(u ; u_{\mathrm{m} 0}\right)$ and $\breve{g}(u ; 0)+s$ at $t=0$. There are three main subcases: the first increasing part of $\hat{f}\left(u ; u_{\mathrm{m} 0}\right)$ intersects the plateau of $\breve{g}(u ; 0)+s\left(\mathcal{O}_{2 \mathrm{a}}\right)$; the increasing part of $\hat{f}\left(u ; u_{\mathrm{m} 0}\right)$ intersects the decreasing part of $\check{g}(u ; 0)+s\left(\mathcal{O}_{2 \mathrm{~b}}\right)$; the plateau of $\hat{f}\left(u ; u_{\mathrm{m} 0}\right)$ intersects the decreasing part of $\check{g}(u ; 0)+s\left(\mathcal{O}_{2 \mathrm{c}}\right)$. All the different transients will, however, lead to the same steady state.

4.7.1. $\left(u_{\mathrm{f}}, s\right) \in \mathcal{O}_{2 \mathrm{a}}$ and $s<\hat{f}\left(u_{\mathrm{f}} ; u_{\mathrm{m} 0}\right)$

First we note that $s<f\left(u_{0}^{\mathrm{M}}\right)$ holds. According to Figure 10 (left) the intersection of $\hat{f}\left(u ; u_{\mathrm{m} 0}\right)$ and $\check{g}(u ; 0)+s$ occurs at the point $\left(u_{1}, f\left(u_{1}\right)\right)$, where $u_{1}$ is defined by

$$
f\left(u_{1}\right)=s, \quad u_{1}<u_{0}^{\mathrm{M}},
$$

and the boundary concentrations are $u^{-}(t)=0$ and $u^{+}(t)=u_{1}$ until the sludge blanket reaches the feed level at $t=t_{3}$. At this time point $u_{+}\left(t_{3}\right)=u_{1}^{*}$ and $u_{-}\left(t_{3}\right)=0$, and Figure 10 (right) shows that the intersection of $\hat{f}\left(u ; u_{1}^{*}\right)$ and $\check{g}(u ; 0)+s$ occurs at the point $\left(u_{2}, g\left(u_{2}\right)\right)$. Hence, $u_{2}$ is defined by

$$
f\left(u_{1}^{*}\right)=g\left(u_{2}\right)+s
$$

and the new boundary concentrations satisfy $u^{-}\left(t_{3}\right)=u_{2}$ and $u^{+}\left(t_{3}\right)=u_{1}^{*}$. The solution is shown in Figure 11. The lines of continuity, $x_{1}$ and $x_{2}$, and the discontinuities, $x_{4}$ and $x_{5}$, satisfy

$$
\begin{aligned}
x_{1}(t) & =f^{\prime}\left(u_{\mathrm{m} 0}\right) t, & & 0<t<t_{1}, \\
x_{2}(t) & =f^{\prime}\left(u_{1}\right) t, & & 0<t<t_{2}, \\
x_{4}(t)-x_{2}\left(t_{2}\right) & =S_{f}\left(u_{1}, u_{1}^{*}\right)\left(t-t_{2}\right)=f^{\prime}\left(u_{1}^{*}\right)\left(t-t_{2}\right), & & t_{2}<t<t_{3},
\end{aligned}
$$



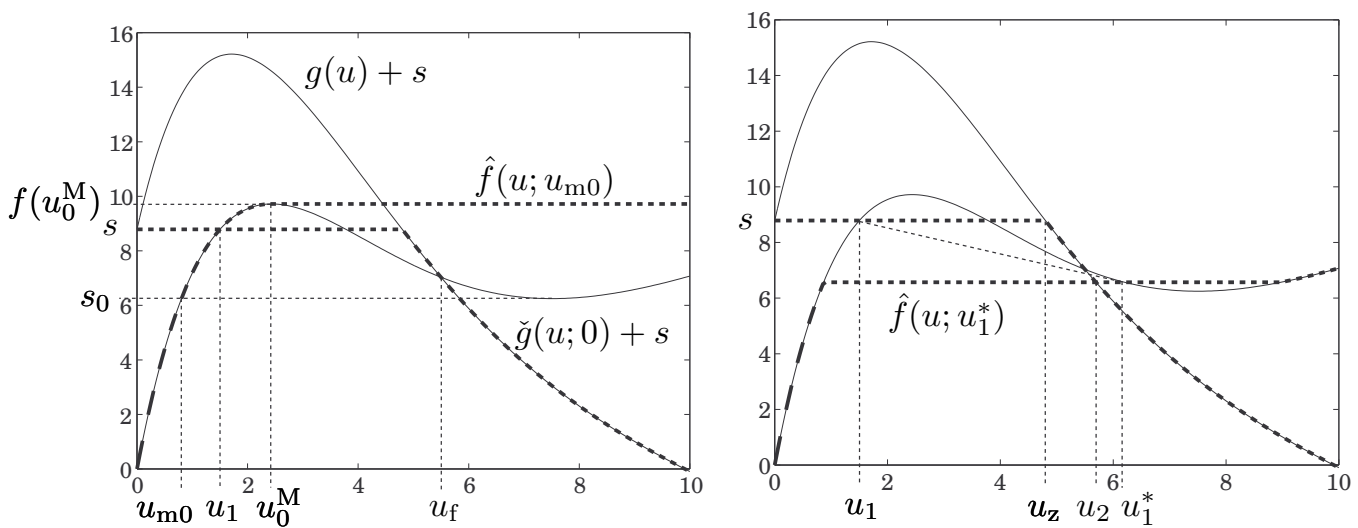

Figure 10. The case $\left(u_{\mathrm{f}}, s\right) \in \mathcal{O}_{2 \mathrm{a}}$ and $s<f\left(u_{0}^{\mathrm{M}}\right)$. The situation at the feed level at $t=0$ (left) and at $t=t_{3}$ (right).

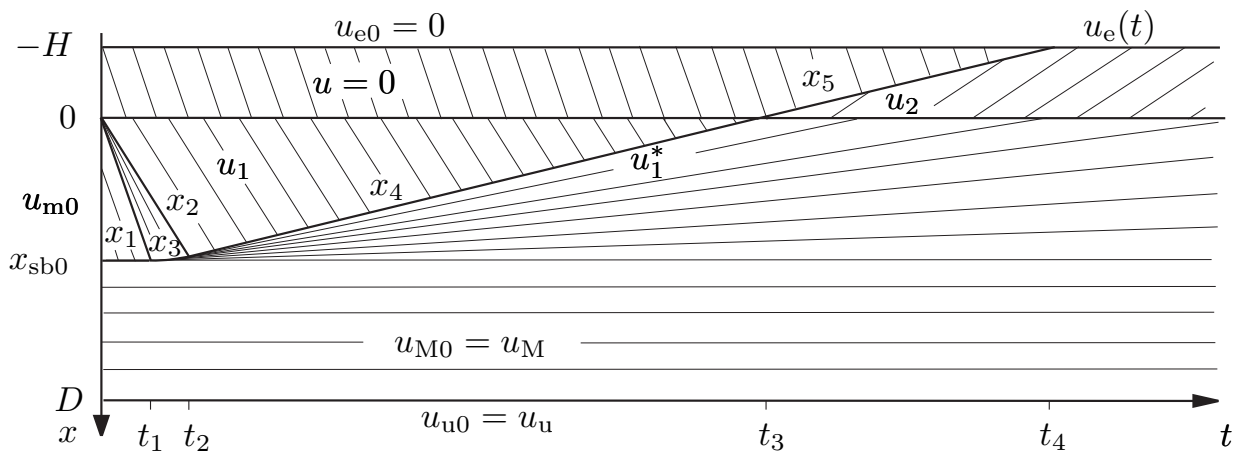

Figure 11. Step response as $\left(u_{\mathrm{f}}, s\right) \in \mathcal{O}_{2 \mathrm{a}}$ and $s<\hat{f}\left(u_{\mathrm{f}} ; u_{\mathrm{m} 0}\right)$. The settler is in optimal operation during $0 \leq t<t_{3}$.

$$
x_{5}(t)=S_{g}\left(u_{2}, 0\right)\left(t-t_{3}\right)=\frac{g\left(u_{2}\right)}{u_{2}}\left(t-t_{3}\right), \quad t_{3}<t<t_{4} .
$$

Inside the region bounded by $x_{1}, x_{2}$ and $x_{3}$ there is an expansion wave, within which the concentration is

$$
u(x, t)=\left(\tilde{f}^{\prime}\right)^{-1}\left(\frac{x}{t}\right),
$$

where $\tilde{f}=\left.f\right|_{\left[0, u_{\mathrm{inf}}\right]}\left(\tilde{f}^{\prime}\right.$ is strictly decreasing, hence invertible). The contact discontinuity $x_{3}(t)$ is defined implicitly by the jump condition (3):

$$
x_{3}^{\prime}(t)=S_{f}\left(u_{3}(t), u_{3}^{*}(t)\right) \stackrel{\text { Lemma } 2.1}{=} f^{\prime}\left(u_{3}^{*}(t)\right), \quad u_{3}(t) \equiv\left(f^{\prime}\right)^{-1}\left(\frac{x_{3}(t)}{t}\right), \quad t_{1}<t \leq t_{2} .
$$

Note that $x_{3}^{\prime}\left(t_{1}+0\right)=S_{f}\left(u_{\mathrm{m} 0}, u_{\mathrm{M} 0}\right)=0, u_{\mathrm{m} 0} \leq u_{3}(t) \leq u_{1}$ and that $u_{3}(t)$ and $u_{3}^{*}(t)$ are the concentrations above and below the discontinuity, respectively. Unfortunately, the differential equation (15) cannot be solved explicitly for a general $f$. The time points are defined by

$$
t_{1}=\frac{x_{\mathrm{sb} 0}}{f^{\prime}\left(u_{\mathrm{m} 0}\right)}, \quad x_{3}\left(t_{2}\right)=x_{2}\left(t_{2}\right),
$$




$$
\begin{aligned}
& t_{3}=\left(1+\frac{f^{\prime}\left(u_{1}\right)}{-f^{\prime}\left(u_{1}^{*}\right)}\right) t_{2}, \\
& t_{4}=t_{3}+\frac{H u_{2}}{-g\left(u_{2}\right)} .
\end{aligned}
$$

The solution above $x=x_{\mathrm{sb} 0}$ and below $x_{4}$ is determined by the characteristics emanating tangentially from the contact discontinuity $x_{3}(t)$ for $t_{1}<t<t_{2}$. The concentration is increasing with depth and time and converges to $u_{\mathrm{M} 0}$ as $t \rightarrow \infty$ for every fixed $x \in\left(0, x_{\mathrm{sb} 0}\right)$. The same is thus true for the boundary concentration $u^{+}(t)=u_{+}(t)$ for $t>t_{3}$. The intersection of the plateau of $\hat{f}\left(u ; u_{+}(t)\right)$ and the graph of $\check{g}\left(u ; u_{-}(t)\right)+s$ uniquely defines the boundary concentration $u^{-}(t)=u_{-}(t)$ for every $t>t_{3}$. Hence, $u^{-}(t)$ will be a continuously increasing function given implicitly by

$$
g\left(\left(u^{-}(t)\right)+s=f\left(u^{+}(t)\right), \quad t \geq t_{3},\right.
$$

with the limit $u_{\mathrm{cl}}$ as $t \rightarrow \infty$ satisfying $g\left(u_{\mathrm{cl}}\right)+s=f\left(u_{\mathrm{m} 0}\right)=f\left(u_{\mathrm{M} 0}\right)=s_{0}$. The same is true for the concentration in the clarification zone at any level $x \in(-H, 0)$. Accordingly, the effluent concentration $u_{\mathrm{e}}(t)$ will be slightly increasing for $t>t_{3}$ with the limit

$$
u_{\mathrm{e} \infty}=\frac{-g\left(u_{\mathrm{cl}}\right)}{q_{\mathrm{e}}}=\frac{s-f\left(u_{\mathrm{M} 0}\right)}{q_{\mathrm{e}}}=\frac{\Delta s}{q_{\mathrm{e}}} .
$$

The mass in the settler increases linearly with the rate $A \Delta s$ for $0<t<t_{4}$ and thereafter it increases with smaller rates asymptotically to the limit

$$
m_{\infty}=A\left(H u_{\mathrm{cl}}+D u_{\mathrm{M}}\right)=m_{0}+A\left(H u_{\mathrm{cl}}+x_{\mathrm{sb} 0}\left(u_{\mathrm{M} 0}-u_{\mathrm{m} 0}\right)\right) .
$$

Thus, an upper limit of $t_{4}$ is given by the inequality

$$
m\left(t_{4}\right)=m_{0}+t_{4} A \Delta s \leq m_{\infty} .
$$

An expression for $t_{3}$ can be obtained from the mass balance

$$
m\left(t_{3}\right)=m_{0}+t_{3} A \Delta s=A\left(\int_{0}^{x_{\mathrm{sb} 0}} u\left(x, t_{3}\right) d x+\left(D-x_{\mathrm{sb} 0}\right) u_{\mathrm{M} 0}\right),
$$

which yields

$$
t_{3}=\frac{A\left(\int_{0}^{x_{\mathrm{sb} 0}} u\left(x, t_{3}\right) d x+\left(D-x_{\mathrm{sb} 0}\right) u_{\mathrm{M} 0}\right)-m_{0}}{A \Delta s} .
$$

A crude approximation of the quadrature can be obtained by approximating $u\left(x, t_{3}\right)$ by a straight line joining $u\left(0+, t_{3}\right)=u_{1}^{*}$ and $u\left(x_{\mathrm{sb} 0}, t_{3}\right)=u_{\mathrm{M} 0}$. Then $\int_{0}^{x_{\mathrm{sb} 0}} u\left(x, t_{3}\right) d x \approx x_{\mathrm{sb} 0} \frac{u_{1}^{*}+u_{\mathrm{M} 0}}{2}$ and we get the approximate formula

$$
t_{3} \approx \frac{A\left(x_{\mathrm{sb} 0}\left(u_{1}^{*}+u_{\mathrm{M} 0}\right) / 2+\left(D-x_{\mathrm{sb} 0}\right) u_{\mathrm{M} 0}\right)-m_{0}}{A \Delta s} .
$$

Numerical values corresponding to Figure 10 obtained by the formulae above are

$$
\begin{array}{lll}
u_{\mathrm{f}}=5.52 \mathrm{~kg} / \mathrm{m}^{3} & u_{\mathrm{m} 0}=0.80 \mathrm{~kg} / \mathrm{m}^{3} & u_{\mathrm{u} 0}=u_{\mathrm{u}}=8.83 \mathrm{~kg} / \mathrm{m}^{3} \\
s_{0}=6.25 \mathrm{~kg} /\left(\mathrm{m}^{2} \mathrm{~h}\right) & u_{\mathrm{M} 0}=7.50 \mathrm{~kg} / \mathrm{m}^{3} & m_{0}=47.0 \text { tonnes } \\
s=8.79 \mathrm{~kg} /\left(\mathrm{m}^{2} \mathrm{~h}\right) & u_{0}^{\mathrm{M}}=2.44 \mathrm{~kg} / \mathrm{m}^{3} & m_{\infty}=101.4 \text { tonnes } \\
f\left(u_{0}^{\mathrm{M}}\right)=9.72 \mathrm{~kg} /\left(\mathrm{m}^{2} \mathrm{~h}\right) & u_{1}=1.50 \mathrm{~kg} / \mathrm{m}^{3} & t_{1}=23 \mathrm{~min} \\
Q_{\mathrm{f}}=4500 \mathrm{~m}^{3} / \mathrm{h} & u_{1}^{*}=6.30 \mathrm{~kg} / \mathrm{m}^{3} & t_{3} \approx 4.80 \mathrm{~h} \\
Q_{\mathrm{u} 0}=2000 \mathrm{~m}^{3} / \mathrm{h} & u_{2}=5.73 \mathrm{~kg} / \mathrm{m}^{3} & t_{4} \approx 7.33 \mathrm{~h} \\
Q_{\mathrm{e}}=2500 \mathrm{~m}^{3} / \mathrm{h} & u_{\mathrm{cl}}=5.85 \mathrm{~kg} / \mathrm{m}^{3} & t_{4} \leq 7.58 \mathrm{~h} \quad \text { Eq. (20) } \\
u_{\mathrm{z}}=4.81 \mathrm{~kg} / \mathrm{m}^{3} & u_{\mathrm{e} \infty}=2.87 \mathrm{~kg} / \mathrm{m}^{3} &
\end{array}
$$




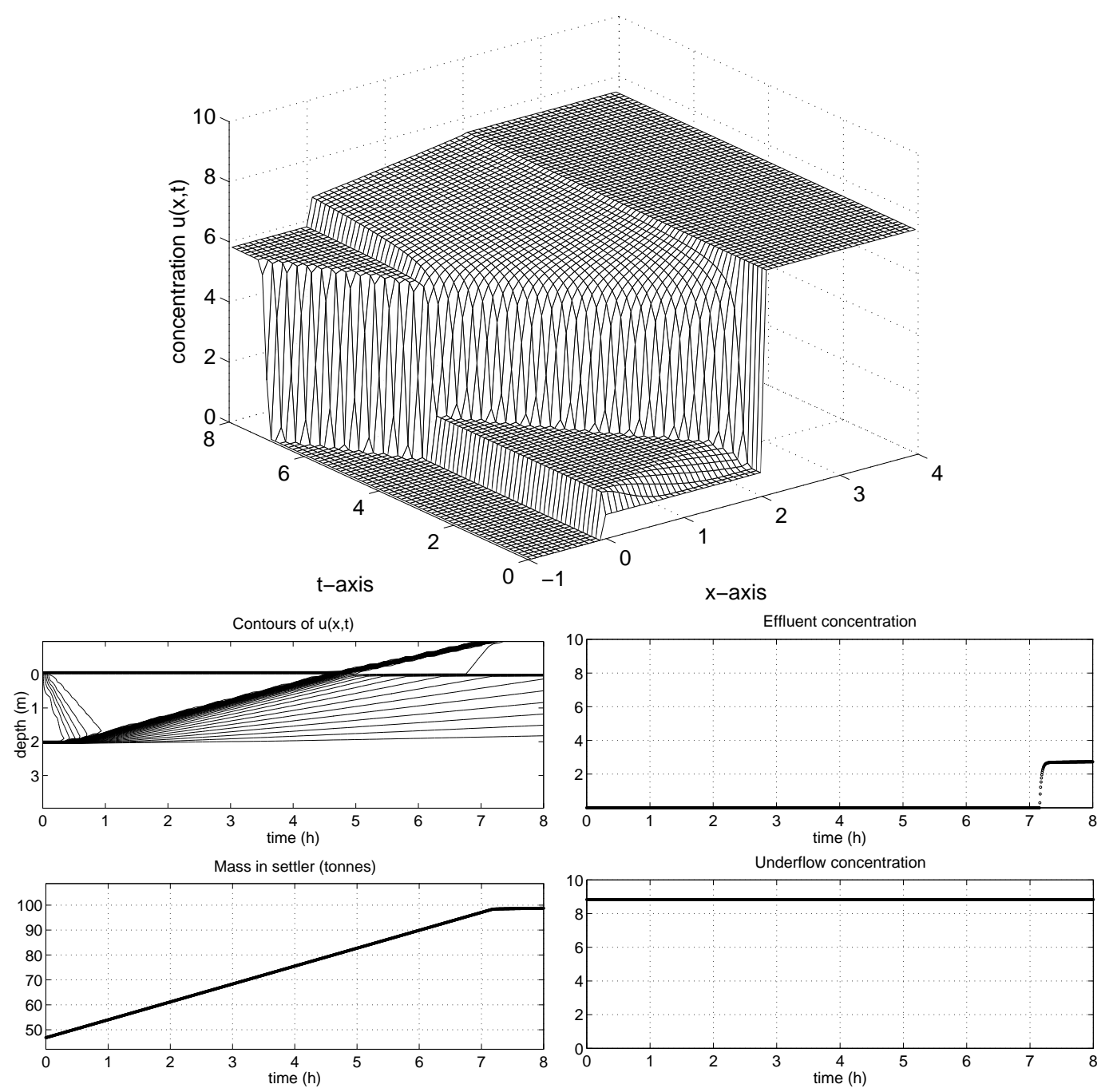

Figure 12. Step response as $\left(u_{\mathrm{f}}, s\right) \in \mathcal{O}_{2 \mathrm{a}}$ and $s<\hat{f}\left(u_{\mathrm{f}} ; u_{\mathrm{m} 0}\right)$.

A numerical simulation is shown in Figure 12.

4.7.2. $\left(u_{\mathrm{f}}, s\right) \in \mathcal{O}_{2 \mathrm{~b}}$

We note that $u_{\mathrm{f}}$ is the unique concentration value of the intersection of $\hat{f}\left(u ; u_{\mathrm{m} 0}\right)$ and $\check{g}(u ; 0)+$ $s$, see Figure 13 (left). Hence the new boundary values after $t=0$ are $u^{-}(t)=u^{+}(t)=u_{\mathrm{f}}$ and the solution is shown in Figure 14. In the clarification zone a rising discontinuity is created immediately:

$$
x_{5}(t)=S_{g}\left(u_{\mathrm{f}}, 0\right) t=\frac{g\left(u_{\mathrm{f}}\right)}{u_{\mathrm{f}}} t, \quad 0<t<\tau_{1} .
$$

If the speed of this is sufficiently large (and/or $H$ is not too large and/or the depth $x_{\mathrm{sb} 0}$ not too small) it reaches the effluent at time

$$
\tau_{1}=\frac{H u_{\mathrm{f}}}{-g\left(u_{\mathrm{f}}\right)}=\frac{H u_{\mathrm{f}}}{s-f\left(u_{\mathrm{f}}\right)} \leq \tau_{2}
$$



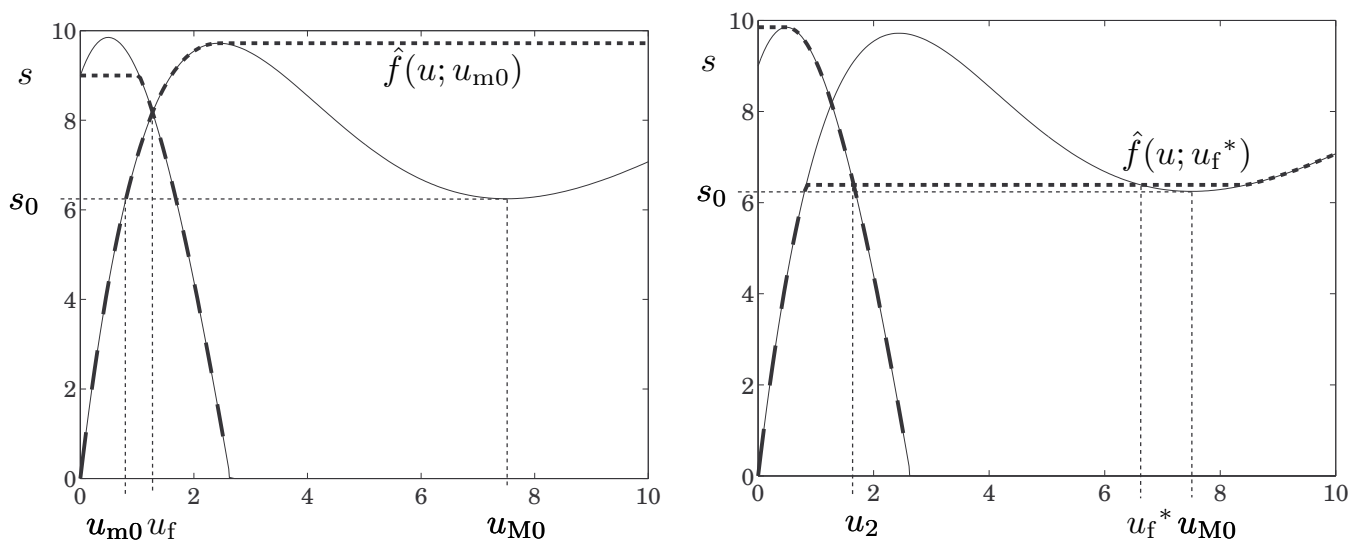

Figure 13. The case $\left(u_{\mathrm{f}}, s\right) \in \mathcal{O}_{2 \mathrm{~b}}$. The situation at the feed level at $t=0$ (left) and at $t=t_{3}$ (right).

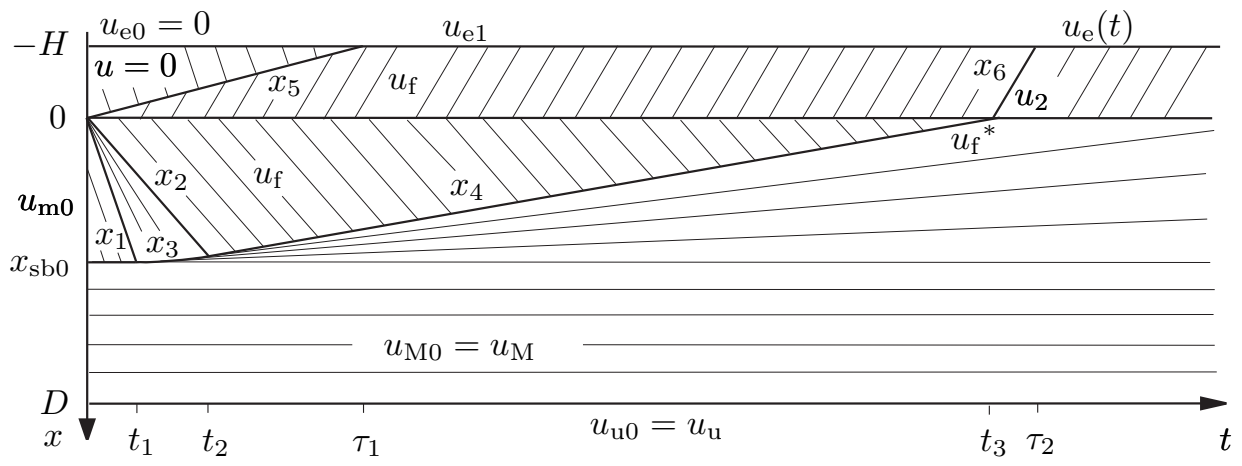

Figure 14. Step response as $\left(u_{\mathrm{f}}, s\right) \in \mathcal{O}_{2 \mathrm{~b}}$. Analytical solution in the case $x_{5}$ and $x_{6}$ do not intersect. The settler leaves the state of optimal operation at $t=0+$.

as is shown in Figure 14. The effluent concentration between $\tau_{1}$ and $\tau_{2}$ is

$$
u_{\mathrm{e} 1}=-\frac{A g\left(u_{\mathrm{f}}\right)}{Q_{\mathrm{e}}}, \quad \tau_{1} \leq t<\tau_{2} .
$$

In the thickening zone the solution is qualitatively the same as in Figure 11 with $u_{1}=u_{\mathrm{f}}$ and the formulae in Section 4.7.1 hold up to time $t_{3}$. At this time point the auxiliary functions, see Figure 13 (right), define the new boundary values $u^{-}\left(t_{3}\right)=u_{2}$ and $u^{+}\left(t_{3}\right)=u_{\mathrm{f}}{ }^{*}$. If $u_{2}<u_{\text {infl }}$ then there is a discontinuity

$$
x_{6}(t)=S_{g}\left(u_{\mathrm{f}}, u_{2}\right)\left(t-t_{3}\right), \quad t_{3}<t<\tau_{2} .
$$

If $u_{2} \geq u_{\mathrm{f}}^{*}$, then there is a small expansion wave below $x_{6}$. If $x_{5}$ and $x_{6}$ do not intersect in the clarification zone, we have

$$
\tau_{2}=t_{3}-\frac{H\left(u_{2}-u_{\mathrm{f}}\right)}{g\left(u_{2}\right)-g\left(u_{\mathrm{f}}\right)} .
$$

The asymptotic behaviour is qualitatively the same as in the previous case with the limit of the effluent concentration given by (18) and the limit mass by (19). Assuming that $\tau_{1} \leq \tau_{2}$ the 
mass in the settler is

$$
m(t)= \begin{cases}m_{0}+t A \Delta s, & 0 \leq t<\tau_{1} \\ m_{0}+t A \Delta s-\left(t-\tau_{1}\right) Q_{\mathrm{e}} u_{\mathrm{e} 1}, & \tau_{1} \leq t<\tau_{2} \\ m_{0}+t A \Delta s-\left(t-\tau_{2}\right) Q_{\mathrm{e}} u_{\mathrm{e}}(t), & t \geq \tau_{2}\end{cases}
$$

where $u_{\mathrm{e}}(t)$ continuously increasing for $t \geq \tau_{2}$. An exact expression for $t_{3}$ is given by (21) with $u_{1}^{*}$ substituted for $u_{\mathrm{f}}{ }^{*}$. A crude approximation can be obtained by approximating the concentration distribution in the region $0<x<x_{\mathrm{sb} 0}$ at $t=t_{3}$ by a straight line joining $u_{\mathrm{f}}{ }^{*}$ and $u_{\mathrm{M} 0}$. Assuming also that $\tau_{1} \leq t_{3}$ and equalizing the two expressions for the mass:

$$
m\left(t_{3}\right)=m_{0}+t_{3} A \Delta s-\left(t_{3}-\tau_{1}\right) Q_{\mathrm{e}} u_{\mathrm{e} 1} \approx A\left(H u_{\mathrm{f}}+x_{\mathrm{sb} 0} \frac{u_{\mathrm{f}}^{*}+u_{\mathrm{M} 0}}{2}+\left(D-x_{\mathrm{sb} 0}\right) u_{\mathrm{M} 0}\right)
$$

yields (note that $q_{\mathrm{e}} u_{\mathrm{e} 1}=-g\left(u_{\mathrm{f}}\right)=s-f\left(u_{\mathrm{f}}\right)$ )

$$
t_{3} \approx \frac{H u_{1}+x_{\mathrm{sb} 0}\left(u_{\mathrm{f}}^{*}+u_{\mathrm{M} 0}\right) / 2+\left(D-x_{\mathrm{sb} 0}\right) u_{\mathrm{M} 0}-m_{0} / A-\tau_{1}\left(s-f\left(u_{\mathrm{f}}\right)\right)}{f\left(u_{\mathrm{f}}\right)-s_{0}} .
$$

Numerical values corresponding to Figure 13 and obtained by the formulae are

$$
\begin{array}{lll}
u_{\mathrm{f}}=1.27 \mathrm{~kg} / \mathrm{m}^{3} & u_{\mathrm{m} 0}=0.80 \mathrm{~kg} / \mathrm{m}^{3} & u_{\mathrm{u} 0}=u_{\mathrm{u}}=8.83 \mathrm{~kg} / \mathrm{m}^{3} \\
s_{0}=6.25 \mathrm{~kg} /\left(\mathrm{m}^{2} \mathrm{~h}\right) & u_{\mathrm{M} 0}=7.50 \mathrm{~kg} / \mathrm{m}^{3} & m_{0}=47.0 \text { tonnes } \\
s=9 \mathrm{~kg} /\left(\mathrm{m}^{2} \mathrm{~h}\right) & u_{\mathrm{f}}^{*}=6.63 \mathrm{~kg} / \mathrm{m}^{3} & m_{\infty}=88.5 \text { tonnes } \\
Q_{\mathrm{f}}=20000 \mathrm{~m}^{3} / \mathrm{h} & u_{2}=1.66 \mathrm{~kg} / \mathrm{m}^{3} & t_{1}=23 \min \\
Q_{\mathrm{u} 0}=2000 \mathrm{~m}^{3} / \mathrm{h} & u_{\mathrm{cl}}=1.69 \mathrm{~kg} / \mathrm{m}^{3} & t_{3} \approx 6.5 \mathrm{~h} \\
Q_{\mathrm{e}}=18000 \mathrm{~m}^{3} / \mathrm{h} & u_{\mathrm{e}}=0.13 \mathrm{~kg} / \mathrm{m}^{3} & \tau_{2} \approx 6.7 \mathrm{~h} \\
u_{\mathrm{z}}=1.04 \mathrm{~kg} / \mathrm{m}^{3} & u_{\mathrm{e} \infty}=0.43 \mathrm{~kg} / \mathrm{m}^{3} &
\end{array}
$$

A numerical simulation yields the results shown in Figure 15.

Finally, we mention the case when $s-f\left(u_{\mathrm{f}}\right)$ is so small, and/or the SBL is so close to the feed level, that the discontinuity $x_{5}$ intersects $x_{6}$ within the clarification zone. Then a new discontinuity is created with zero concentration above. We are content with showing a numerical simulation of this situation in Figure 16, for which the feed point lies close to the lower boundary of $\mathcal{O}_{2 \mathrm{~b}}$. We have kept $u_{\mathrm{f}}=1.27 \mathrm{~kg} / \mathrm{m}^{3}$ and only decreased $Q_{\mathrm{f}}$ to $18500 \mathrm{~m}^{3} / \mathrm{h}$, hence, $s=8.325 \mathrm{~kg} /\left(\mathrm{m}^{2} \mathrm{~h}\right)$.

4.7.3. $\left(u_{\mathrm{f}}, s\right) \in \mathcal{O}_{2 \mathrm{a}}, s=\hat{f}\left(u_{\mathrm{f}} ; u_{\mathrm{m} 0}\right)$ and $u_{\mathrm{f}}<u_{0}^{\mathrm{M}}$

This is the boundary subcase between $\mathcal{O}_{2 \mathrm{a}}$ and $\mathcal{O}_{2 \mathrm{~b}}$. Since the feed point lies on the graph of $f$ and $u_{\mathrm{f}}$ is always the intersection of $f$ and $g(\cdot)+s, g\left(u_{\mathrm{f}}\right)=0$ holds. This means that the boundary concentration below the feed inlet at $t=0+$ is $u_{1}=u_{\mathrm{f}}=u_{\mathrm{z}}$, cf. Figure 10, and there is no immediate discontinuity in the clarification zone. The solution is qualitatively as in Figure 11 with $u_{1}=u_{\mathrm{f}}$.

4.7.4. $\left(u_{\mathrm{f}}, s\right) \in \mathcal{O}_{2 \mathrm{c}}$

Figure 17 (left) shows that the intersection of the auxiliary function occurs at the decreasing part of $\check{g}(u ; 0)+s$ and the plateau of $\hat{f}\left(u ; u_{\mathrm{m} 0}\right)$ at the concentration $u_{1}>u_{\mathrm{z}}$ defined by

$$
g\left(u_{1}\right)+s=f\left(u_{0}^{\mathrm{M}}\right) .
$$




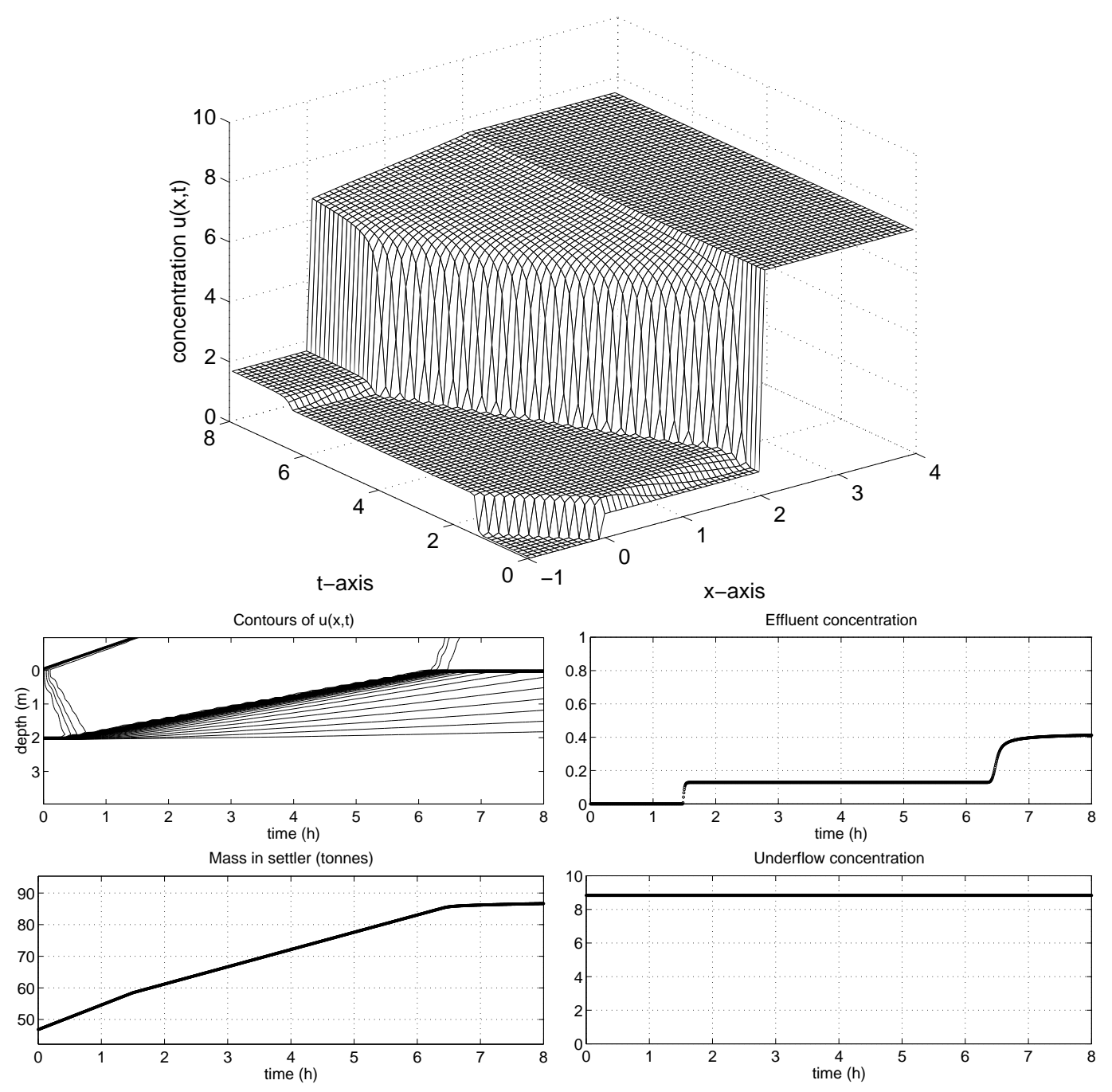

Figure 15. Numerical simulation in the case $\left(u_{\mathrm{f}}, s\right) \in \mathcal{O}_{2 \mathrm{~b}}$.

Condition $\Gamma$ then implies that the boundary concentrations are $u^{-}(t)=u_{1}$ and $u^{+}(t)=u_{0}^{\mathrm{M}}$ for $0<t<t_{3}$, see the solution in Figure 18. The high concentration $u_{1}$ in the clarification zone implies that a rising discontinuity $x_{2}$ is formed immediately:

$$
x_{2}(t)=S_{g}\left(u_{1}, 0\right) t=\frac{g\left(u_{1}\right)}{u_{1}} t, \quad 0<t<\tau_{1} .
$$

If the speed of this is sufficiently high (and the depth $x_{\mathrm{sb0}}$ not too small) it reaches the effluent at time

$$
\tau_{1}=\frac{H u_{1}}{-g\left(u_{1}\right)}=\frac{H u_{1}}{s-f\left(u_{0}^{\mathrm{M}}\right)} \leq \tau_{2} .
$$

Above the line of continuity $x_{1}(t)=f^{\prime}\left(u_{\mathrm{m} 0}\right) t, 0<t<t_{1}$, and below the feed level, there is an expansion wave defined as in the previous subcases, and the discontinuity $x_{3}(t)$ is defined by (15). This rising discontinuity reaches the feed level at $t=t_{3}$ and the situation shown in Figure 17 (right) applies. Then $u_{-}\left(t_{3}\right)=u_{1}$ and $u_{+}\left(t_{3}\right)=u_{0}^{\mathrm{M}^{*}}$ hold. The intersection of the 


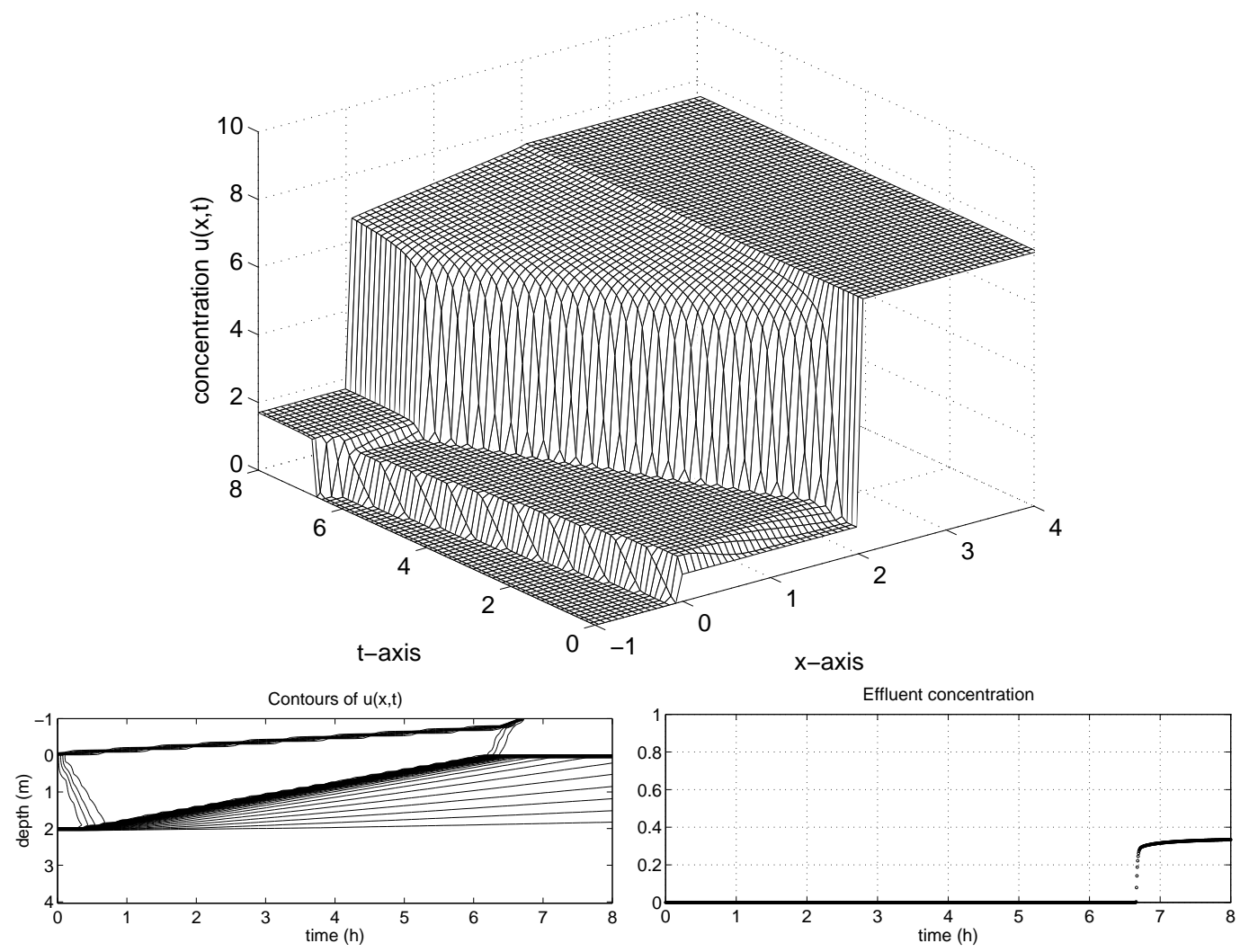

Figure 16. Numerical simulation in the case $\left(u_{\mathrm{f}}, s\right) \in \mathcal{O}_{2 \mathrm{~b}}$ and where $s-f\left(u_{\mathrm{f}}\right)=0.15 \mathrm{~kg} /\left(\mathrm{m}^{2} \mathrm{~h}\right)$ is so small that the discontinuity $x_{5}$ intersects the discontinuity $x_{6}$ in the clarification zone.
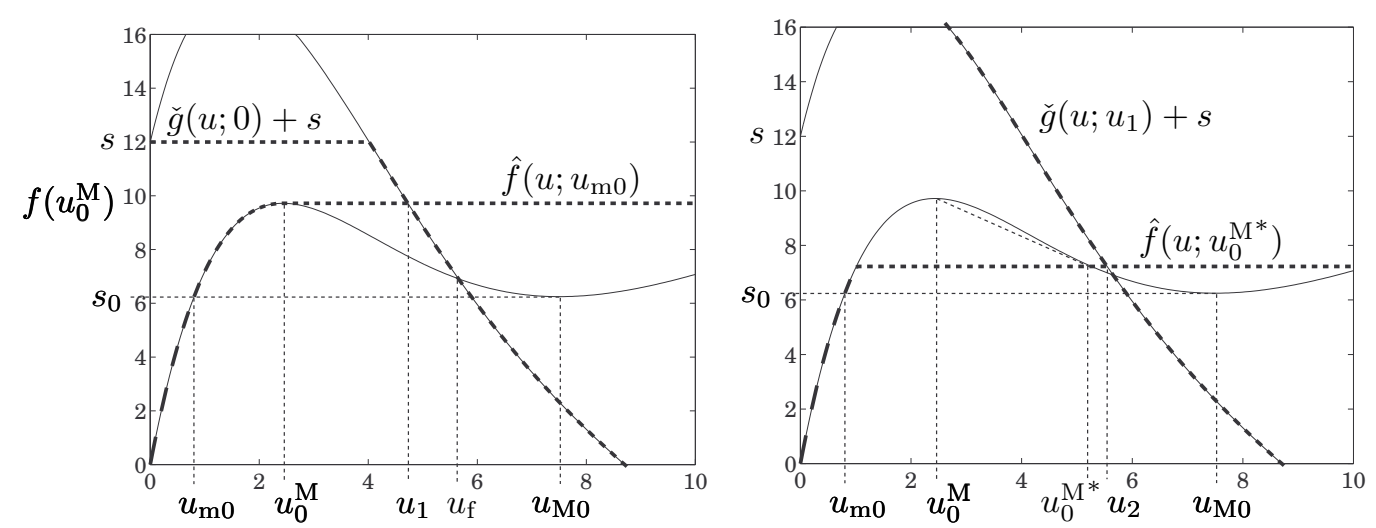

Figure 17. The case $\left(u_{\mathrm{f}}, s\right) \in \mathcal{O}_{2 \mathrm{c}}$. The situation at the feed level at $t=0$ (left) and at $t=t_{3}$ (right).

auxiliary functions occurs at the point $\left(u_{2}, g\left(u_{2}\right)+s\right)$ where $u_{2}$ is defined by the equation $g\left(u_{2}\right)+s=f\left(u_{0}^{\mathrm{M}^{*}}\right)$. Condition $\Gamma$ yields $u^{-}\left(t_{3}\right)=u_{2}$ and $u^{+}\left(t_{3}\right)=u_{+}\left(t_{3}\right)=u_{0}^{\mathrm{M}^{*}}$ and the boundary concentrations are continuously increasing for $t>t_{3}$. In Figure 17 both $u_{1}$ and $u_{2}>u_{\text {infl }}=4.15$. Then

$$
x_{4}(t)=g^{\prime}\left(u_{1}\right)\left(t-t_{3}\right), \quad t_{3}<t<\tau_{2}
$$




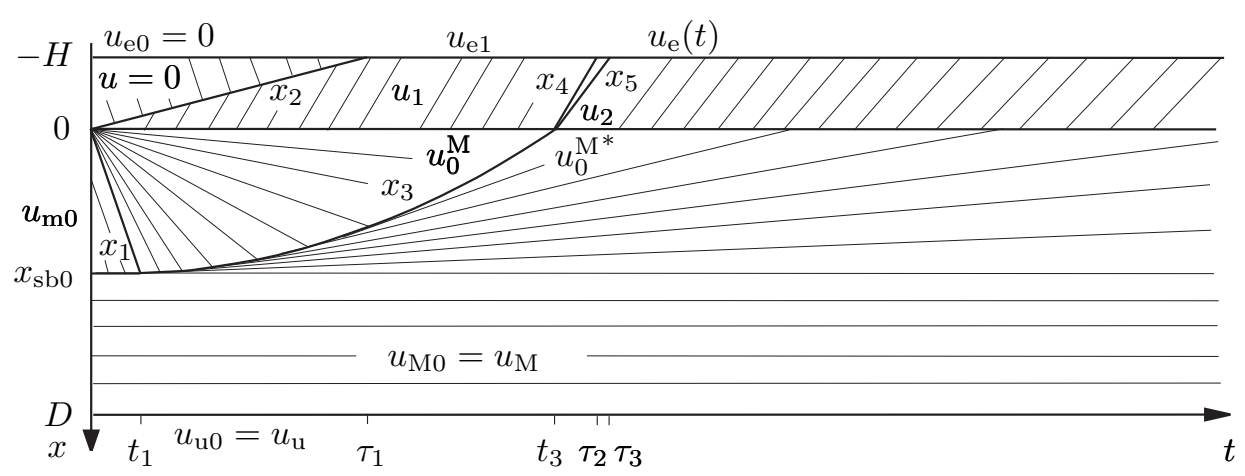

Figure 18. Step response as $\left(u_{\mathrm{f}}, s\right) \in \mathcal{O}_{2 \mathrm{c}}$ and in the case when $x_{2}$ and $x_{4}$ do not intersect. The settler leaves the state of optimal operation at $t=0$.

$$
x_{5}(t)=g^{\prime}\left(u_{2}\right)\left(t-t_{3}\right), \quad t_{3}<t<\tau_{3},
$$

and there is an expansion wave between these two lines of continuity where the concentration increases from $u_{1}$ and $u_{2}$. If $u_{1}<u_{2} \leq u_{\text {infl, }}$, then there is a single shock wave

$$
x_{4}(t)=x_{5}(t)=S_{g}\left(u_{1}, u_{2}\right)\left(t-t_{3}\right), \quad t_{3}<t<\tau_{2} .
$$

If $u_{1} \leq u_{\text {infl }} \leq u_{2}$, then there is a either a single shock wave or an expansion wave where the slope of $x_{5}$ is $g^{\prime}\left(u_{1}^{*}\right)$. The time points are defined by (assuming $u_{\text {infl }} \leq u_{1}<u_{2}$ )

$$
\begin{aligned}
t_{1} & =\frac{x_{\mathrm{sb} 0}}{f^{\prime}\left(u_{\mathrm{m} 0}\right)}, \quad x_{3}\left(t_{3}\right)=0, \\
\tau_{2} & =t_{3}+\frac{H}{-g^{\prime}\left(u_{1}\right)}, \\
\tau_{3} & =t_{3}+\frac{H}{-g^{\prime}\left(u_{2}\right)} .
\end{aligned}
$$

The concentrations in the thickening zone above $x=x_{\mathrm{sb} 0}$ and below $x_{3}$ are uniquely defined by the characteristics emanating tangentially from $x_{3}$. The effluent concentration satisfies

$$
u_{\mathrm{e}}(t)= \begin{cases}0, & 0 \leq t<\tau_{1} \\ u_{\mathrm{e} 1}=-\frac{A g\left(u_{1}\right)}{Q_{\mathrm{e}}}, & \tau_{1} \leq t<\tau_{2} \\ \text { continuously increasing }, & t \geq \tau_{2}\end{cases}
$$

and, particularly, $u_{\mathrm{e}}\left(\tau_{3}\right)=-A g\left(u_{2}\right) / Q_{\mathrm{e}}$. The asymptotic behaviour is qualitatively the same as those in the previous two subcases with the limits $u_{\mathrm{cl}}$ and $u_{\mathrm{M} 0}$ in the clarification and thickening zone, respectively. The effluent concentration and total mass are given by (18) and (19), respectively. Assuming that $\tau_{1} \leq \tau_{2}$ the mass in the settler is given by (23). An exact expression for $t_{3}$ is given by (21) with $u_{1}^{*}$ substituted for $u_{0}^{\mathrm{M} *}$. A crude approximation can be obtained by approximating the concentration distribution in the region $0<x<x_{\mathrm{sb} 0}$ at $t=t_{3}$ by a straight line joining $u_{0}^{\mathrm{M}^{*}}$ and $u_{\mathrm{M} 0}$. Assuming also that $\tau_{1} \leq t_{3}$ and equating the two expressions for the mass

$m\left(t_{3}\right)=m_{0}+t_{3} A \Delta s-\left(t_{3}-\tau_{1}\right) Q_{\mathrm{e}} u_{\mathrm{e} 1} \approx A\left(H u_{1}+x_{\mathrm{sb} 0} \frac{u_{0}^{\mathrm{M}^{*}}+u_{\mathrm{M} 0}}{2}+\left(D-x_{\mathrm{sb} 0}\right) u_{\mathrm{M} 0}\right)$ 


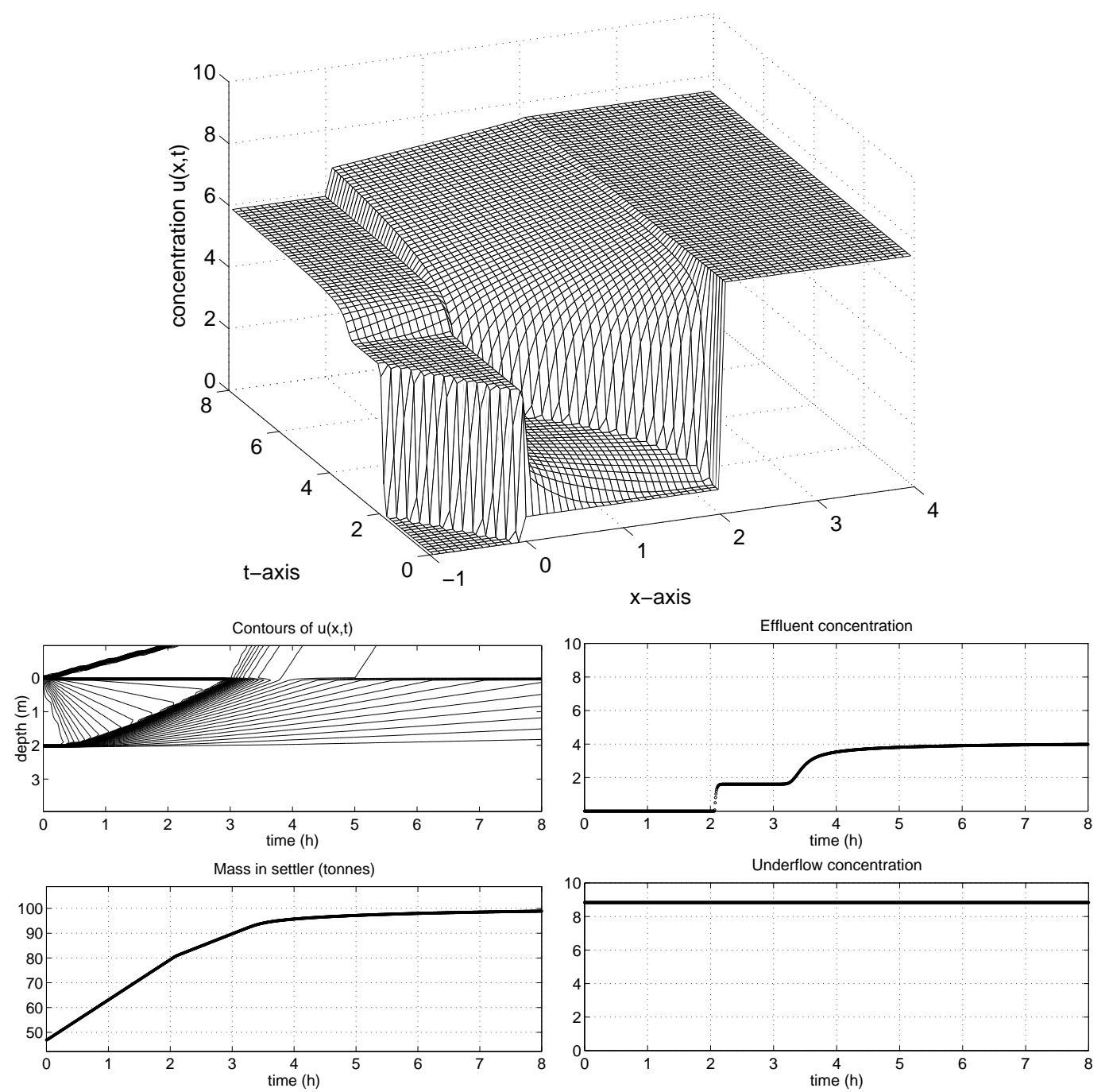

Figure 19. Numerical simulation in the case $\left(u_{\mathrm{f}}, s\right) \in \mathcal{O}_{2 \mathrm{c}}$.

we obtain (note that $q_{\mathrm{e}} u_{\mathrm{e} 1}=-g\left(u_{1}\right)=s-f\left(u_{0}^{\mathrm{M}}\right)$ )

$$
t_{3} \approx \frac{H u_{1}+x_{\mathrm{sb} 0}\left(u_{0}^{\mathrm{M}^{*}}+u_{\mathrm{M} 0}\right) / 2+\left(D-x_{\mathrm{sb} 0}\right) u_{\mathrm{M} 0}-m_{0} / A-\tau_{1}\left(s-f\left(u_{0}^{\mathrm{M}}\right)\right)}{f\left(u_{0}^{\mathrm{M}}\right)-s_{0}} .
$$

Numerical values corresponding to Figure 17 and obtained by the formulae are

$$
\begin{array}{lll}
u_{\mathrm{f}}=5.65 \mathrm{~kg} / \mathrm{m}^{3} & u_{\mathrm{m} 0}=0.80 \mathrm{~kg} / \mathrm{m}^{3} & u_{\mathrm{e} \infty}=4.07 \mathrm{~kg} / \mathrm{m}^{3} \\
s_{0}=6.25 \mathrm{~kg} /\left(\mathrm{m}^{2} \mathrm{~h}\right) & u_{\mathrm{M} 0}=7.50 \mathrm{~kg} / \mathrm{m}^{3} & u_{\mathrm{u} 0}=u_{\mathrm{u}}=8.83 \mathrm{~kg} / \mathrm{m}^{3} \\
s=12 \mathrm{~kg} /\left(\mathrm{m}^{2} \mathrm{~h}\right) & u_{0}^{\mathrm{M}}=2.44 \mathrm{~kg} / \mathrm{m}^{3} & t_{1}=22 \mathrm{~min} \\
f\left(u_{0}^{\mathrm{M}}\right)=9.72 \mathrm{~kg} /\left(\mathrm{m}^{2} \mathrm{~h}\right) & u_{0}^{\mathrm{M}}=5.26 \mathrm{~kg} / \mathrm{m}^{3} & t_{3} \approx 3.2 \mathrm{~h} \\
Q_{\mathrm{f}}=6000 \mathrm{~m}^{3} / \mathrm{h} & u_{1}=4.73 \mathrm{~kg} / \mathrm{m}^{3} & \tau_{2} \approx 3.53 \mathrm{~h} \\
Q_{\mathrm{u} 0}=2000 \mathrm{~m}^{3} / \mathrm{h} & u_{2}=5.54 \mathrm{~kg} / \mathrm{m}^{3} & \tau_{3} \approx 3.56 \mathrm{~h} \\
Q_{\mathrm{e}}=4000 \mathrm{~m}^{3} / \mathrm{h} & u_{\mathrm{cl}}=5.89 \mathrm{~kg} / \mathrm{m}^{3} & m_{0}=47.0 \text { tonnes } \\
u_{\mathrm{z}}=4.02 \mathrm{~kg} / \mathrm{m}^{3} & u_{\mathrm{e} 1}=1.61 \mathrm{~kg} / \mathrm{m}^{3} & m_{\infty}=101.5 \text { tonnes }
\end{array}
$$



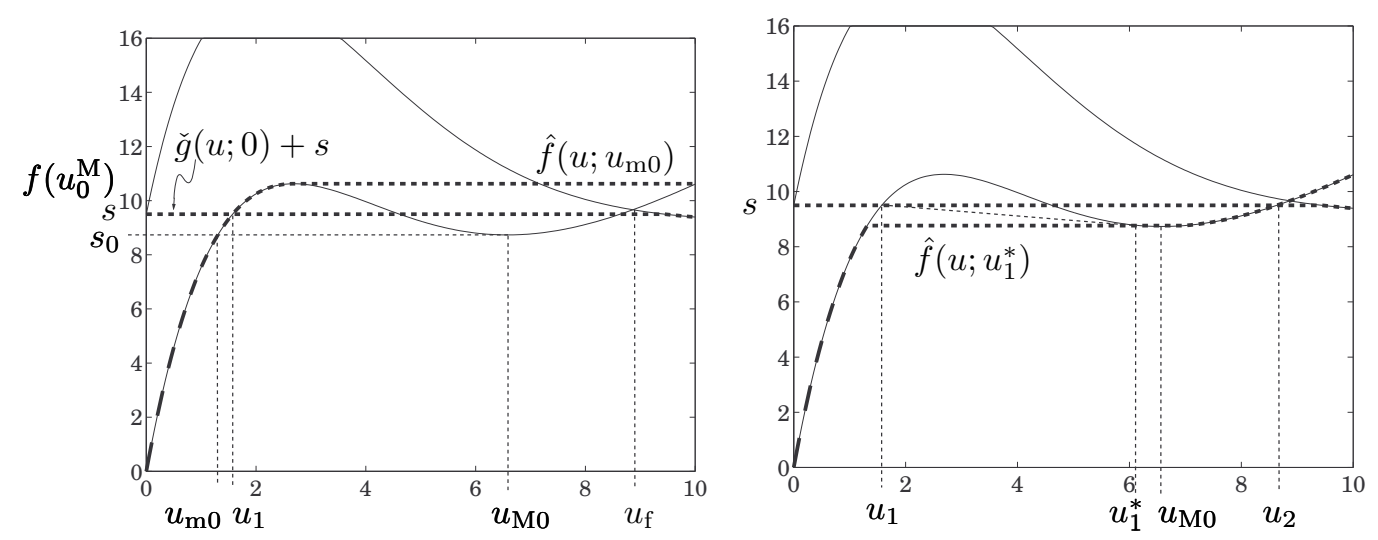

Figure 20. The case $\left(u_{\mathrm{f}}, s\right) \in \mathcal{U}_{2 \mathrm{a}}$ and $s<f\left(u_{0}^{\mathrm{M}}\right)$. The situation at $t=0$ (left) and at $t=t_{3}$ (right).

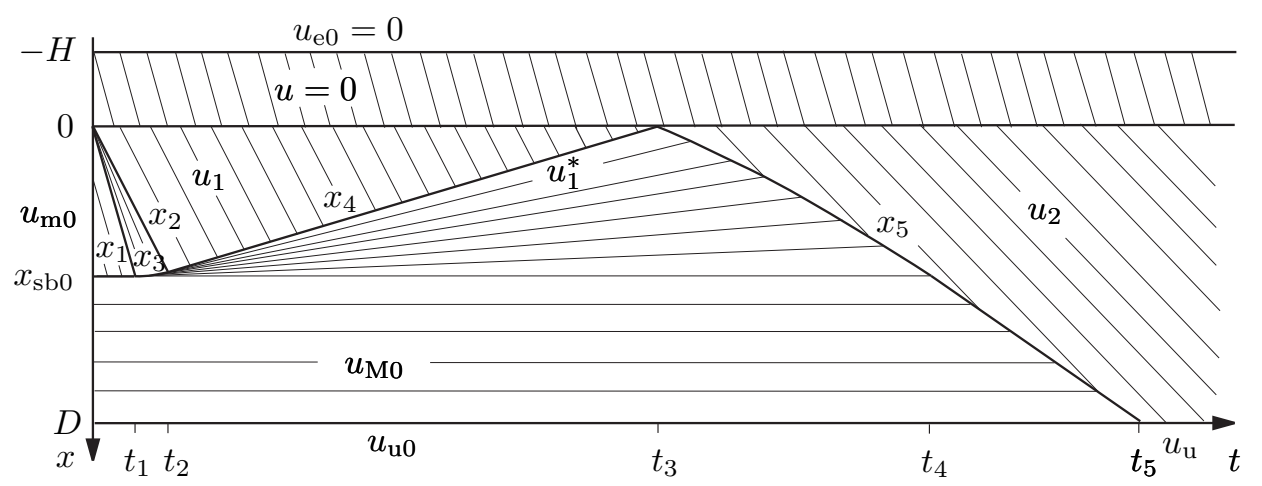

Figure 21. Step response as $\left(u_{\mathrm{f}}, s\right) \in \mathcal{U}_{2 \mathrm{a}}$ and $s<f\left(u_{0}^{\mathrm{M}}\right)$. The settler is in optimal operation during $t \in\left[0, t_{3}\right) \cup\left(t_{3}, t_{5}\right)$.

A numerical simulation yields the result shown in Figure 19.

\subsection{5. $\left(u_{\mathrm{f}}, s\right) \in \mathcal{O}_{2 \mathrm{a}}$ and $s=f\left(u_{0}^{\mathrm{M}}\right)$}

This is the boundary case between $\mathcal{O}_{2 \mathrm{a}}$ and $\mathcal{O}_{2 \mathrm{c}}$, in which $u_{1}$ in Figure 10 equals $u_{0}^{\mathrm{M}}$. The solution in the clarification zone is the one shown in Figure 11 and in the thickening zone the one in Figure 18. The settler is in optimal operation until $t=t_{3}$.

\subsection{STEP RESPONSE AS $\left(u_{\mathrm{f}}, s\right) \in \mathcal{U}_{2}$}

In this case $u_{\mathrm{f}}>u_{\mathrm{f} 0}$ and $s>s_{0}$. As in the case $\mathcal{O}_{2}$ there are different subcases depending on whether $s \lessgtr f\left(u_{0}^{\mathrm{M}}\right)$.

\subsection{1. $\left(u_{\mathrm{f}}, s\right) \in \mathcal{U}_{2 \mathrm{a}}$ and $s<f\left(u_{0}^{\mathrm{M}}\right)$}

(Note that in $\mathcal{U}_{2 \mathrm{a}} s \leq f\left(u_{0}^{\mathrm{M}}\right)$ holds.) Initially, the solution is qualitatively the same as in the case $\mathcal{O}_{2 \mathrm{a}}$ (Figures 10 and 11), see Figures 20 (left) and 21. When the SBL reaches the feed level at $t=t_{3}$ a new situation arises, see Figure 20 (right). The intersection of $\hat{f}\left(u ; u_{1}^{*}\right)$ and $\check{g}(u ; 0)+s$ occurs at the concentration $u_{2}>u_{\mathrm{M} 0}$ that satisfies $f\left(u_{2}\right)=s$. The declining discontinuity $x_{5}$ has a slightly increasing speed for $t_{3}<t<t_{4}$, since the concentration is 
constant $u_{2}$ above it and slightly increasing from $u_{1}^{*}$ to $u_{\mathrm{M} 0}$ below it. After it has reached the depth $x=x_{\mathrm{sb} 0}$ at $t=t_{4}$ the speed is constant $x_{5}^{\prime}(t)=S_{f}\left(u_{\mathrm{M} 0}, u_{2}\right)$. At $t=t_{5}$ the new steady state begins. The mass increases linearly with the rate $A \Delta s$ for $0<t<t_{5}$ and has thereafter the constant value $m\left(t_{5}\right)=m_{0}+t_{5} A \Delta s=A D u_{2}$, which implies that

$$
t_{5}=\frac{A D u_{2}-m_{0}}{A \Delta s} .
$$

An approximation of $t_{3}$ is obtained by (22). Numerical values corresponding to Figure 20 and obtained by the formulae are

$$
\begin{array}{lll}
u_{\mathrm{f}}=8.86 \mathrm{~kg} / \mathrm{m}^{3} & u_{\mathrm{m} 0}=1.30 \mathrm{~kg} / \mathrm{m}^{3} & u_{\mathrm{u} 0}=8.23 \mathrm{~kg} / \mathrm{m}^{3} \\
s_{0}=8.73 \mathrm{~kg} /\left(\mathrm{m}^{2} \mathrm{~h}\right) & u_{\mathrm{M} 0}=6.58 \mathrm{~kg} / \mathrm{m}^{3} & u_{\mathrm{u}}=8.95 \mathrm{~kg} / \mathrm{m}^{3} \\
s=9.5 \mathrm{~kg} /\left(\mathrm{m}^{2} \mathrm{~h}\right) & u_{0}^{\mathrm{M}}=2.69 \mathrm{~kg} / \mathrm{m}^{3} & m_{0}=44.6 \text { tonnes } \\
f\left(u_{0}^{\mathrm{M}}\right)=9.72 \mathrm{~kg} /\left(\mathrm{m}^{2} \mathrm{~h}\right) & u_{0}^{\mathrm{M}^{*}}=5.06 \mathrm{~kg} / \mathrm{m}^{3} & m\left(t_{5}\right)=97.7 \text { tonnes } \\
Q_{\mathrm{f}}=3030 \mathrm{~m}^{3} / \mathrm{h} & u_{1}=1.57 \mathrm{~kg} / \mathrm{m}^{3} & t_{3} \approx 13.3 \mathrm{~h} \\
Q_{\mathrm{u} 0}=3000 \mathrm{~m}^{3} / \mathrm{h} & u_{1}^{*}=6.20 \mathrm{~kg} / \mathrm{m}^{3} & t_{5}=24.5 \mathrm{~h} \\
Q_{\mathrm{e}}=30 \mathrm{~m}^{3} / \mathrm{h} & u_{2}=8.63 \mathrm{~kg} / \mathrm{m}^{3} &
\end{array}
$$

A numerical simulation is shown in Figure 22.

4.8.2. $\left(u_{\mathrm{f}}, s\right) \in \mathcal{U}_{2 \mathrm{~b}}$

Figure 23 shows the situation at $t=0$. The intersection of $\hat{f}\left(u ; u_{\mathrm{m} 0}\right)$ and $\check{g}(u ; 0)+s$ defines the new boundary concentration in the thickening zone. It satisfies $f\left(u_{2}\right)=s$ and $u_{2}>u_{\mathrm{M} 0}$. At $t=0$ a discontinuity $x_{2}$ is created in the thickening zone having low speed downwards and with the concentration $u_{2}$ above and the lower concentration $u_{2 *}$ below it. Below $x_{2}$ there is an expansion wave described in several cases above. Analogously, this holds also for $x_{3}$ and the solution on the right of this discontinuity. At $t=t_{3}$ the discontinuities $x_{2}$ and $x_{3}$ meet resulting in $x_{5}$, which is qualitatively the same type of discontinuity as in case $\mathcal{U}_{2 \mathrm{a}}$. The evolution of the mass in the settler is the same as in the previous case and the time for the new steady state is given by (30). Numerical values corresponding to Figure 23 and obtained by the formulae are

$$
\begin{array}{lll}
u_{\mathrm{f}}=8.48 \mathrm{~kg} / \mathrm{m}^{3} & u_{\mathrm{m} 0}=1.89 \mathrm{~kg} / \mathrm{m}^{3} & u_{\mathrm{u} 0}=7.76 \mathrm{~kg} / \mathrm{m}^{3} \\
s_{0}=10.71 \mathrm{~kg} /\left(\mathrm{m}^{2} \mathrm{~h}\right) & u_{\mathrm{M} 0}=5.81 \mathrm{~kg} / \mathrm{m}^{3} & u_{\mathrm{u}}=8.70 \mathrm{~kg} / \mathrm{m}^{3} \\
s=12 \mathrm{~kg} /\left(\mathrm{m}^{2} \mathrm{~h}\right) & u_{0}^{\mathrm{M}}=2.99 \mathrm{~kg} / \mathrm{m}^{3} & m_{0}=43.6 \text { tonnes } \\
f\left(u_{0}^{\mathrm{M}}\right)=10.89 \mathrm{~kg} /\left(\mathrm{m}^{2} \mathrm{~h}\right) & u_{0}^{\mathrm{M}}{ }^{*}=4.83 \mathrm{~kg} / \mathrm{m}^{3} & m\left(t_{5}\right)=94.8 \text { tonnes } \\
Q_{\mathrm{f}}=4000 \mathrm{~m}^{3} / \mathrm{h} & u_{2}=8.38 \mathrm{~kg} / \mathrm{m}^{3} & t_{5}=14.0 \mathrm{~h} \\
Q_{\mathrm{u} 0}=3900 \mathrm{~m}^{3} / \mathrm{h} & u_{2 *}=2.89 \mathrm{~kg} / \mathrm{m}^{3} & \\
Q_{\mathrm{e}}=100 \mathrm{~m}^{3} / \mathrm{h} & \left(u_{2 *}\right)^{*}=4.90 \mathrm{~kg} / \mathrm{m}^{3} &
\end{array}
$$

A numerical simulation is shown in Figure 25.

\subsection{3. $\left(u_{\mathrm{f}}, s\right) \in \mathcal{U}_{2 \mathrm{a}}$ and $s=f\left(u_{0}^{\mathrm{M}}\right)$}

This is an intermediate case of $\mathcal{U}_{2 \mathrm{a}}$ and $\mathcal{U}_{2 \mathrm{~b}}$, where the plateaus of $\hat{f}\left(u ; u_{\mathrm{m} 0}\right)$ and $\check{g}(u ; 0)+s$ coincide (at $t=0)$. The boundary concentration below the feed level is initially $u^{+}(0)=u_{1}=$ $u_{0}^{\mathrm{M}}$, which means that the discontinuity $x_{2}$ in Figure 24 has zero slope, i.e., it coincides with the feed level. The concentration is zero in the clarification zone. At $t=t_{3}$ the SBL reaches the feed level, the settler leaves the state of optimal operation, and there is a discontinuity $x_{5}(t)$ 


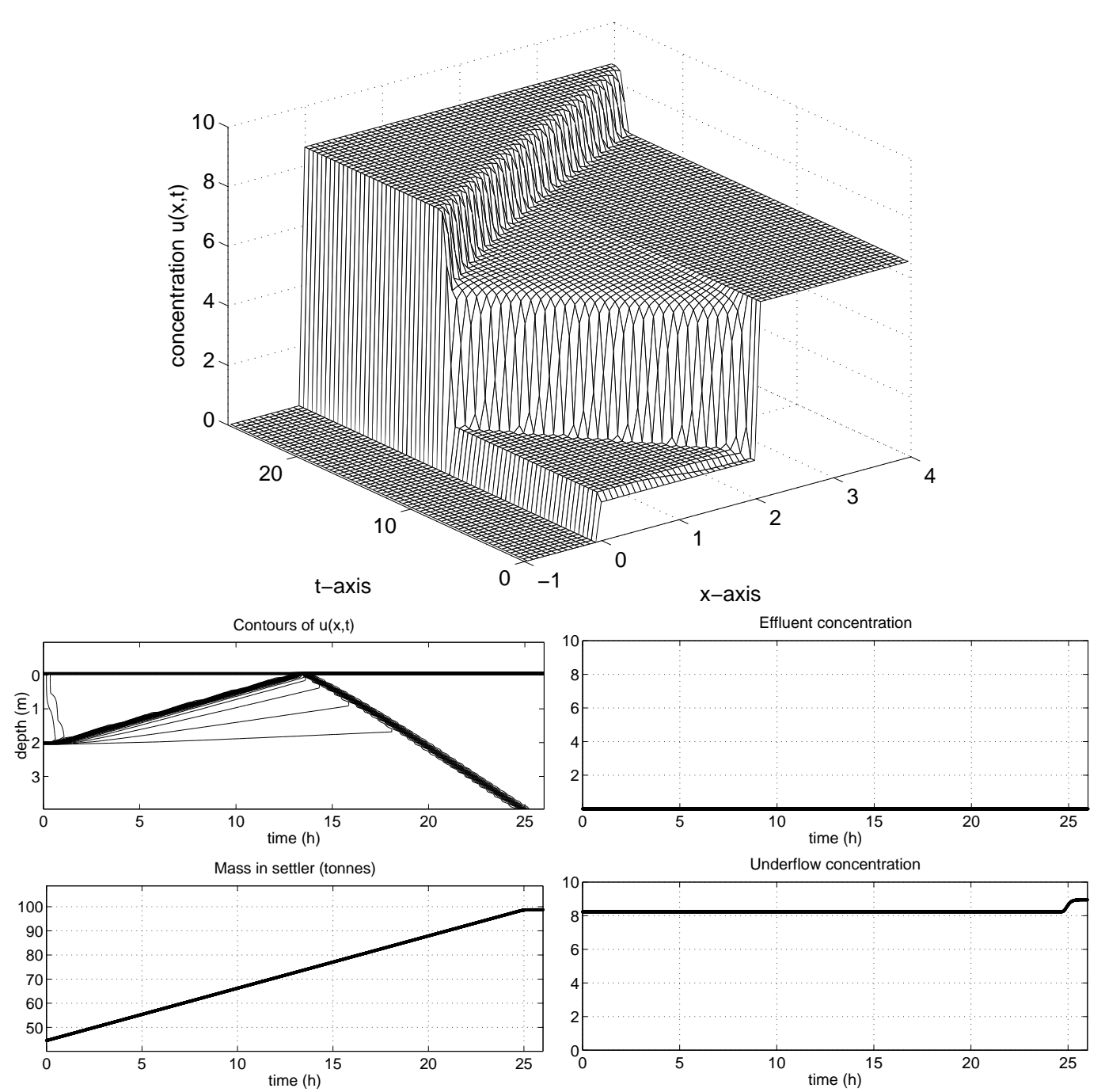

Figure 22. Numerical simulation in the case $\left(u_{\mathrm{f}}, s\right) \in \mathcal{U}_{2 \mathrm{a}}$ and $s<f\left(u_{0}^{\mathrm{M}}\right)$.

moving down to the bottom as in Figures 21 and 24. The final concentration in the thickening zone $u_{2}>u_{\mathrm{M}}$ satisfies $f\left(u_{2}\right)=f\left(u_{0}^{\mathrm{M}}\right)$.

\subsection{STEP RESPONSE AS $\left(u_{\mathrm{f}}, s\right) \in \ell_{4}$}

The solution is qualitatively the same as in the cases $\mathcal{U}_{2 \mathrm{a}}$ and $\mathcal{U}_{2 \mathrm{~b}}$ as is shown in Figures 21 and 24, respectively. The only difference is that in those cases (Figures 21 and 24) $u_{2}<u_{\mathrm{f}}$ but now $u_{2}=u_{\mathrm{f}}$.

\subsection{STEP RESPONSE AS $\left(u_{\mathrm{f}}, s\right) \in \mathcal{O}_{3}$}

There are several qualitatively different subcases. As in the case of a jump to $\mathcal{O}_{2}$ there may be interactions of waves in the clarification zone. We do not consider such cases in detail here since the qualitative behaviour is already demonstrated in Figure 16 and since we can obtain sufficiently informative operating charts for describing the step responses anyway. 


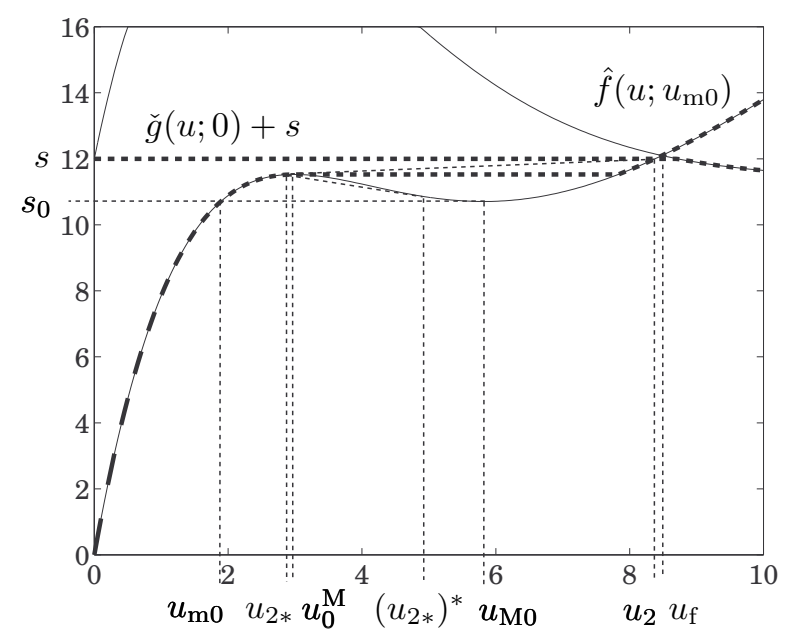

Figure 23. The situation at $t=0$ in the case $\left(u_{\mathrm{f}}, s\right) \in \mathcal{U}_{2 \mathrm{~b}}$.

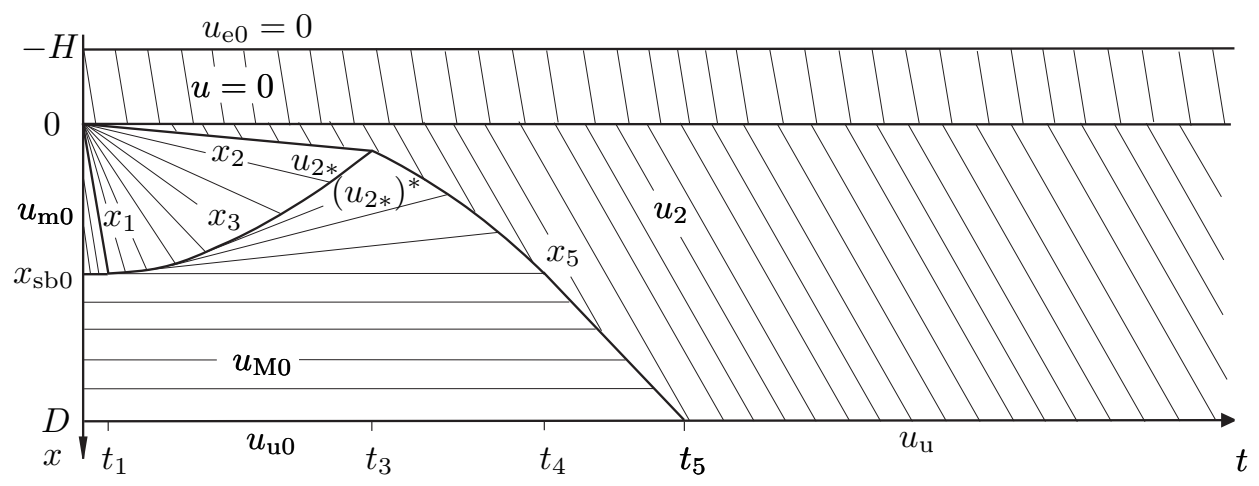

Figure 24. Step response as $\left(u_{\mathrm{f}}, s\right) \in \mathcal{U}_{2 \mathrm{~b}}$. Note that there is neither a time point $t_{2}$ nor a discontinuity $x_{4}$ to facilitate a comparison with Figure 21. Optimal operation is left immediately since $u_{2}>u_{\text {inff }}$.

4.10.1. $\left(u_{\mathrm{f}}, s\right) \in \mathcal{O}_{3 \mathrm{a}}$ and $s<f\left(u_{0}^{\mathrm{M}}\right)$

Initially, the situation is qualitatively the same as in the subcases of $\mathcal{O}_{2 \mathrm{a}}$ (Figures 10 and 11) and $\mathcal{U}_{2 \mathrm{a}}$ (Figures 20 and 21), see Figure 26 (left) and 27. The previous formulae hold up to $t=$ $t_{3}$. As the sludge blanket reaches the feed level at $t=t_{3}$ a new situation arises, see Figure 26 (right). The intersection of $\hat{f}\left(u ; u_{1}^{*}\right)$ and $\check{g}(u ; 0)+s$ occurs at the concentration $u_{\mathrm{f}}$, which will be the new boundary concentration on both sides of the feed level. The rising discontinuity in the clarification zone $x_{6}(t)=S_{g}\left(u_{\mathrm{f}}, 0\right)\left(t-t_{3}\right)=\frac{g\left(u_{\mathrm{f}}\right)}{u_{\mathrm{f}}}\left(t-t_{3}\right)$ reaches the effluent level at time $\tau_{1}=t_{3}+\frac{H u_{f}}{-g\left(u_{\mathrm{f}}\right)}$. The solution in the thickening zone is qualitatively the same as in the case $\mathcal{U}_{2 \mathrm{a}}$, see Figure 21 , with $u_{2}=u_{\mathrm{f}}$. The new steady state begins at $t=\max \left(t_{5}, \tau_{1}\right)$. Using the mass balances $A s_{0}=Q_{\mathrm{u} 0} u_{\mathrm{u} 0}($ at $t=0)$ and $A s=Q_{\mathrm{e}} u_{\mathrm{e}}+Q_{\mathrm{u} 0} u_{\mathrm{u}}=Q_{\mathrm{e}} u_{\mathrm{e}}+A f\left(u_{\mathrm{f}}\right)$ (in the new steady state) the evolution of the mass in the settler can be written as follows. If 


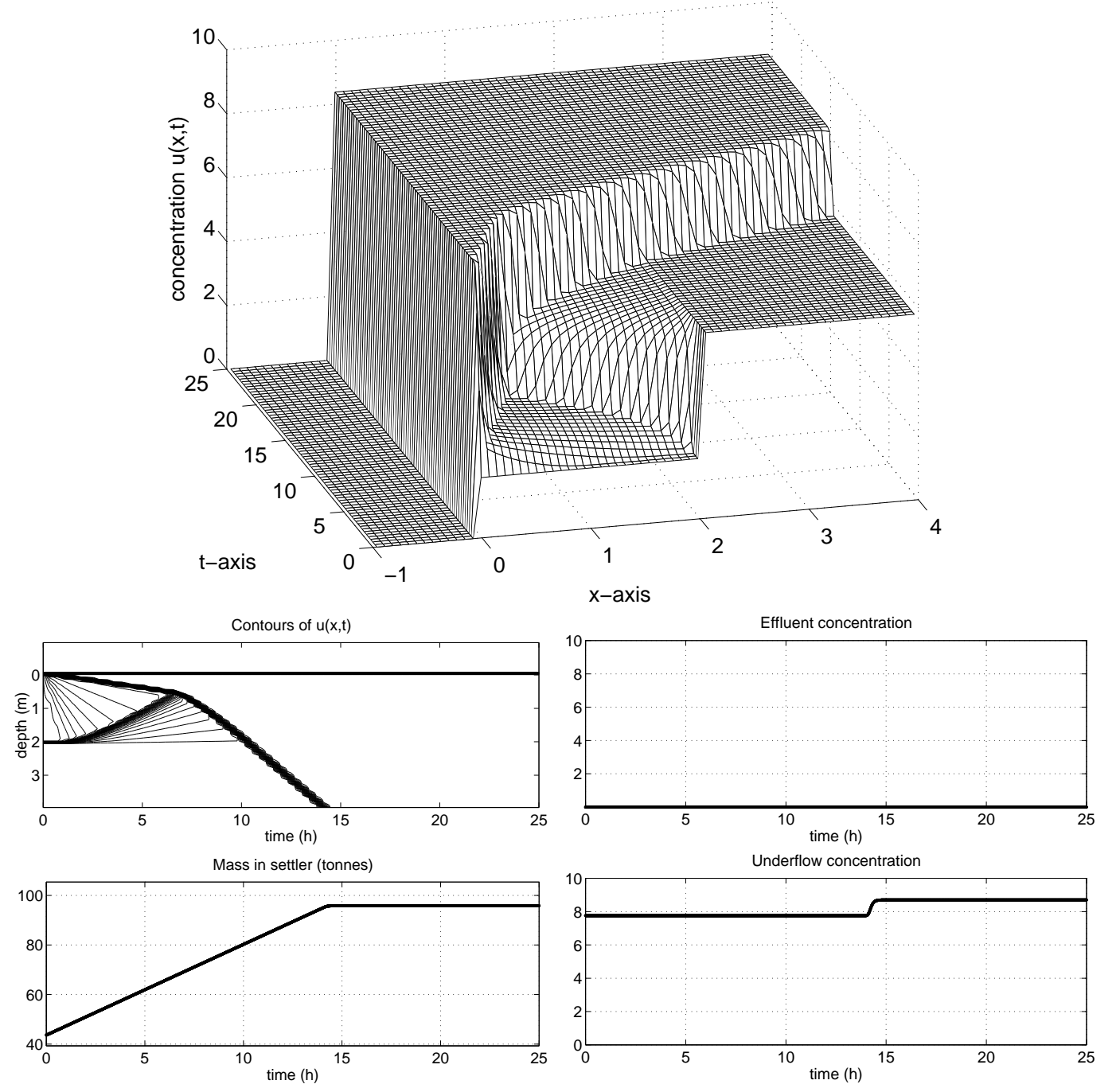

Figure 25. Numerical simulation in the case $\left(u_{\mathrm{f}}, s\right) \in \mathcal{U}_{2 \mathrm{~b}}$. The settler leaves the state of optimal operation immediately.

$\underline{\tau_{1} \leq t_{5}}$, then

$$
m(t)= \begin{cases}m_{0}+t A \Delta s, & 0 \leq t<\tau_{1} \\ m_{0}+t A \Delta s-\left(t-\tau_{1}\right) Q_{\mathrm{e}} u_{\mathrm{e}}, & \tau_{1} \leq t<t_{5} \\ m_{0}+t_{5} A \Delta s-\left(t_{5}-\tau_{1}\right) Q_{\mathrm{e}} u_{\mathrm{e}} & \\ \quad=m_{0}+t_{5} A\left(f\left(u_{\mathrm{f}}\right)-s_{0}\right)+\tau_{1} A\left(s-f\left(u_{\mathrm{f}}\right)\right), & t \geq t_{5} .\end{cases}
$$

If $\underline{\tau_{1}>t_{5}}$, then

$$
m(t)= \begin{cases}m_{0}+t A \Delta s, & 0<t \leq t_{5} \\ m_{0}+t_{5} A \Delta s+\left(t-t_{5}\right)\left(A s-Q_{\mathrm{u} 0} u_{\mathrm{u}}\right) & \\ \quad=m_{0}+t A\left(s-f\left(u_{\mathrm{f}}\right)\right)-t_{5} A\left(s_{0}-f\left(u_{\mathrm{f}}\right)\right), & t_{5}<t \leq \tau_{1} \\ m_{0}+\tau_{1} A\left(s-f\left(u_{\mathrm{f}}\right)\right)-t_{5} A\left(s_{0}-f\left(u_{\mathrm{f}}\right)\right), & t>\tau_{1} .\end{cases}
$$



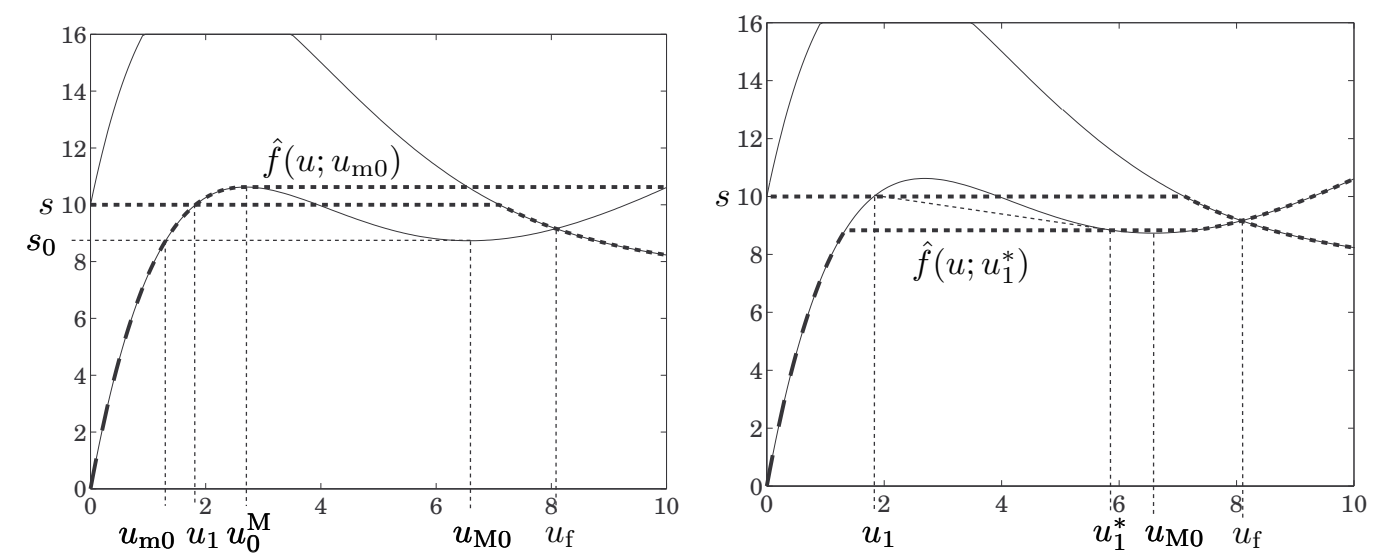

Figure 26. The case $\left(u_{\mathrm{f}}, s\right) \in \mathcal{O}_{3 \mathrm{a}}$ with $s<f\left(u_{0}^{\mathrm{M}}\right)$. The situation at $t=0$ (left) and at $t=t_{3}$ (right).

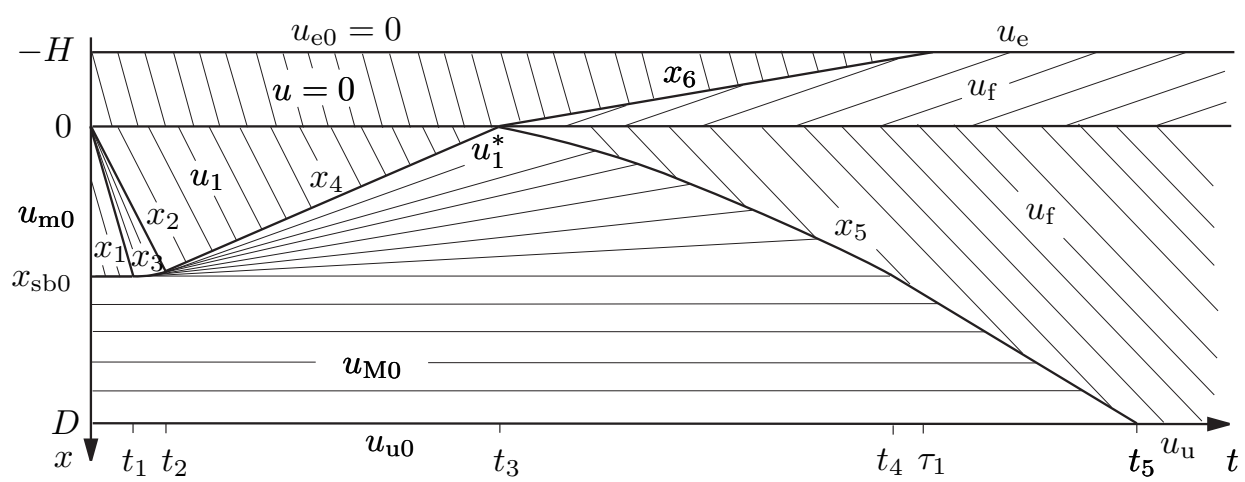

Figure 27. Step response as $\left(u_{\mathrm{f}}, s\right) \in \mathcal{O}_{3 \mathrm{a}}$ with $s<f\left(u_{0}^{\mathrm{M}}\right)$. The settler leaves optimal operation at $t=t_{3}$.

Note that the expressions for the mass in the new steady state in (31) and (32) are the same. Using $m\left(t_{5}\right)=A(H+D) u_{\mathrm{f}}$ we get, independently of whether $\tau_{1} \lessgtr t_{5}$, the expression

$$
A(H+D) u_{\mathrm{f}}=m_{0}+\tau_{1} A\left(s-f\left(u_{\mathrm{f}}\right)\right)-t_{5} A\left(s_{0}-f\left(u_{\mathrm{f}}\right)\right),
$$

from which we obtain

$$
t_{5}=\frac{A(H+D) u_{\mathrm{f}}-\tau_{1} A\left(s-f\left(u_{\mathrm{f}}\right)\right)-m_{0}}{A\left(f\left(u_{\mathrm{f}}\right)-s_{0}\right)} .
$$

An approximation of $t_{3}$ is obtained by (22). Numerical values corresponding to Figure 26 and obtained by the formulae are

$$
\begin{aligned}
& u_{\mathrm{f}}=8.08 \mathrm{~kg} / \mathrm{m}^{3} \\
& s_{0}=8.73 \mathrm{~kg} /\left(\mathrm{m}^{2} \mathrm{~h}\right) \\
& s=10 \mathrm{~kg} /\left(\mathrm{m}^{2} \mathrm{~h}\right) \\
& f\left(u_{0}^{\mathrm{M}}\right)=11.20 \mathrm{~kg} /\left(\mathrm{m}^{2} \mathrm{~h}\right) \\
& Q_{\mathrm{f}}=3500 \mathrm{~m}^{3} / \mathrm{h} \\
& Q_{\mathrm{u} 0}=3000 \mathrm{~m}^{3} / \mathrm{h} \\
& Q_{\mathrm{e}}=500 \mathrm{~m}^{3} / \mathrm{h}
\end{aligned}
$$$$
\begin{aligned}
& u_{\mathrm{m} 0}=1.30 \mathrm{~kg} / \mathrm{m}^{3} \\
& u_{\mathrm{M} 0}=6.58 \mathrm{~kg} / \mathrm{m}^{3} \\
& u_{0}^{\mathrm{M}}=2.69 \mathrm{~kg} / \mathrm{m}^{3} \\
& u_{1}=1.82 \mathrm{~kg} / \mathrm{m}^{3} \\
& u_{1}^{*}=5.89 \mathrm{~kg} / \mathrm{m}^{3} \\
& u_{\mathrm{e}}=4.75 \mathrm{~kg} / \mathrm{m}^{3} \\
& u_{\mathrm{u} 0}=8.23 \mathrm{~kg} / \mathrm{m}^{3}
\end{aligned}
$$$$
u_{\mathrm{u}}=8.63 \mathrm{~kg} / \mathrm{m}^{3}
$$$$
m_{0}=44.6 \text { tonnes }
$$$$
m\left(t_{5}\right)=114 \text { tonnes }
$$$$
t_{3} \approx 7.8 \mathrm{~h}
$$$$
\tau_{1} \approx 17.4 \mathrm{~h}
$$$$
t_{5}=23.5 \mathrm{~h}
$$ 

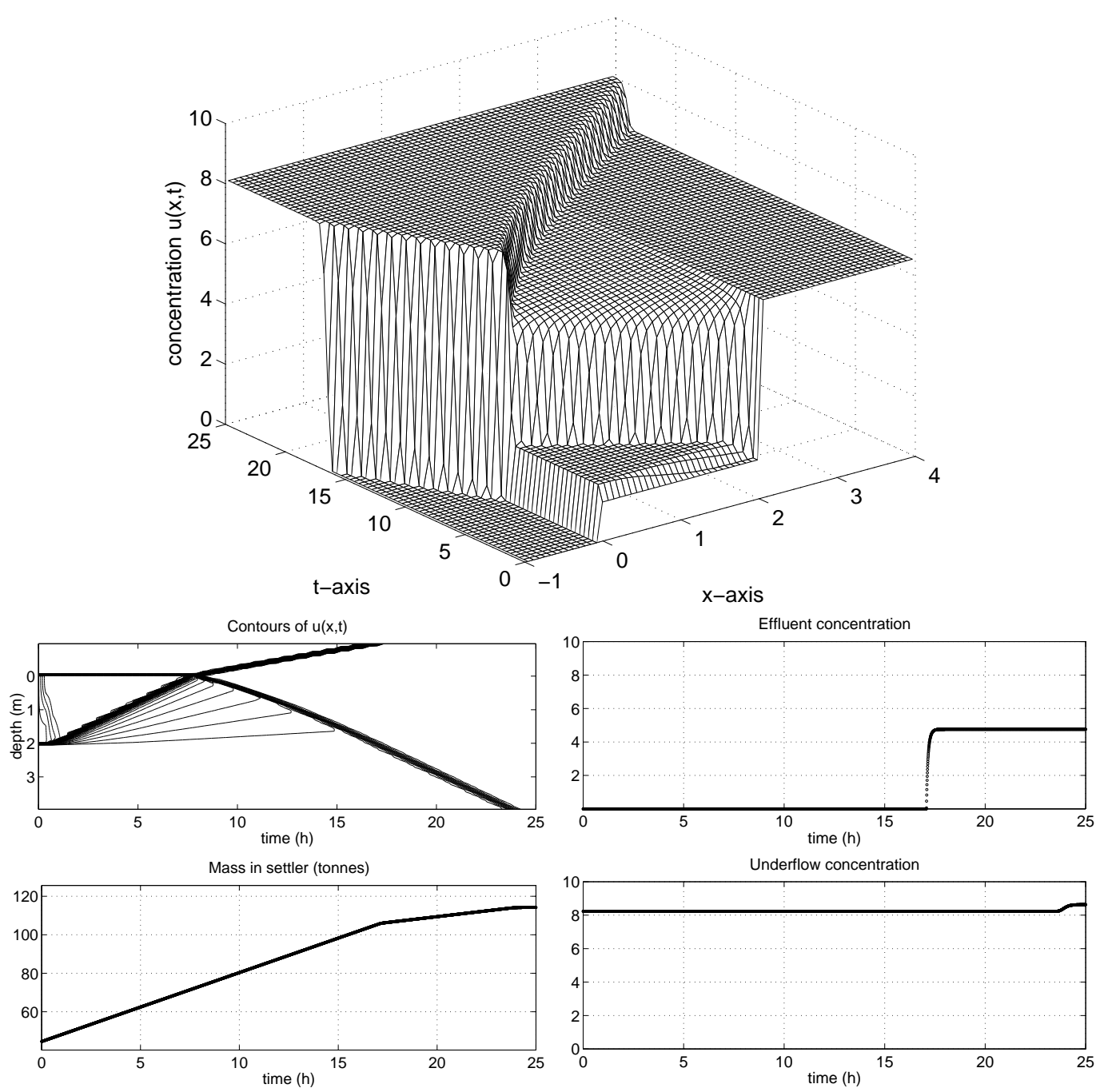

Figure 28. Numerical simulation in the case $\left(u_{\mathrm{f}}, s\right) \in \mathcal{O}_{3 \mathrm{a}}$ and $s<f\left(u_{0}^{\mathrm{M}}\right)$.

A numerical simulation is shown in Figure 28.

4.10.2. $\left(u_{\mathrm{f}}, s\right) \in \mathcal{O}_{3 \mathrm{a}}$ and $s=f\left(u_{0}^{\mathrm{M}}\right)$

This is the boundary case between $\mathcal{O}_{3 \mathrm{a}}$ and $\mathcal{O}_{3 \mathrm{c}}$. The situation and formulae in case $\mathcal{O}_{3 \mathrm{a}}$ hold in principal, however, with $u_{1}=u_{0}^{\mathrm{M}}$. This means that the discontinuity $x_{2}$ in Figure 27 coincides with the feed level and the solution in the thickening zone is the same as in Figure 18.

4.10.3. $\left(u_{\mathrm{f}}, s\right) \in \mathcal{O}_{3 \mathrm{~b}}$

In this and the following two subcases a rising discontinuity is created immediately in the clarification zone. As for the numerical values we keep $s=13 \mathrm{~kg} /\left(\mathrm{m}^{2} \mathrm{~h}\right)$ and set $u_{\mathrm{f}}$ to 9,8 and $7 \mathrm{~kg} / \mathrm{m}^{3}$ in this and the two following subcases, respectively.

Figure 29 shows that the new boundary concentration on both sides of the feed level is $u_{\mathrm{f}}$. In the clarification zone there is a rising discontinuity $x_{6}(t)=S_{g}\left(u_{\mathrm{f}}, 0\right) t=\frac{g\left(u_{\mathrm{f}}\right)}{u_{\mathrm{f}}} t$, which reaches the effluent level at time $\tau_{1}=\frac{H u_{\mathrm{f}}}{-g\left(u_{\mathrm{f}}\right)} 4$, see Figure 30. Since $f\left(u_{\mathrm{f}}\right)>f\left(u_{0}^{\mathrm{M}}\right)$ there will 


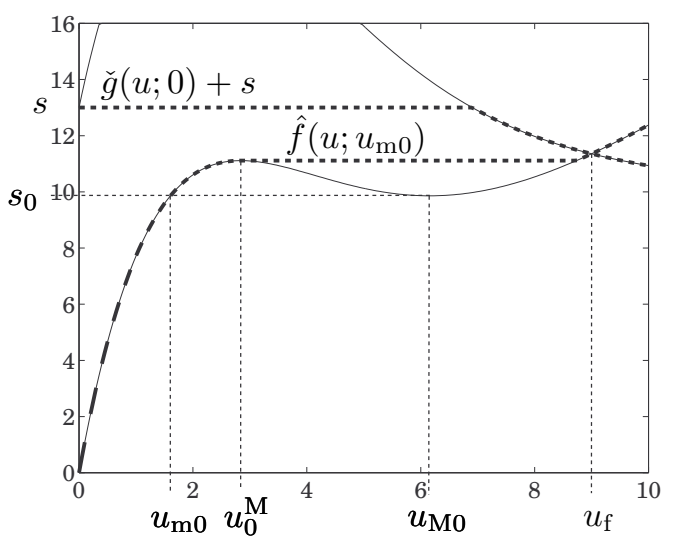

Figure 29. The case $\left(u_{\mathrm{f}}, s\right) \in \mathcal{O}_{3 \mathrm{~b}}$. The situation at $t=0$.

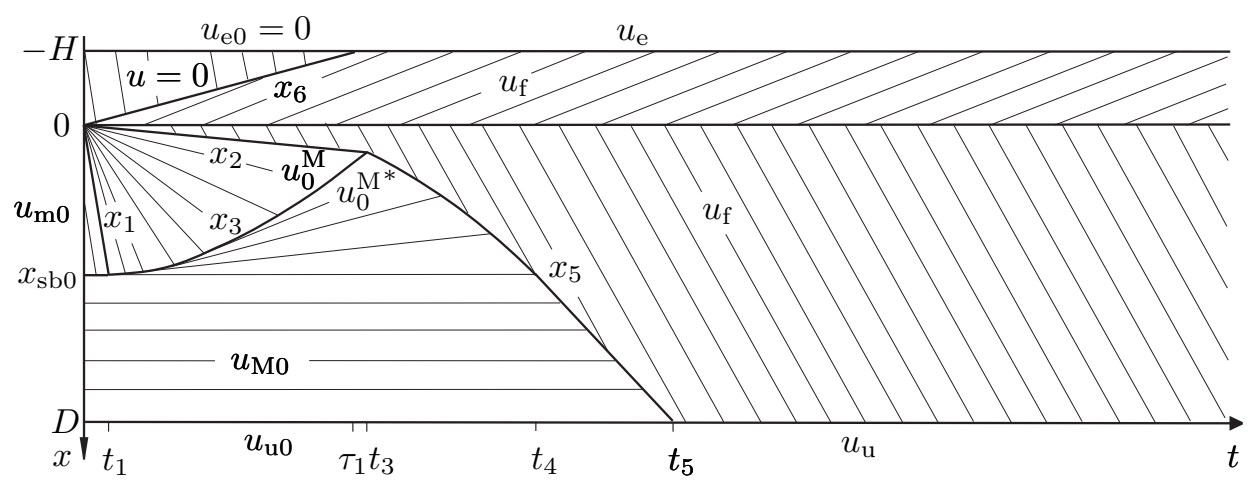

Figure 30. Step response as $\left(u_{\mathrm{f}}, s\right) \in \mathcal{O}_{3 \mathrm{~b}}$. The settler leaves optimal operation immediately.

be a slowly declining discontinuity

$$
x_{2}(t)=S_{f}\left(u_{\mathrm{f}}, u_{0}^{\mathrm{M}}\right) t=\frac{f\left(u_{\mathrm{f}}\right)-f\left(u_{0}^{\mathrm{M}}\right)}{u_{\mathrm{f}}-u_{0}^{\mathrm{M}}} t, \quad 0<t<t_{3}
$$

in the thickening zone. The new steady state begins at $t=\max \left(\tau_{1}, t_{5}\right)$. The evolution of the mass in the settler is given by (31) or (32) depending on whether $\tau_{1} \lessgtr t_{5}$, and $t_{5}$ is given by (34). Numerical values corresponding to Figure 29 and obtained by the formulae are

$$
\begin{array}{lll}
u_{\mathrm{f}}=9 \mathrm{~kg} / \mathrm{m}^{3} & Q_{\mathrm{e}}=584 \mathrm{~m}^{3} / \mathrm{h} & u_{\mathrm{u}}=9.17 \mathrm{~kg} / \mathrm{m}^{3} \\
s_{0}=9.86 \mathrm{~kg} /\left(\mathrm{m}^{2} \mathrm{~h}\right) & u_{\mathrm{m} 0}=1.61 \mathrm{~kg} / \mathrm{m}^{3} & m_{0}=43.9 \text { tonnes } \\
s=13 \mathrm{~kg} /\left(\mathrm{m}^{2} \mathrm{~h}\right) & u_{\mathrm{M} 0}=6.16 \mathrm{~kg} / \mathrm{m}^{3} & m\left(t_{5}\right)=127 \text { tonnes } \\
f\left(u_{0}^{\mathrm{M}}\right)=11.11 \mathrm{~kg} /\left(\mathrm{m}^{2} \mathrm{~h}\right) & u_{0}^{\mathrm{M}}=2.84 \mathrm{~kg} / \mathrm{m}^{3} & \tau_{1}=5.5 \mathrm{~h} \\
Q_{\mathrm{f}}=4084 \mathrm{~m}^{3} / \mathrm{h} & u_{\mathrm{e}}=7.96 \mathrm{~kg} / \mathrm{m}^{3} & t_{5}=13.7 \mathrm{~h} \\
Q_{\mathrm{u} 0}=3500 \mathrm{~m}^{3} / \mathrm{h} & u_{\mathrm{u} 0}=7.96 \mathrm{~kg} / \mathrm{m}^{3} &
\end{array}
$$

A numerical simulation is shown in Figure 31.

4.10.4. $\left(u_{\mathrm{f}}, s\right) \in \mathcal{O}_{3 \mathrm{c}}$ and $f\left(u_{\mathrm{f}}\right) \geq f\left(u_{0}^{\mathrm{M}^{*}}\right)$

This set is a right substrip of $\mathcal{O}_{3 c}$. Initially, the situation is qualitatively the same as in the transition to $\mathcal{O}_{2 \mathrm{c}}$ for $t<t_{3}$; see Figures 17 and 18. The formulae given there are valid for the 

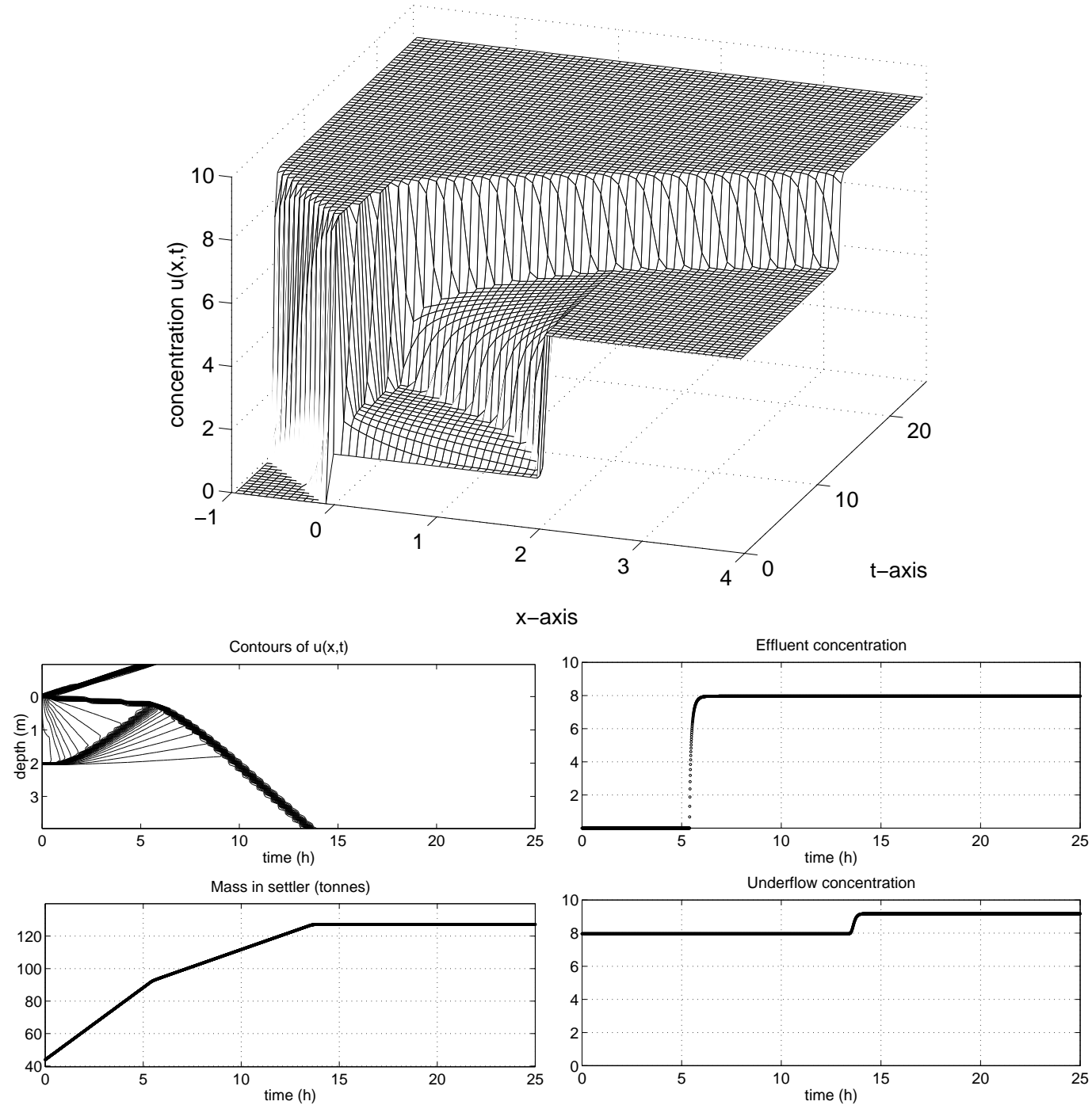

Figure 31. Numerical simulation in the case $\left(u_{\mathrm{f}}, s\right) \in \mathcal{O}_{3 \mathrm{~b}}$.

concentrations and time points up to $t_{3}$ for the thickening zone and $\tau_{3}$ for the clarification zone. Figures 32 and 33 show the solution in the case $f\left(u_{0}^{\mathrm{M}^{*}}\right)<f\left(u_{\mathrm{f}}\right)$. (If $f\left(u_{\mathrm{f}}\right)=f\left(u_{0}^{\mathrm{M}^{*}}\right)$, then $u_{1}=u_{\mathrm{f}}$ is the concentration in the clarification zone on the right of $x_{2}$.) We assume that $x_{2}$ and $x_{4}$ do not intersect, i.e., $\tau_{1}<\tau_{2}$ (otherwise modifications can be made to take into account the known discontinuity $x_{2}$ ). Figure 32 (right) shows that after $t_{3}$ the new concentration above and below the feed level is $u_{\mathrm{f}}$, which will be the concentration at the new steady state in the whole settler. The discontinuity $x_{5}$ in the thickening zone is qualitatively the same as in several previous cases. The effluent concentration satisfies

$$
u_{\mathrm{e}}(t)= \begin{cases}0, & 0 \leq t<\tau_{1} \\ u_{\mathrm{e} 1}=-\frac{A g\left(u_{1}\right)}{Q_{\mathrm{e}}}, & \tau_{1} \leq t \leq \tau_{2} \\ \text { continuously increasing }, & \tau_{2} \leq t \leq \tau_{3} \\ \frac{A g\left(u_{\mathrm{f}}\right)}{Q_{\mathrm{e}}}, & t \geq \tau_{3} .\end{cases}
$$



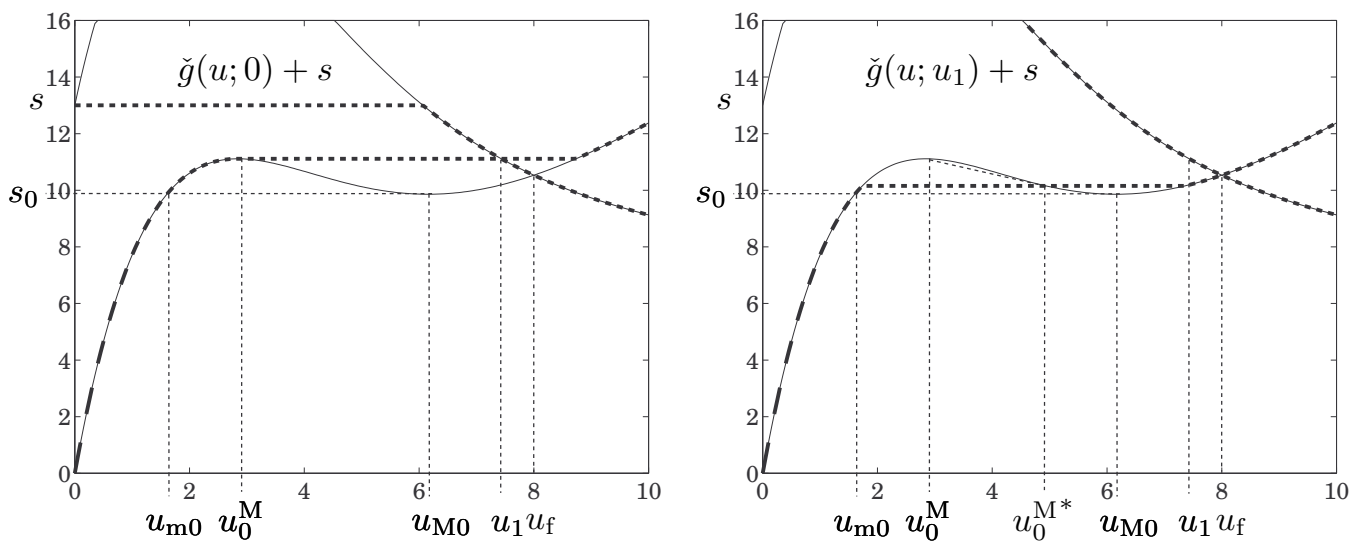

Figure 32. The situation at $t=0$ (left) and at $t=t_{3}$ (right) in the case $\left(u_{\mathrm{f}}, s\right) \in \mathcal{O}_{3 \mathrm{c}}$ with $f\left(u_{\mathrm{f}}\right)>f\left(u_{0}^{\mathrm{M} *}\right)$.

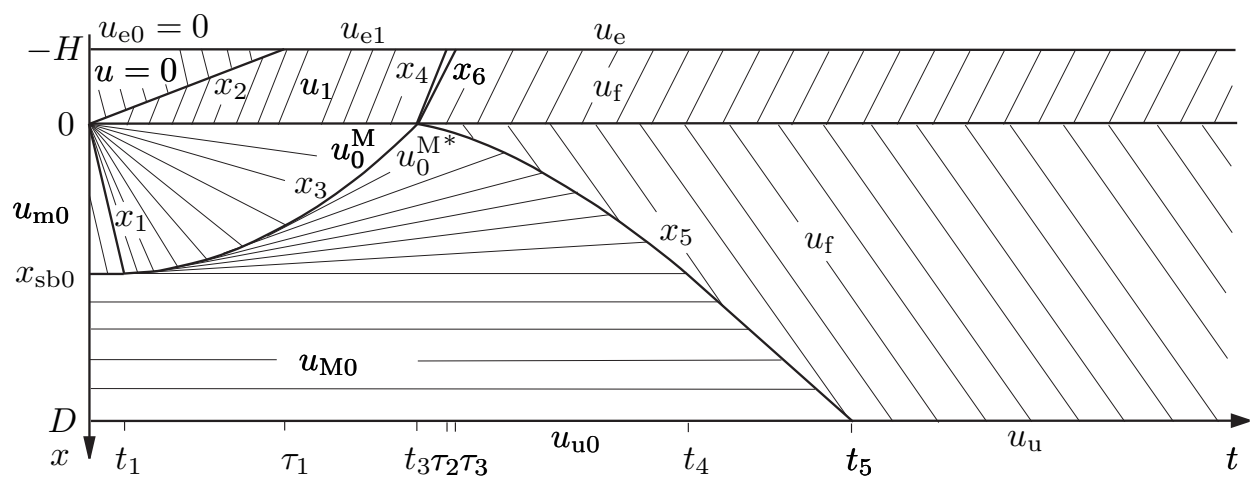

Figure 33. Step response as $\left(u_{\mathrm{f}}, s\right) \in \mathcal{O}_{3 \mathrm{c}}$ and $f\left(u_{\mathrm{f}}\right)>f\left(u_{0}^{\mathrm{M} *}\right)$. Optimal operation is left at $t=0$.

The mass evolution has to be computed numerically between $\tau_{2}$ and $t_{5}$ (assuming $\tau_{2}<t_{5}$ ). Approximating the continuously increasing effluent concentration between $\tau_{2}$ and $\tau_{3}$ with a linear function we get the following approximate mass balance (assuming $\tau_{1} \leq \tau_{2}$ and $\left.\tau_{3} \leq t_{5}\right)$

$A(H+D) u_{\mathrm{f}}=m\left(t_{5}\right) \approx m_{0}+t_{5} A \Delta s-\left(\tau_{2}-\tau_{1}\right) Q_{\mathrm{e}} u_{\mathrm{e} 1}-\left(\tau_{3}-\tau_{2}\right) Q_{\mathrm{e}} \frac{u_{\mathrm{e} 1}+u_{\mathrm{e}}}{2}-\left(t_{5}-\tau_{3}\right) Q_{\mathrm{e}} u_{\mathrm{e}}$

Noting that $Q_{\mathrm{e}} u_{\mathrm{e} 1}=-A g\left(u_{1}\right)=A\left(s-f\left(u_{0}^{\mathrm{M}}\right)\right)$ and $Q_{\mathrm{e}} u_{\mathrm{e}}=-A g\left(u_{\mathrm{f}}\right)=A\left(s-f\left(u_{\mathrm{f}}\right)\right)$ we get

$$
t_{5} \approx \frac{(H+D) u_{\mathrm{f}}-m_{0} / A-\tau_{1}\left(s-f\left(u_{0}^{\mathrm{M}}\right)\right)-\frac{\tau_{2}+\tau_{3}}{2}\left(f\left(u_{0}^{\mathrm{M}}\right)-f\left(u_{\mathrm{f}}\right)\right)}{f\left(u_{\mathrm{f}}\right)-s_{0}}
$$

Numerical values corresponding to Figures 32 and 33 and obtained by the formulae are 

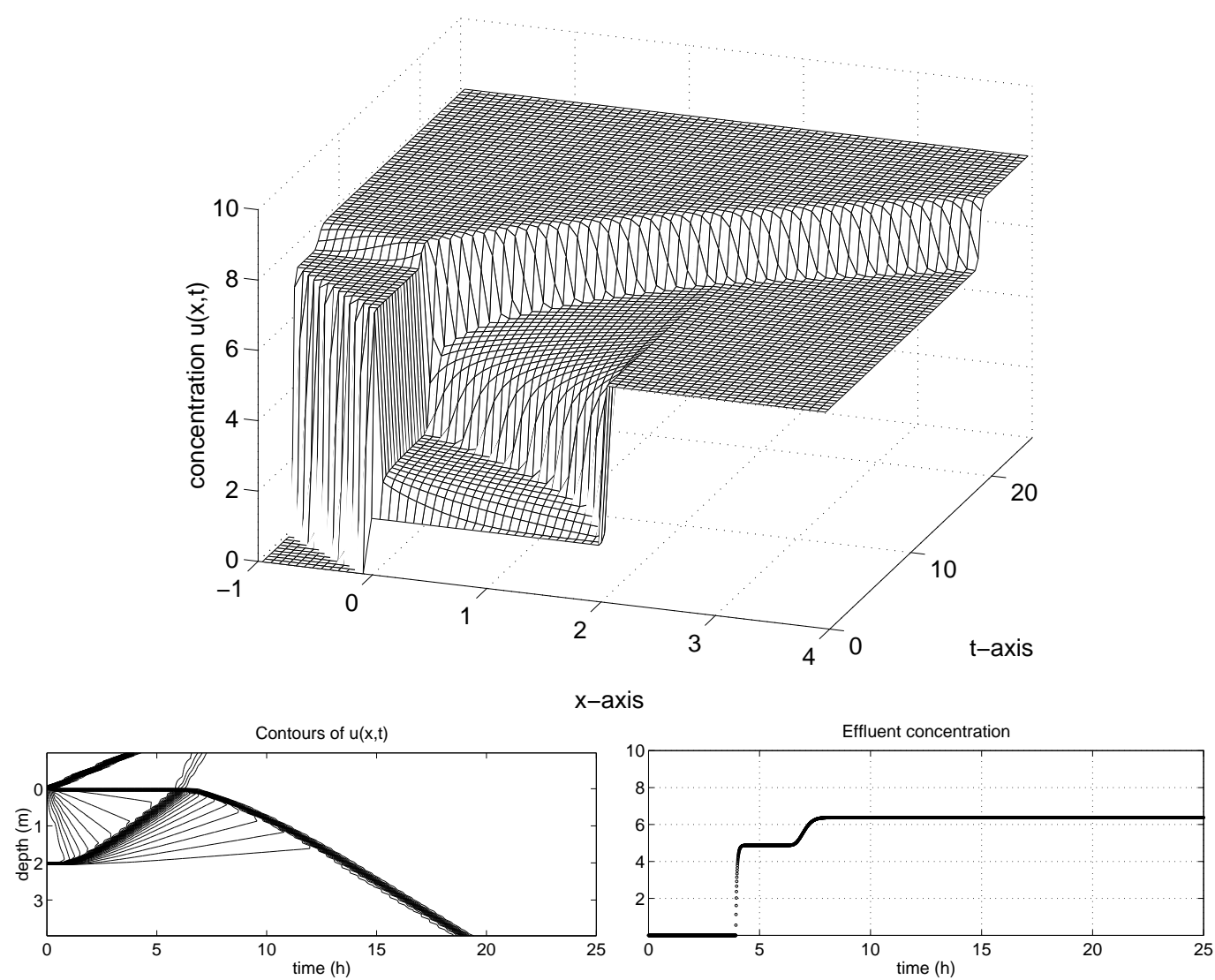

Mass in settler (tonnes)
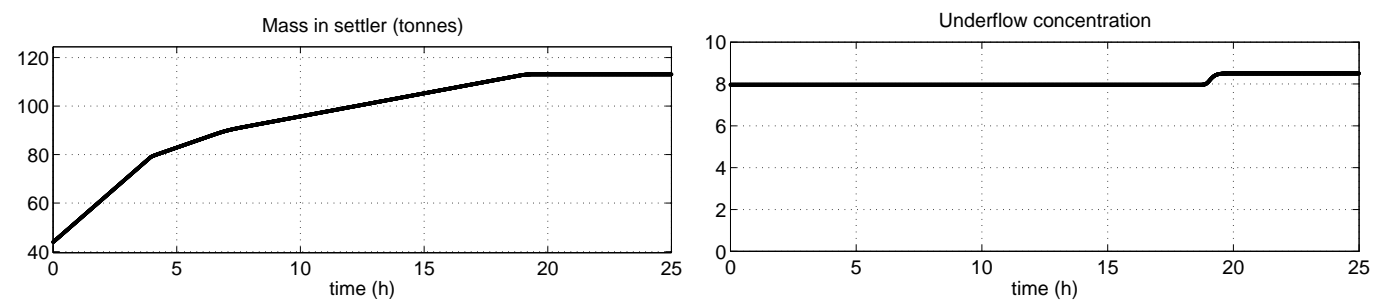

Figure 34. Numerical simulation in the case $\left(u_{\mathrm{f}}, s\right) \in \mathcal{O}_{3 \mathrm{c}}$ and $f\left(u_{\mathrm{f}}\right)>f\left(u_{0}^{\mathrm{M} *}\right)$.

$$
\begin{aligned}
& u_{\mathrm{f}}=8 \mathrm{~kg} / \mathrm{m}^{3} \\
& s_{0}=9.86 \mathrm{~kg} /\left(\mathrm{m}^{2} \mathrm{~h}\right) \\
& s=13 \mathrm{~kg} /\left(\mathrm{m}^{2} \mathrm{~h}\right) \\
& f\left(u_{0}^{\mathrm{M}}\right)=11.11 \mathrm{~kg} /\left(\mathrm{m}^{2} \mathrm{~h}\right) \\
& f\left(u_{0}^{\mathrm{M} *}\right)=10.15 \mathrm{~kg} /\left(\mathrm{m}^{2} \mathrm{~h}\right) \\
& Q_{\mathrm{f}}=4595 \mathrm{~m}^{3} / \mathrm{h} \\
& Q_{\mathrm{u} 0}=3500 \mathrm{~m}^{3} / \mathrm{h} \\
& Q_{\mathrm{e}}=1095 \mathrm{~m}^{3} / \mathrm{h}
\end{aligned}
$$

$$
\begin{aligned}
& u_{\mathrm{m} 0}=1.61 \mathrm{~kg} / \mathrm{m}^{3} \\
& u_{\mathrm{M} 0}=6.16 \mathrm{~kg} / \mathrm{m}^{3} \\
& u_{0}^{\mathrm{M}}=2.84 \mathrm{~kg} / \mathrm{m}^{3} \\
& u_{0}^{\mathrm{M}}{ }^{*}=4.94 \mathrm{~kg} / \mathrm{m}^{3} \\
& u_{1}=7.43 \mathrm{~kg} / \mathrm{m}^{3} \\
& u_{\mathrm{e} 1}=4.87 \mathrm{~kg} / \mathrm{m}^{3} \\
& u_{\mathrm{e}}=6.38 \mathrm{~kg} / \mathrm{m}^{3} \\
& u_{\mathrm{u} 0}=7.96 \mathrm{~kg} / \mathrm{m}^{3}
\end{aligned}
$$

$$
\begin{aligned}
& u_{\mathrm{u}}=8.51 \mathrm{~kg} / \mathrm{m}^{3} \\
& m_{0}=43.9 \text { tonnes } \\
& m\left(t_{5}\right)=113 \text { tonnes } \\
& \tau_{1}=3.9 \mathrm{~h} \\
& t_{3} \approx 5.6 \mathrm{~h} \\
& \tau_{2} \approx 6.5 \mathrm{~h} \\
& \tau_{3} \approx 6.6 \mathrm{~h} \\
& t_{5} \approx 19.7 \mathrm{~h}
\end{aligned}
$$

A numerical simulation is shown in Figure 34. 

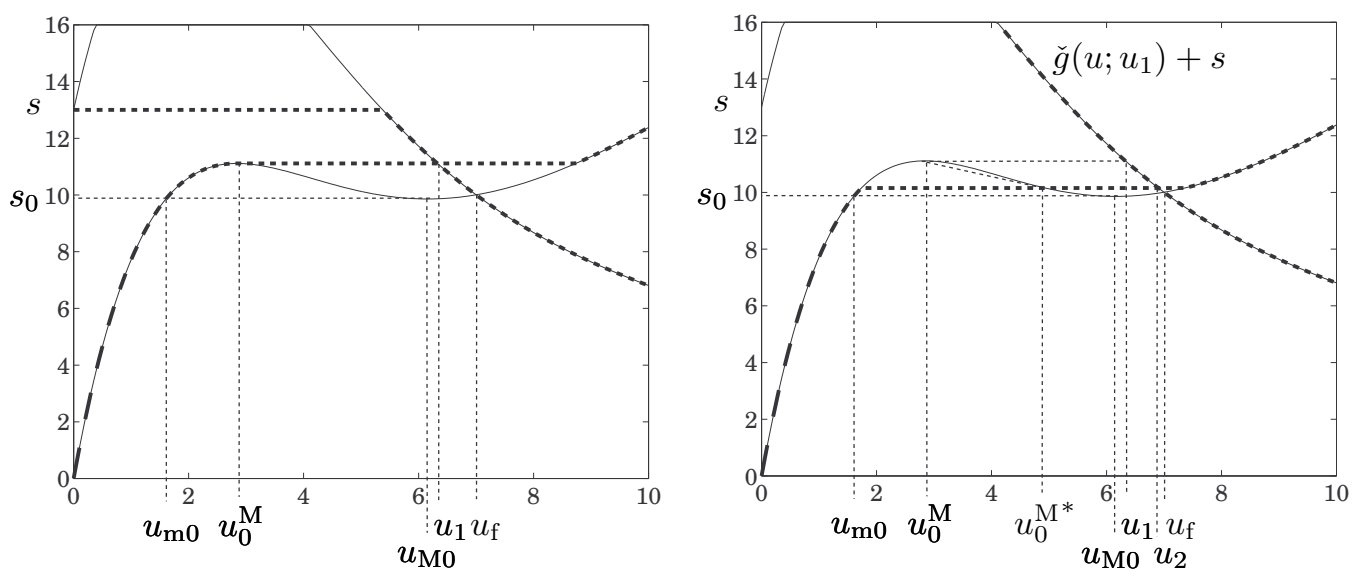

Figure 35. Step response as $\left(u_{\mathrm{f}}, s\right) \in \mathcal{O}_{3 \mathrm{c}}$ with $f\left(u_{\mathrm{f}}\right)<f\left(u_{0}^{\mathrm{M} *}\right)$. The situation at $t=0$ (left) and at $t=t_{3}$ (right).

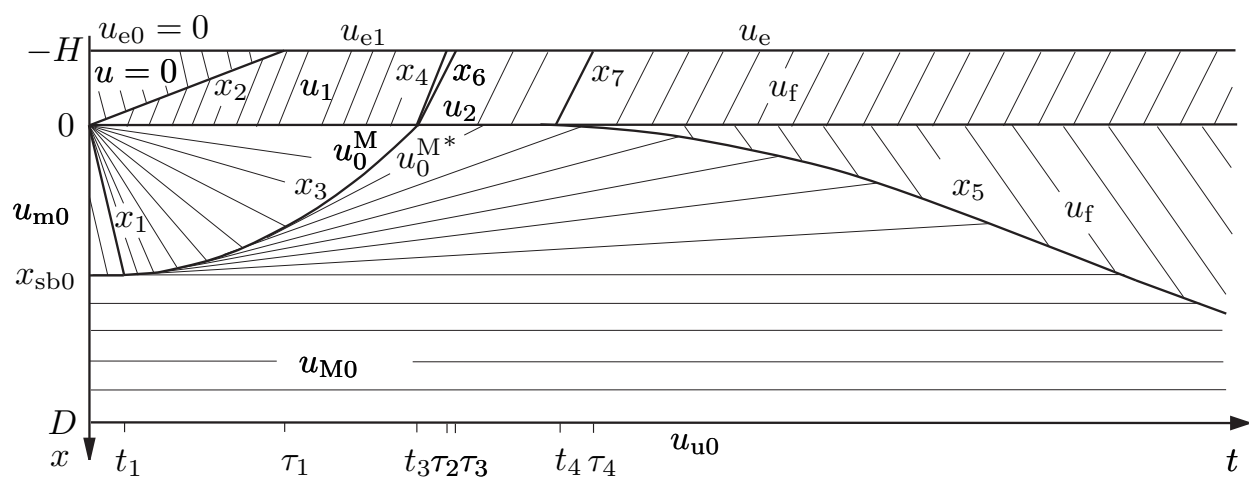

Figure 36. Step response as $\left(u_{\mathrm{f}}, s\right) \in \mathcal{O}_{3 \mathrm{c}}$ and $f\left(u_{\mathrm{f}}\right)<f\left(u_{0}^{\mathrm{M}^{*}}\right)$.

4.10.5. $\left(u_{\mathrm{f}}, s\right) \in \mathcal{O}_{3 \mathrm{c}}$ and $f\left(u_{\mathrm{f}}\right)<f\left(u_{0}^{\mathrm{M} *}\right)$

This set is a left substrip of $\mathcal{O}_{3 \mathrm{c}}$ and the behaviour is similar to that of the previous case. The difference is that in this case there is a 'time-delay' after $t_{3}$ until the discontinuity $x_{5}$ leaves the feed level and moves downwards. This occurs at $t=t_{4}$, see Figure 36. The reason for this is that at $t=t_{3}$ the intersection of $\hat{f}\left(u ; u_{0}^{\mathrm{M}^{*}}\right)$ and $\check{g}\left(u ; u_{1}\right)+s$ occurs at the concentration $u_{2}<u_{\mathrm{f}}$, see Figure 35 (right). For $t_{3}<t<t_{4}$ the boundary concentration $u^{+}(t)=u_{+}(t)$ increases with time from $u^{+}\left(t_{3}\right)=u_{0}^{\mathrm{M}^{*}}$. Hence the corresponding flux value of the plateau of $\hat{f}\left(u ; u_{+}(t)\right)$ decreases with time, see Figure 35 (right). Its intersection with $\check{g}\left(u ; u_{1}\right)+s$ defines the boundary concentration in the clarification zone that increases slightly from $u^{-}\left(t_{3}\right)=u_{2}$. At $t=t_{4}$ the plateau has reached the level $f\left(u_{\mathrm{f}}\right)$ and the new boundary concentration is $u_{\mathrm{f}}$ (for $t>t_{4}$ ) both above and below the feed level. At this time the declining discontinuity $x_{5}$ is created with the initial speed zero. Note that $x_{4}, x_{6}$ and $x_{7}$ are lines of continuity. The new steady state begins at $t_{5}$, which can be calculated approximately by (35) together with the additional approximation $u_{2} \approx u_{\mathrm{f}}$. Numerical values corresponding to Figure 35 and obtained by the formulae are 

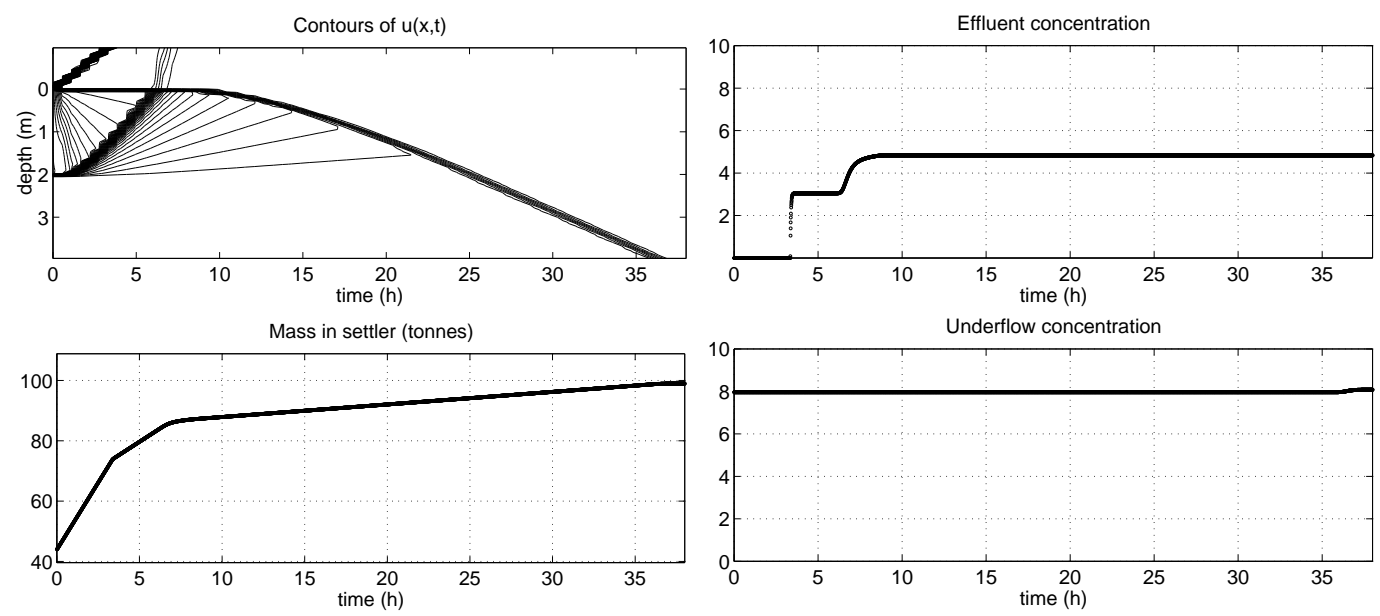

Figure 37. Numerical simulation in the case $\left(u_{\mathrm{f}}, s\right) \in \mathcal{O}_{3 \mathrm{c}}$ and $f\left(u_{\mathrm{f}}\right)<f\left(u_{0}^{\mathrm{M} *}\right)$.

$$
\begin{aligned}
& u_{\mathrm{f}}=7 \mathrm{~kg} / \mathrm{m}^{3} \\
& s_{0}=9.86 \mathrm{~kg} /\left(\mathrm{m}^{2} \mathrm{~h}\right) \\
& s=13 \mathrm{~kg} /\left(\mathrm{m}^{2} \mathrm{~h}\right) \\
& f\left(u_{0}^{\mathrm{M}}\right)=11.11 \mathrm{~kg} /\left(\mathrm{m}^{2} \mathrm{~h}\right) \\
& f\left(u_{0}^{\mathrm{M}}\right)=10.15 \mathrm{~kg} /\left(\mathrm{m}^{2} \mathrm{~h}\right) \\
& Q_{\mathrm{f}}=5251 \mathrm{~m}^{3} / \mathrm{h} \\
& Q_{\mathrm{u} 0}=3500 \mathrm{~m}^{3} / \mathrm{h} \\
& Q_{\mathrm{e}}=1751 \mathrm{~m}^{3} / \mathrm{h}
\end{aligned}
$$

$$
\begin{aligned}
& u_{\mathrm{m} 0}=1.61 \mathrm{~kg} / \mathrm{m}^{3} \\
& u_{\mathrm{M} 0}=6.16 \mathrm{~kg} / \mathrm{m}^{3} \\
& u_{0}^{\mathrm{M}}=2.84 \mathrm{~kg} / \mathrm{m}^{3} \\
& u_{0}^{\mathrm{M}}=4.94 \mathrm{~kg} / \mathrm{m}^{3} \\
& u_{1}=6.32 \mathrm{~kg} / \mathrm{m}^{3} \\
& u_{2}=6.90 \mathrm{~kg} / \mathrm{m}^{3} \\
& u_{\mathrm{e} 1}=3.04 \mathrm{~kg} / \mathrm{m}^{3} \\
& u_{\mathrm{e}}=4.83 \mathrm{~kg} / \mathrm{m}^{3}
\end{aligned}
$$$$
u_{\mathrm{u} 0}=7.96 \mathrm{~kg} / \mathrm{m}^{3}
$$$$
u_{\mathrm{u}}=8.08 \mathrm{~kg} / \mathrm{m}^{3}
$$$$
m_{0}=43.9 \text { tonnes }
$$$$
m\left(t_{5}\right)=99.0 \text { tonnes }
$$$$
\tau_{1}=3.4 \mathrm{~h}
$$$$
t_{3} \approx 6.3 \mathrm{~h}
$$$$
\tau_{2} \approx 6.8 \mathrm{~h}
$$$$
\tau_{3} \approx 6.9 \mathrm{~h}
$$$$
t_{5} \approx 37 \mathrm{~h}
$$

A numerical simulation is shown in Figure 37.

\subsection{AdDITIONAL OPERATING CHARTS FOR STEP RESPONSES}

As we have seen above, the qualitatively different transient behaviours of step responses from optimal operation can be classified in terms of the operating chart in Figure 3. In this section we sum up the general features and present how quantitative information can be added onto this chart. In order to do this we define the following variables. As functions of the feed point $\left(u_{\mathrm{f}}, s\right)$ we define the characteristic time point

- $T$ as the time point at which the new steady state begins.

- $T_{\mathrm{u}}$ as the first time point when the underflow concentration changes.

- $T_{\mathrm{cl}}$ as the first time point when the concentration in the clarification zone is nonzero.

- $T_{\mathrm{o}}$ as the first time point when the effluent concentration is nonzero, that is, overflow occurs.

Some common properties for all step responses can be drawn directly from the solutions presented above.

THEOREM 4.1. Given a settler in optimal operation in steady state and a step change in the feed variables from $\left(u_{\mathrm{f} 0}, s_{0}\right) \in p \cup \ell_{2} \cup \ell_{3}$ to $\left(u_{\mathrm{f}}, s\right)$. Then the following holds: 


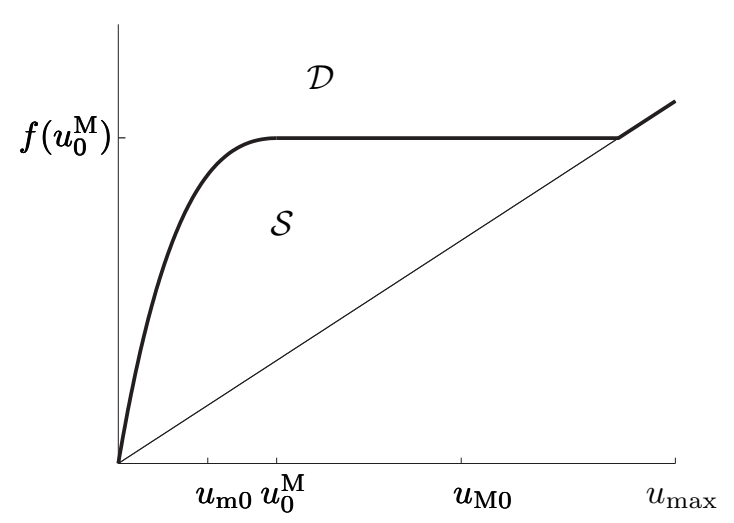

Figure 38. The 'safe' and 'dangerous' regions of the operating chart with respect to whether optimal operation is maintained or not after a step response.

- The solution is independent of $u_{\mathrm{f} 0}$.

- If $\left(u_{\mathrm{f}}, s\right) \in p \cup \ell_{2} \cup \ell_{3}$, then $u(x, t)=u(x, 0), t>0$, i.e., the solution is unchanged.

- The settler leaves the state of optimal operation immediately if and only if $\left(u_{\mathrm{f}}, s\right) \in$ $\mathcal{D} \equiv \mathcal{O}_{1} \cup \ell_{5} \cup \mathcal{O}_{2 \mathrm{~b}} \cup \mathcal{O}_{2 \mathrm{c}} \cup \mathcal{O}_{3 \mathrm{~b}} \cup \mathcal{O}_{3 \mathrm{c}} \cup \ell_{4 \mathrm{~b}} \cup \mathcal{U}_{2 \mathrm{~b}}$, see Figure 38. If $Q_{\mathrm{u}}<\bar{Q}_{\mathrm{u}}$ and $\left(u_{\mathrm{f}}, s\right) \in \mathcal{S} \equiv \mathcal{C D}=\mathcal{O}_{2 \mathrm{a}} \cup \mathcal{O}_{3 \mathrm{a}} \cup \ell_{4 \mathrm{a}} \cup \mathcal{U}_{2 \mathrm{a}} \cup \ell_{1} \cup \mathcal{U}_{1} \cup \ell_{2} \cup \ell_{3}$, then the settler stays in optimal operation for a while.

- If $\left(u_{\mathrm{f}}, s\right) \in \ell_{5} \cup \mathcal{O}_{2} \cup \ell_{2} \cup \ell_{3}$, then the solution in the region below the $S B L, x_{\mathrm{sb} 0}<$ $x<D$, and the underflow concentration are unchanged. If $\left(u_{\mathrm{f}}, s\right) \notin \ell_{5} \cup \mathcal{O}_{2} \cup \ell_{2} \cup \ell_{3}$, then the underflow concentration makes exactly one jump, at the finite and non-zero time point $t=T_{\mathrm{u}}$, from $u_{\mathrm{u} 0}=s_{0} / q_{\mathrm{u} 0}$ to the constant final concentration

$$
u_{\mathrm{u}}= \begin{cases}s / q_{\mathrm{u}}, & \text { if }\left(u_{\mathrm{f}}, s\right) \in \ell_{1} \cup \mathcal{U}_{1} \cup \mathcal{U}_{2} \cup \ell_{4} \\ f\left(u_{\mathrm{f}}\right) / q_{\mathrm{u}}, & \text { if } \quad\left(u_{\mathrm{f}}, s\right) \in \mathcal{O}_{1} \cup \mathcal{O}_{3} .\end{cases}
$$

\subsubsection{Transition to underloaded or critically loaded settler}

Transitions between two steady states from optimal operation to an underloaded state are described in Sections 4.2 and 4.8. We have seen that transitions to a critically loaded settler with the new feed point in $\ell_{1}$ or $\ell_{4}$ show the same type of solution as in the cases $\mathcal{U}_{1}$ and $\mathcal{U}_{2}$, respectively. For any of these transitions the clarification zone is unchanged. If the feed point moves within $\ell_{2} \cup \ell_{3}$, the initial steady-state solution is unchanged. Despite the qualitatively different solutions that may occur within the thickening zone, the common properties are gathered in the following theorem, cf. Figure 39.

THEOREM 4.2. Given a settler in optimal operation in steady state and a step change of the feed point to $\left(u_{\mathrm{f}}, s\right) \in \ell_{1} \cup \mathcal{U}_{1} \cup \mathcal{U}_{2} \cup \ell_{4}$ at $t=0$. Then, as functions on this region, the new concentration in the thickening zone $u_{\mathrm{th}}$, the new mass $m$ and the characteristic time points satisfy

$$
f\left(u_{\mathrm{th}}\right)=s \quad \text { with } \quad \begin{cases}u_{\mathrm{th}}<u_{\mathrm{m} 0}, & s<s_{0} \\ u_{\mathrm{th}}>u_{\mathrm{M} 0}, & s>s_{0}\end{cases}
$$




$$
\begin{aligned}
& m=A D u_{\mathrm{th}}\left\{\begin{array}{l}
<A D u_{\mathrm{m} 0}<m_{0}, \quad s<s_{0} \\
>A D u_{\mathrm{M} 0}>m_{0}, \quad s>s_{0}
\end{array},\right. \\
& \frac{\partial m}{\partial u_{\mathrm{f}}}=0, \quad \frac{\partial m}{\partial s}>0, \\
& T=T_{\mathrm{u}}=\frac{\Delta m}{A \Delta s}=\frac{m-m_{0}}{A\left(s-s_{0}\right)}, \\
& \frac{\partial T}{\partial u_{\mathrm{f}}}=0, \quad \frac{\partial T}{\partial s} \gtrless 0 \quad \text { for } s \lessgtr s_{0}, \\
& T(u, y) \rightarrow \infty \quad \text { as } \quad(u, y) \rightarrow\left(u_{\mathrm{f}}, s_{0}\right) .
\end{aligned}
$$

Proof. Properties (36), (37) and (38) follow from the analytical solutions in Sections 4.2 and 4.8. Since $u_{\text {th }}$ is defined implicitly by (36) it follows that $u_{\mathrm{th}}, m$ and $T$ are independent of $u_{\mathrm{f}}$. Differentiation of (37) and (36) with respect to $s$ yields

$$
\frac{\partial m}{\partial s}=A D \frac{\partial u_{\mathrm{th}}}{\partial s}=\frac{A D}{f^{\prime}\left(u_{\mathrm{th}}\right)}>0 .
$$

Equation (36) also implies that $s \nearrow s_{0} \Leftrightarrow u_{\mathrm{th}} \nearrow u_{\mathrm{m} 0}$ and $s \searrow s_{0} \Leftrightarrow u_{\mathrm{th}} \searrow u_{\mathrm{M} 0}$. This property implies that the numerator of $T(u, y)$ is bounded and has a sign such that $T(u, y) \rightarrow$ $\infty$ as $(u, y) \rightarrow\left(u_{\mathrm{f}}, s_{0}\right)$. To show the properties of

$$
\frac{\partial T}{\partial s}=\frac{1}{A\left(s-s_{0}\right)} \frac{\partial m}{\partial s}-\frac{m-m_{0}}{A\left(s-s_{0}\right)}=\frac{1}{s-s_{0}}\left(\frac{D}{f^{\prime}\left(u_{\mathrm{th}}\right)}-T\right)
$$

we rewrite and estimate

$$
\begin{aligned}
& T=\frac{A D u_{\mathrm{th}}-A\left(x_{\mathrm{sb} 0} u_{\mathrm{m} 0}+\left(D-x_{\mathrm{sb} 0}\right) u_{\mathrm{M} 0}\right)}{A\left(s-s_{0}\right)}= \\
& =\frac{D\left(u_{\mathrm{th}}-u_{\mathrm{m} 0}\right)}{f\left(u_{\mathrm{th}}\right)-f\left(u_{\mathrm{M} 0}\right)}+\frac{\left(D-x_{\mathrm{sb} 0}\right)\left(u_{\mathrm{M} 0}-u_{\mathrm{m} 0}\right)}{s-s_{0}}> \\
& \quad>\frac{D\left(u_{\mathrm{th}}-u_{\mathrm{m} 0}\right)}{f\left(u_{\mathrm{th}}\right)-f\left(u_{\mathrm{M} 0}\right)}>\frac{D}{f^{\prime}\left(u_{\mathrm{th}}\right)}, \quad s<s_{0},
\end{aligned}
$$

where the last inequality follows from the concavity of $f(u)$ for $u<u_{\mathrm{m} 0}$ (recall that $f\left(u_{\mathrm{M} 0}\right)=$ $\left.f\left(u_{\mathrm{m} 0}\right)\right)$. Similarly, the convexity of $f(u)$ for $u>u_{\mathrm{M} 0}$ yields

$$
T=\frac{D\left(u_{\mathrm{th}}-u_{\mathrm{M} 0}\right)+x_{\mathrm{sb} 0}\left(u_{\mathrm{M} 0}-u_{\mathrm{m} 0}\right)}{f\left(u_{\mathrm{th}}\right)-f\left(u_{\mathrm{M} 0}\right)}>\frac{D\left(u_{\mathrm{th}}-u_{\mathrm{M} 0}\right)}{f\left(u_{\mathrm{th}}\right)-f\left(u_{\mathrm{M} 0}\right)}>\frac{D}{f^{\prime}\left(u_{\mathrm{th}}\right)}, \quad s>s_{0} .
$$

The sign property of $\partial T / \partial s$ shows that the further away from $s_{0}$ the new feed flux $s$ is, the shorter is the time to reach the new steady state, see Figure 39.

\subsubsection{Transition to overloaded settler}

When the feed point makes a step change to $\mathcal{O}_{1} \cup \mathcal{O}_{3}$ there will be a period during which both the clarification and thickening zones undergo transient behaviour and reach steady state at different time points. If $\left(u_{\mathrm{f}}, s\right) \in \ell_{5} \cup \mathcal{O}_{2}$, only the clarification zone is changed (Theorem 4.1). If $\left(u_{\mathrm{f}}, s\right) \in \mathcal{O}_{2 \mathrm{~b}} \cup \mathcal{O}_{2 \mathrm{c}} \cup \mathcal{O}_{3 \mathrm{c}}$, there is a possible interaction of two discontinuities in the clarification zone and it is not always possible to obtain an explicit formula for the time point 

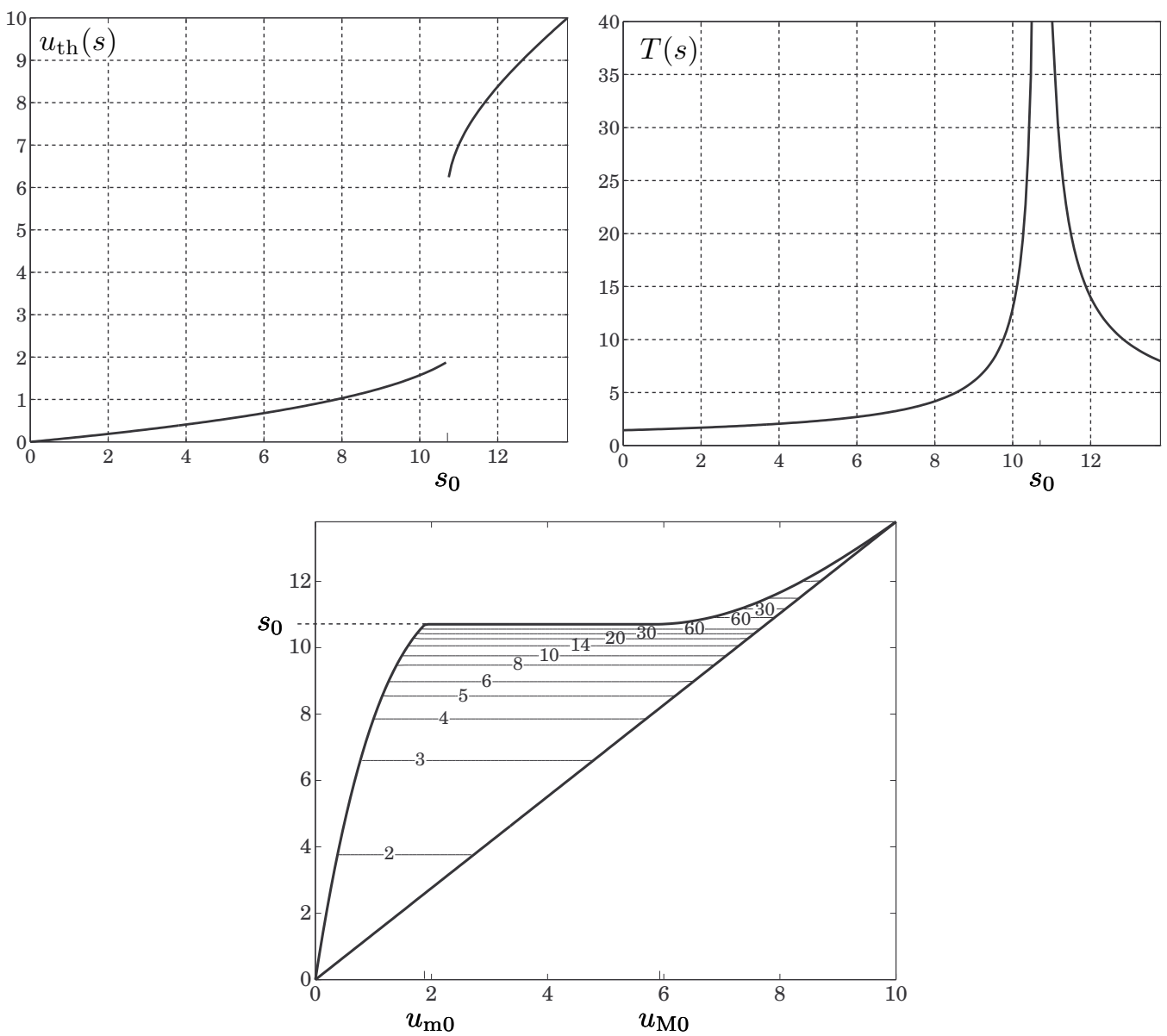

Figure 39. Operating charts for the transition to $\ell_{1} \cup \mathcal{U}_{1} \cup \mathcal{U}_{2} \cup \ell_{4}$ (Theorem 4.2) with the example value $s_{0}=10.71 \mathrm{~kg} /\left(\mathrm{m}^{2} \mathrm{~h}\right)$; cf. Section 4.8.2. Upper left: The new (constant) concentration in the thickening zone as a function of $s$ within the region shown in the lower diagram. Upper right: The time (in hours) to reach the new steady state. (Note that this information is also contained in the lower diagram.) Lower: The horizontal straight lines are contours of $T\left(u_{\mathrm{f}}, s\right)$ and the labels show the time in hours to reach the new steady state.

at which overflow occurs. The mass increases during the transient if $\left(u_{\mathrm{f}}, s\right) \in \ell_{5} \cup \mathcal{O}_{2} \cup \mathcal{O}_{3}$. For a transition to $\mathcal{O}_{1}$, if $\Delta s>0$, the mass first increases and then decreases to a new lower value than the initial one. The properties of the characteristic time points for the respective region are given in the following theorem. In the cases when there is more than one discontinuity in the clarification zone the (constant) speed $\sigma>0$ of the first rising discontinuity is given instead of properties on $T_{\mathrm{o}}$. For those cases where $T_{\mathrm{o}}$ is given, the relation $\sigma=H / T_{\mathrm{o}}$ holds.

THEOREM 4.3. Given a settler in optimal operation in steady state and a step change of the feed point to $\left(u_{\mathrm{f}}, s\right) \in \mathcal{O}_{1} \cup \ell_{5} \cup \mathcal{O}_{2} \cup \mathcal{O}_{3}$. Then the following holds for the characteristic time points and $\sigma$ as functions of $\left(u_{\mathrm{f}}, s\right)$ in the respective region (the derivatives refer to the interior of the regions except for $\left.\ell_{5}\right)$ :

$$
\begin{aligned}
\mathcal{O}_{1} \cup \mathcal{O}_{3 \mathrm{~b}}: & T_{\mathrm{cl}}=0, \quad T=\max \left(T_{\mathrm{o}}, T_{\mathrm{u}}\right), \quad T_{\mathrm{o}}=\frac{H u_{\mathrm{f}}}{s-f\left(u_{\mathrm{f}}\right)}, \quad \frac{\partial T_{\mathrm{o}}}{\partial u_{\mathrm{f}}}>0, \quad \frac{\partial T_{\mathrm{o}}}{\partial s}<0, \\
& T_{\mathrm{o}}(u, y) \rightarrow \infty \quad \text { as } \quad(u, y) \rightarrow\left(u_{\mathrm{f}}, f\left(u_{\mathrm{f}}\right)\right)
\end{aligned}
$$




$$
\begin{aligned}
& T_{\mathrm{u}}=\frac{m_{0}-A D u_{\mathrm{f}}}{A\left(s_{0}-f\left(u_{\mathrm{f}}\right)\right)}, \quad \frac{\partial T_{\mathrm{u}}}{\partial s}=0 \\
& \ell_{5}: \quad T_{\mathrm{cl}}=0, \quad T=T_{\mathrm{o}}, \quad T_{\mathrm{u}}=\infty, \quad T_{\mathrm{o}}=\frac{H u_{\mathrm{m} 0}}{s-f\left(u_{\mathrm{m} 0}\right)}, \quad \frac{d T_{\mathrm{o}}}{d s}<0, \\
& \mathcal{O}_{2 \mathrm{a}}: \quad T_{\mathrm{cl}}=\frac{\int_{0}^{x_{\mathrm{sb} 0}} u\left(x, T_{\mathrm{cl}}\right) d x+\left(D-x_{\mathrm{sb} 0}\right) u_{\mathrm{M} 0}-m_{0} / A}{\Delta s}, \quad T=T_{\mathrm{u}}=\infty, \\
& T_{\mathrm{o}}=T_{\mathrm{cl}}+\frac{H u_{2}}{-g\left(u_{2}\right)} \text {, where } g\left(u_{2}\right)=s-f\left(u_{1}^{*}\right), u_{1} \leq u_{0}^{\mathrm{M}} \text { and } f\left(u_{1}\right)=s, \\
& \frac{\partial T_{\mathrm{cl}}}{\partial u_{\mathrm{f}}}=0, \quad \frac{\partial T_{\mathrm{cl}}}{\partial s}<0, \quad \frac{\partial T_{\mathrm{o}}}{\partial u_{\mathrm{f}}}>0, \\
& T_{\mathrm{cl}}(u, y) \text { and } T_{\mathrm{o}}(u, y) \rightarrow \infty \text { as }(u, y) \rightarrow\left(u_{\mathrm{f}}, s_{0}\right),
\end{aligned}
$$

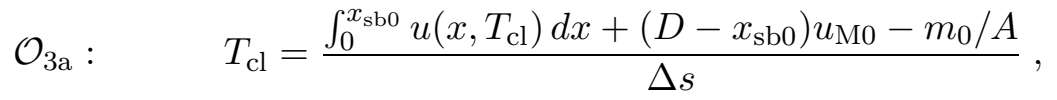

$$
\begin{aligned}
& T_{\mathrm{o}}=T_{\mathrm{cl}}+\frac{H u_{\mathrm{f}}}{s-f\left(u_{\mathrm{f}}\right)}, \quad T_{\mathrm{o}}(u, y) \rightarrow \infty \quad \text { as } \quad(u, y) \rightarrow\left(u_{\mathrm{f}}, f\left(u_{\mathrm{f}}\right)\right), \\
& T_{\mathrm{u}}=\frac{(H+D) u_{\mathrm{f}}-T_{\mathrm{o}}\left(s-f\left(u_{\mathrm{f}}\right)\right)-m_{0} / A}{f\left(u_{\mathrm{f}}\right)-s_{0}}, \quad T=\max \left(T_{\mathrm{o}}, T_{\mathrm{u}}\right), \\
& \frac{\partial T_{\mathrm{cl}}}{\partial u_{\mathrm{f}}}=0, \quad \frac{\partial T_{\mathrm{cl}}}{\partial s}<0, \quad \frac{\partial T_{\mathrm{o}}}{\partial u_{\mathrm{f}}}>0, \quad \frac{\partial T_{\mathrm{o}}}{\partial s}<0, \\
& \mathcal{O}_{2 \mathrm{~b}}: \quad T_{\mathrm{cl}}=0, \quad T_{\mathrm{o}} \leq \frac{H}{\sigma}, \quad T=T_{\mathrm{u}}=\infty, \\
& \sigma=\frac{s-f\left(u_{\mathrm{f}}\right)}{u_{\mathrm{f}}}, \quad \frac{\partial \sigma}{\partial u_{\mathrm{f}}}<0, \quad \frac{\partial \sigma}{\partial s}>0 \\
& \mathcal{O}_{2 \mathrm{c}}: \quad T_{\mathrm{cl}}=0, \quad T_{\mathrm{o}} \leq \frac{H}{\sigma}, \quad T=T_{\mathrm{u}}=\infty, \\
& \sigma=\frac{s-f\left(u_{0}^{\mathrm{M}}\right)}{u_{1}} \text { where } f\left(u_{1}\right)+s\left(1-\frac{u_{1}}{u_{\mathrm{f}}}\right)=f\left(u_{0}^{\mathrm{M}}\right), \quad \frac{\partial \sigma}{\partial u_{\mathrm{f}}}<0, \quad \frac{\partial \sigma}{\partial s}>0, \\
& \mathcal{O}_{3 \mathrm{c}}: \quad T_{\mathrm{cl}}=0, \quad T_{\mathrm{o}} \leq \frac{H}{\sigma}, \quad T_{\mathrm{u}}<\infty, \quad T=\max \left(T_{\mathrm{o}}, T_{\mathrm{u}}\right), \\
& \sigma=\frac{s-f\left(u_{0}^{\mathrm{M}}\right)}{u_{1}} \text { where } f\left(u_{1}\right)+s\left(1-\frac{u_{1}}{u_{\mathrm{f}}}\right)=f\left(u_{0}^{\mathrm{M}}\right), \quad \frac{\partial \sigma}{\partial u_{\mathrm{f}}}<0, \quad \frac{\partial \sigma}{\partial s}>0 .
\end{aligned}
$$

$\sigma\left(u_{\mathrm{f}}, s\right)$ is a continuous function on the whole overflow region. Likewise is $T_{\mathrm{cl}}\left(u_{\mathrm{f}}, s\right)$, except on the boundary between $\mathcal{O}_{2 \mathrm{a}} \cup \mathcal{O}_{3 \mathrm{a}}$ and $\mathcal{O}_{2 \mathrm{~b}} \cup \mathcal{O}_{2 \mathrm{c}} \cup \mathcal{O}_{3 \mathrm{c}}$.

Proof. Most of the formulae can be found in Section 4. The evolution of the mass is qualitatively the same in $\mathcal{O}_{1}, \mathcal{O}_{3 \mathrm{a}}$ and $\mathcal{O}_{3 \mathrm{~b}}$. In those cases (33) holds with $T_{\mathrm{u}}=t_{5}$ and $\tau_{1}=T_{\mathrm{o}}$ :

$$
A(H+D) u_{\mathrm{f}}=m_{0}+T_{\mathrm{o}} A\left(s-f\left(u_{\mathrm{f}}\right)\right)-T_{\mathrm{u}} A\left(s_{0}-f\left(u_{\mathrm{f}}\right)\right) .
$$

Consider $\mathcal{O}_{1} \cup \mathcal{O}_{3 \mathrm{~b}}$. We substitute the expression for $T_{\mathrm{o}}$ into (41) and obtain the formula for $T_{\mathrm{u}}$. The derivatives of $T_{\mathrm{o}}$ are

$$
\frac{\partial T_{\mathrm{o}}}{\partial u_{\mathrm{f}}}=H \frac{s-f\left(u_{\mathrm{f}}\right)+u_{\mathrm{f}} f^{\prime}\left(u_{\mathrm{f}}\right)}{\left(s-f\left(u_{\mathrm{f}}\right)\right)^{2}}>0 \quad \text { and } \quad \frac{\partial T_{\mathrm{o}}}{\partial s}=-\frac{H}{\left(s-f\left(u_{\mathrm{f}}\right)\right)^{2}}<0 .
$$


The limit for $T_{\mathrm{o}}$ is obtained directly from its expression. The properties of $\underline{\ell_{5}}$ are trivial and they can be obtained as limit cases of $\mathcal{O}_{1}$. For $\underline{\mathcal{O}}_{2 a}$ we refer to the notation of Section 4.7.1. The expression for $T_{\mathrm{cl}}=t_{3}$ is (21) and for $T_{\mathrm{o}}=t_{4}$ it is (17). To decide the signs of their partial derivatives in the interior of $\mathcal{O}_{2 \mathrm{a}}$, we start by using Lemma 2.1 and Equation (13) to obtain (note that $u_{1}<u_{0}^{\mathrm{M}}$ )

$$
\begin{gathered}
\frac{\partial u_{1}}{\partial u_{\mathrm{f}}}=0, \quad \frac{\partial u_{1}}{\partial s}=\frac{1}{f^{\prime}\left(u_{1}\right)}>0, \quad \frac{\partial u_{1}^{*}}{\partial u_{\mathrm{f}}}=\frac{d u_{1}^{*}}{d u_{1}} \frac{\partial u_{1}}{\partial u_{\mathrm{f}}}=0, \\
\frac{\partial u_{1}^{*}}{\partial s}=\frac{d u_{1}^{*}}{d u_{1}} \frac{\partial u_{1}}{\partial s}=\frac{f^{\prime}\left(u_{1}\right)-f^{\prime}\left(u_{1}^{*}\right)}{f^{\prime \prime}\left(u_{1}^{*}\right)\left(u_{1}-u_{1}^{*}\right)} \frac{\partial u_{1}}{\partial s}<0 .
\end{gathered}
$$

The time point $t_{2}$ is defined by $0=f^{\prime}\left(u_{1}\right) t_{2}-x_{3}\left(t_{2}\right)$. Differentiation of this with respect to $u_{\mathrm{f}}$ and noting that $x_{3}^{\prime}\left(t_{2}\right)=f^{\prime}\left(u_{3}^{*}\left(t_{2}\right)\right)=f^{\prime}\left(u_{1}^{*}\right)$ yields

$$
0=\frac{\partial t_{2}}{\partial u_{\mathrm{f}}}\left(f^{\prime}\left(u_{1}\right)-x_{3}^{\prime}\left(t_{2}\right)\right)=\frac{\partial t_{2}}{\partial u_{\mathrm{f}}}\left(f^{\prime}\left(u_{1}\right)-f^{\prime}\left(u_{1}^{*}\right)\right) \quad \Longrightarrow \quad \frac{\partial t_{2}}{\partial u_{\mathrm{f}}}=0
$$

hence

$$
\frac{\partial T_{\mathrm{cl}}}{\partial u_{\mathrm{f}}}=\frac{\partial t_{3}}{\partial u_{\mathrm{f}}}=\left(1+\frac{f^{\prime}\left(u_{1}\right)}{-f^{\prime}\left(u_{1}^{*}\right)}\right) \frac{\partial t_{2}}{\partial u_{\mathrm{f}}}=0 .
$$

Analogously, differentiation with respect to $s$ gives

$$
\frac{\partial t_{2}}{\partial s}=\frac{f^{\prime \prime}\left(u_{1}\right) t_{2}}{f^{\prime}\left(u_{1}^{*}\right)-f^{\prime}\left(u_{1}\right)} \frac{\partial u_{1}}{\partial s},
$$

which is strictly positive according to Lemma 2.1. Differentiation of (16) now yields

$$
\begin{gathered}
\frac{\partial T_{\mathrm{cl}}}{\partial s}=\frac{\partial t_{3}}{\partial s}=-\frac{f^{\prime \prime}\left(u_{1}\right)}{f^{\prime}\left(u_{1}^{*}\right)} \frac{\partial u_{1}}{\partial s} t_{2}+\frac{f^{\prime}\left(u_{1}\right) f^{\prime \prime}\left(u_{1}^{*}\right)}{f^{\prime}\left(u_{1}^{*}\right)^{2}} \frac{\partial u_{1}^{*}}{\partial s} t_{2}+\frac{f^{\prime}\left(u_{1}^{*}\right)-f^{\prime}\left(u_{1}\right)}{f^{\prime}\left(u_{1}^{*}\right)} \frac{\partial t_{2}}{\partial s}= \\
\stackrel{(42)}{=}-\frac{f^{\prime \prime}\left(u_{1}\right)}{f^{\prime}\left(u_{1}^{*}\right)} \frac{\partial u_{1}}{\partial s} t_{2}+\frac{f^{\prime}\left(u_{1}\right) f^{\prime \prime}\left(u_{1}^{*}\right)}{f^{\prime}\left(u_{1}^{*}\right)^{2}} \frac{\partial u_{1}^{*}}{\partial s} t_{2}+\frac{f^{\prime \prime}\left(u_{1}\right) t_{2}}{f^{\prime}\left(u_{1}^{*}\right)} \frac{\partial u_{1}}{\partial s}= \\
=\frac{f^{\prime}\left(u_{1}\right) f^{\prime \prime}\left(u_{1}^{*}\right)}{f^{\prime}\left(u_{1}^{*}\right)^{2}} \frac{\partial u_{1}^{*}}{\partial s} t_{2}<0
\end{gathered}
$$

since $f^{\prime}\left(u_{1}\right)>0$ and $f^{\prime \prime}\left(u_{1}^{*}\right)>0$. To investigate the monotonicity properties of $T_{\mathrm{o}}$ we need to know more about $u_{2}$, which is defined by (14). Note that $g$ changes with the operating point, since $q_{\mathrm{e}}$ does via $s=\left(q_{\mathrm{u}}+q_{\mathrm{e}}\right) u_{\mathrm{f}}$. Therefore, we can replace $g(u)$ by

$$
g(u)=f_{\mathrm{b}}(u)-q_{\mathrm{e}} u=f_{\mathrm{b}}(u)-\left(\frac{s}{u_{\mathrm{f}}}-q_{\mathrm{u}}\right) u=f(u)-\frac{s u}{u_{\mathrm{f}}}
$$

in (14) to obtain

$$
f\left(u_{1}^{*}\right)=f\left(u_{2}\right)-\frac{s u_{2}}{u_{\mathrm{f}}}+s .
$$

Differentiation of this equation with respect to $u_{\mathrm{f}}$ yields

$$
0=f^{\prime}\left(u_{2}\right) \frac{\partial u_{2}}{\partial u_{\mathrm{f}}}-\frac{s}{u_{\mathrm{f}}} \frac{\partial u_{2}}{\partial u_{\mathrm{f}}}+\frac{s u_{2}}{u_{\mathrm{f}}^{2}} \Longleftrightarrow \frac{\partial u_{2}}{\partial u_{\mathrm{f}}}=\frac{s u_{2}}{u_{\mathrm{f}}^{2}\left(s / u_{\mathrm{f}}-f^{\prime}\left(u_{2}\right)\right)} \stackrel{(43)}{=} \frac{s u_{2}}{u_{\mathrm{f}}^{2}\left(-g^{\prime}\left(u_{2}\right)\right)}>0 .
$$


(Note that $g^{\prime}\left(u_{2}\right)<0$, since $u_{2}>u_{\mathrm{z}}$, which in turn follows from (14); $0<f\left(u_{1}\right)-f\left(u_{1}^{*}\right)=$ $s-f\left(u_{1}^{*}\right)=-g\left(u_{2}\right)$.) We get

$$
\frac{\partial T_{\mathrm{o}}}{\partial u_{\mathrm{f}}}=\frac{\partial T_{\mathrm{cl}}}{\partial u_{\mathrm{f}}}+H \frac{\partial}{\partial u_{\mathrm{f}}} \frac{u_{2}}{s-f\left(u_{1}^{*}\right)}=0+\frac{H}{s-f\left(u_{1}^{*}\right)} \frac{\partial u_{2}}{\partial u_{\mathrm{f}}}>0 .
$$

Regarding the limits of $T_{\mathrm{cl}}$ and $T_{\mathrm{O}}$ as $s$ approaches $s_{0}$, we first note that the numerators are bounded since any solution takes values in $\left[0, u_{\max }\right]$, see [26]. Independently of $u_{\mathrm{f}}, s \searrow s_{0}$ implies that the denominator of $T_{\mathrm{cl}}$ approaches zero and that $0<-g\left(u_{2}\right)=s-f\left(u_{1}^{*}\right) \rightarrow s_{0}-$ $f\left(u_{\mathrm{M} 0}\right)=0$, since $s \searrow s_{0} \Rightarrow u_{1} \searrow u_{\mathrm{m} 0} \Leftrightarrow u_{1}^{*} \nearrow u_{\mathrm{M} 0}$. Consider $\mathcal{O}_{3 \mathrm{a}}$ and Section 4.10.1. $T_{\mathrm{cl}}$ is the same as in $\mathcal{O}_{2 \mathrm{a}}$ and the time $\left(T_{\mathrm{o}}-T_{\mathrm{cl}}\right)$ for the discontinuity in the clarification zone to reach the effluent level is the same as in $\mathcal{O}_{1} \cup \mathcal{O}_{3 \mathrm{~b}}$. Hence the properties of the derivatives follow. The formula for $T_{\mathrm{u}}$ follows from (41). For $\mathcal{O}_{2 \mathrm{~b}}$ the speed $\sigma$ of the rising discontinuity is the same as in $\mathcal{O}_{1} \cup \mathcal{O}_{3 \mathrm{~b}}\left(\sigma=H / T_{\mathrm{o}}\right)$ and the derivatives therefore follow directly. The cases $\mathcal{O}_{2 \mathrm{c}} \cup \mathcal{O}_{3 \mathrm{c}}$ are covered in Sections 4.7.4, 4.10.4 and 4.10.5. We need the partial derivatives of $u_{1}$. With (43) Equation (25) can be written as

$$
f\left(u_{0}^{\mathrm{M}}\right)=g\left(u_{1}\right)+s=f\left(u_{1}\right)+s\left(1-\frac{u_{1}}{u_{\mathrm{f}}}\right) .
$$

Differentiation gives

$$
\begin{aligned}
& \frac{\partial u_{1}}{\partial u_{\mathrm{f}}}=\frac{s u_{1}}{u_{\mathrm{f}}^{2}\left(s / u_{\mathrm{f}}-f^{\prime}\left(u_{1}\right)\right)}=\frac{s u_{1}}{u_{\mathrm{f}}^{2}\left(-g^{\prime}\left(u_{1}\right)\right)}>0, \\
& \frac{\partial u_{1}}{\partial s}=\frac{u_{\mathrm{f}}-u_{1}}{u_{\mathrm{f}}^{2}\left(s / u_{\mathrm{f}}-f^{\prime}\left(u_{1}\right)\right)}=\frac{s u_{1}}{u_{\mathrm{f}}^{2}\left(-g^{\prime}\left(u_{1}\right)\right)}>0 .
\end{aligned}
$$

Hence

$$
\begin{aligned}
\frac{\partial \sigma}{\partial u_{\mathrm{f}}} & =-\frac{s-f\left(u_{0}^{\mathrm{M}}\right)}{u_{1}^{2}} \frac{\partial u_{1}}{\partial u_{\mathrm{f}}}<0, \\
\frac{\partial \sigma}{\partial s} & =\frac{1}{u_{1}^{2}}\left(u_{1}-\left(s-f\left(u_{0}^{\mathrm{M}}\right)\right) \frac{\partial u_{1}}{\partial s}\right) .
\end{aligned}
$$

To prove that this is positive, we first use the fact that $u_{0}^{\mathrm{M}}<u_{1}<u_{\mathrm{f}}<u_{\mathrm{M} 0}$ implies that $f^{\prime}\left(u_{1}\right)<0$. Hence $f\left(u_{1}\right)>0>u_{1} f^{\prime}\left(u_{1}\right)$ holds, which we use to estimate the positive term

$$
\begin{aligned}
\left(s-f\left(u_{0}^{\mathrm{M}}\right)\right) \frac{\partial u_{1}}{\partial s} \stackrel{(44)}{=}\left(\frac{s u_{1}}{u_{\mathrm{f}}}\right. & \left.-f\left(u_{1}\right)\right) \frac{u_{\mathrm{f}}-u_{1}}{u_{\mathrm{f}}^{2}\left(s / u_{\mathrm{f}}-f^{\prime}\left(u_{1}\right)\right)} \\
< & \left(\frac{s u_{1}}{u_{\mathrm{f}}}-u_{1} f^{\prime}\left(u_{1}\right)\right) \frac{u_{\mathrm{f}}-u_{1}}{u_{\mathrm{f}}^{2}\left(s / u_{\mathrm{f}}-f^{\prime}\left(u_{1}\right)\right)}=u_{1}-\frac{u_{1}^{2}}{u_{\mathrm{f}}}<u_{1} .
\end{aligned}
$$

It follows that $\partial \sigma / \partial s>0$.

Remark In $\mathcal{O}_{2 \mathrm{a}}$ the derivative $\partial T_{\mathrm{o}} / \partial s=\partial T_{\mathrm{cl}} / \partial s+H \frac{\partial}{\partial s}\left(\frac{u_{2}}{-g\left(u_{2}\right)}\right)$ is always negative in the lower part of the region and usually in the whole region (cf. Figure 42). The second term may, however, be positive for the upper part of $\mathcal{O}_{2 \mathrm{a}}$ and if $H$ is large there is a theoretical possibility for $\partial T_{\mathrm{o}} / \partial s$ to be positive there. 

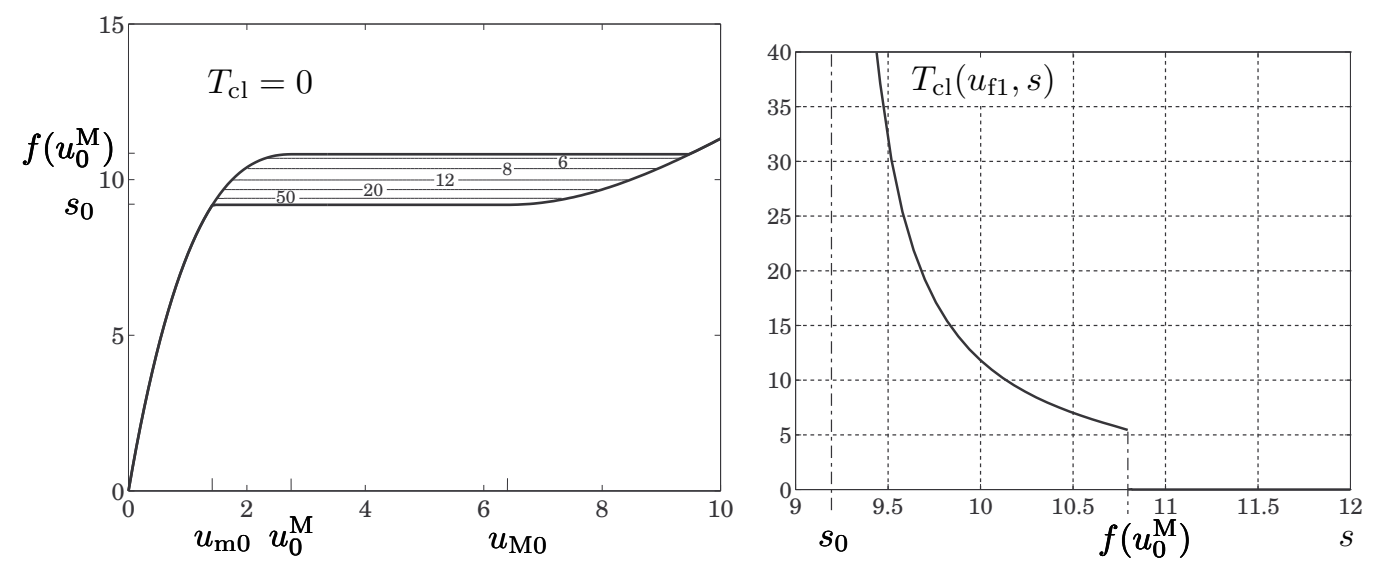

Figure 40. Left: An operating chart with contours of $T_{\mathrm{cl}}[\mathrm{h}]$ in the region $\mathcal{O}_{2 \mathrm{a}} \cup \mathcal{O}_{3 \mathrm{a}}$. Right: $T_{\mathrm{cl}}$ as a function of $s$ for a fixed $u_{\mathrm{f} 1} \in\left[u_{0}^{\mathrm{M}}, u_{\mathrm{M} 0}\right] ; s_{0}=9.2 \mathrm{~kg} /\left(\mathrm{m}^{2} \mathrm{~h}\right), Q_{\mathrm{u} 0}=3200 \mathrm{~m}^{3} / \mathrm{h}, f\left(u_{0}^{\mathrm{M}}\right)=10.8 \mathrm{~kg} /\left(\mathrm{m}^{2} \mathrm{~h}\right)$.

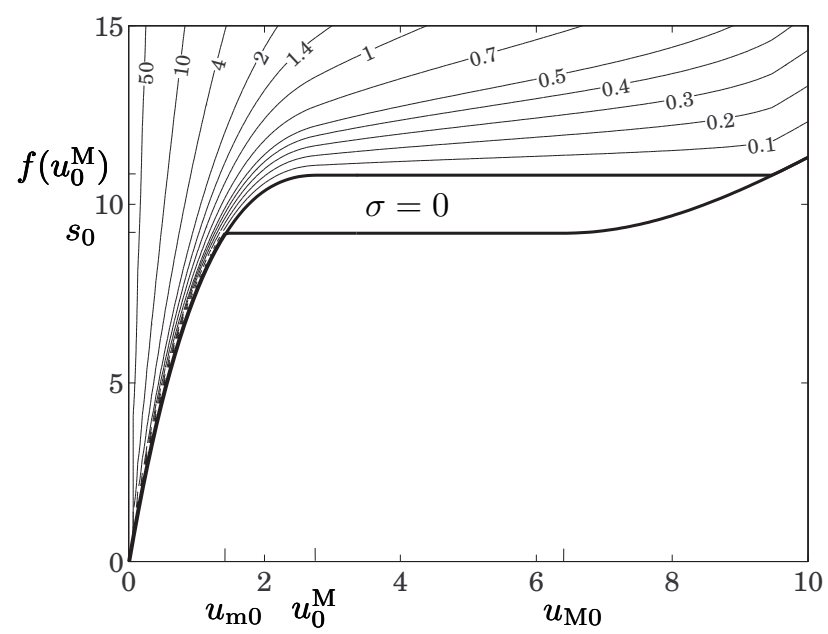

Figure 41. Contours of the speed, $\sigma\left(u_{\mathrm{f}}, s\right)[\mathrm{m} / \mathrm{h}]$, of the first rising discontinuity in the clarification zone.

The general properties given in the theorem can be enlightened graphically by operating charts. Figure 40 shows the region in which $T_{\mathrm{cl}}=0$. Note that this region fills out most of the region $\mathcal{D}$ (the rest is $\ell_{4 \mathrm{~b}} \cup \mathcal{U}_{2 \mathrm{~b}}$ ). Inside the area $\mathcal{O}_{2 \mathrm{a}} \cup \mathcal{O}_{3 \mathrm{a}}$ the approximative formula (22) has been used to obtain the contours of $T_{\mathrm{cl}}\left(u_{\mathrm{f}}, s\right)$. Note the discontinuity between this region and the region where $T_{\mathrm{cl}}=0$. Figure 41 shows the contours of the speed of the first rising discontinuity in the clarification zone. A feed point in the region where $\sigma=0\left(\mathcal{O}_{2 \mathrm{a}} \cup \mathcal{O}_{3 \mathrm{a}}\right)$ thus means that no particles are transported up into the clarification zone at $t=0$, however, there will be after a finite time at which the SBL has reached the feed level.

An operating chart for the time to overflow, $T_{\mathrm{O}}$, of a general appearance is more difficult to obtain; see Figure 42. This is because $T_{\mathrm{o}}$ depends on a possible interaction of two discontinuities (or a discontinuity and an expansion wave) in the clarification zone. This occurs if the feed point is located in the lower part of $\mathcal{O}_{2 \mathrm{~b}} \cup \mathcal{O}_{2 \mathrm{c}} \cup \mathcal{O}_{3 \mathrm{c}}$. The size of this region depends on, among others, the height $H$ of the clarification zone. We do not present (in Theorem 4.3) any explicit formula for $T_{\mathrm{O}}$ there and recommend numerical simulations of the partial differential 


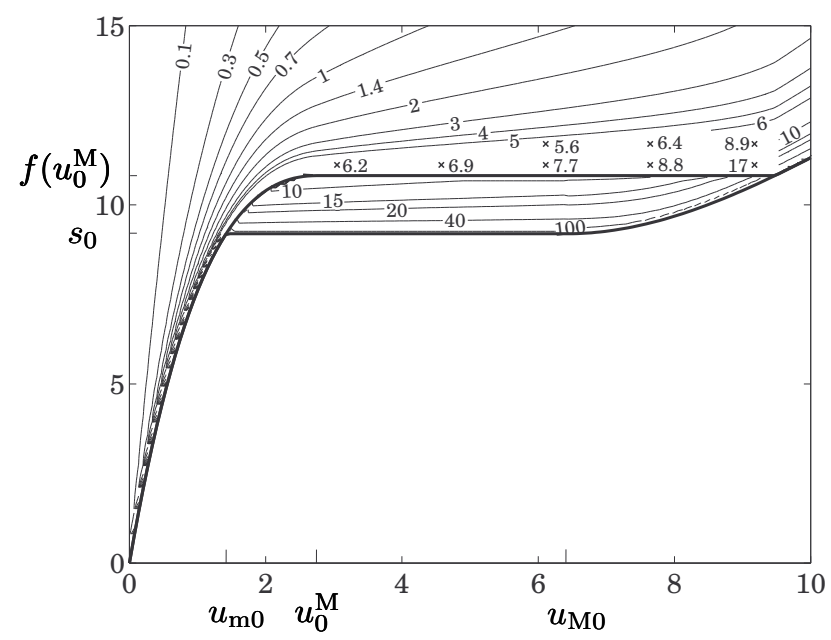

Figure 42. Contours of $T_{\mathrm{o}}\left(u_{\mathrm{f}}, s\right)[\mathrm{h}]$ and some results of numerical simulations. The latter are performed with input data at the crosses, and the corresponding solutions contain interactions in the clarifications zone between the first rising discontinuity and later rising waves after the SBL has reached the clarification zone. In the region $\mathcal{O}_{2 \mathrm{a}} \cup \mathcal{O}_{3 \mathrm{a}}$ we have used the approximate formula (22) for $T_{\mathrm{cl}}$ to compute $T_{\mathrm{o}}$.

equation (1) instead (see the crosses in Figure 42). For the upper part of $\mathcal{O}_{2 \mathrm{~b}} \cup \mathcal{O}_{2 \mathrm{c}} \cup \mathcal{O}_{3 \mathrm{c}}$ the first rising discontinuity has a sufficiently high speed $\sigma>0$ so that it reaches the effluent level, at $T_{\mathrm{o}}=H / \sigma$, without interaction with another wave. Note that $\partial T_{\mathrm{o}} / \partial s<0$ in $\mathcal{O}_{2 \mathrm{a}}$ in the example in the figure; see the remark of Theorem 4.3. The function $T_{\mathrm{o}}\left(u_{\mathrm{f}}, s\right)$ is generally not continuous on the boundary between $\mathcal{O}_{2 \mathrm{a}}$ and the rest of the overflow region. For the region with only one rising discontinuity with the speed $\sigma>0, T_{\mathrm{o}}=H / \sigma$ holds.

In a situation when the settler is going to be overloaded, the operating charts shown above are of primary interest. The time when the underflow concentration makes a jump may also be of interest, particularly, in the case $\mathcal{O}_{1} \cup \mathcal{O}_{3}$, since this jump may occur before the overflow. Therefore, we show in Figure 43 an operating chart for $T_{\mathrm{u}}$ for the overloaded region. Comparing Figures 42 and 43 we can conclude that for the majority of the overflow region an overflow will occur before the underflow concentration is changed. The exceptions are small strips above $\ell_{1}$ and $\ell_{4}$. Note that the values on the contours in these two figures depend on the chosen initial data $\left(x_{\mathrm{sb} 0}=2 \mathrm{~m}\right)$ and the size of the settler $(H=1 \mathrm{~m}, D=4 \mathrm{~m})$. The time $T_{\mathrm{o}}$ increases linearly with $H$ (except in the region with the crosses) and $T_{\mathrm{u}}$ decreases as $x_{\mathrm{sb} 0}$ approaches $D$. For example, if the SBL is close to the bottom initially and $\left(u_{\mathrm{f}}, s\right) \in \mathcal{O}_{1}$ at $t=0$, then the width of the strip above $\ell_{1}$ in which $T_{\mathrm{u}}<T_{\mathrm{o}}$ is much larger than in the example provided by Figures 42 and 43 .

\section{Conclusions}

A linear time-invariant system with two input and two output signals is uniquely determined by its response to only two (linearly independent) step inputs. For a non-linear system a step response only yields information on the system's behaviour for specific input data. Several step responses may, however, give a good understanding of the system and yield information on different regions of the two-dimensional input-data space where the system shows qualitatively different behaviours. The process of continuous sedimentation can be seen as 


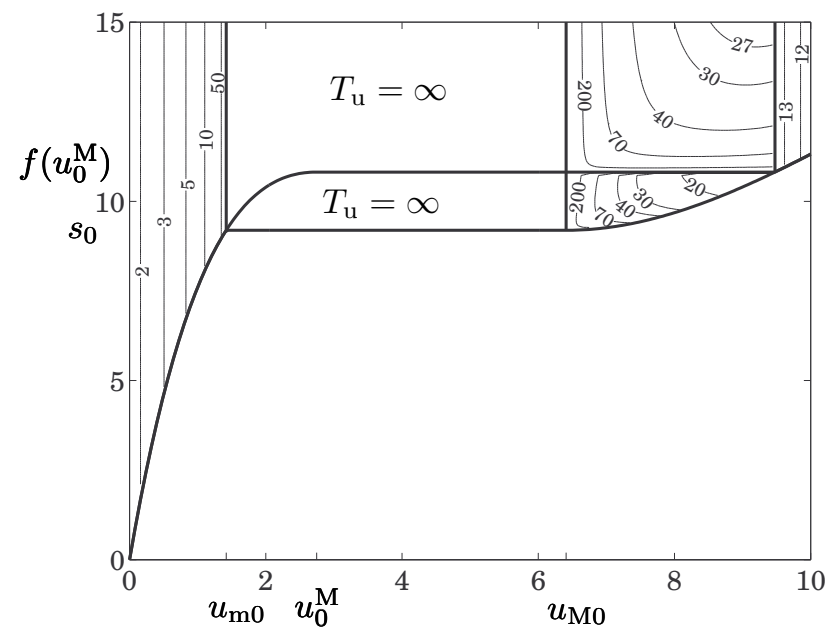

Figure 43. Contours of $T_{\mathrm{u}}\left(u_{\mathrm{f}}, s\right)[\mathrm{h}]$ for an overloaded settler and the chosen data. For the region $\mathcal{O}_{3 \mathrm{c}}$ the approximate formula (35) has been used (which utilizes (26), (27) and (28) for $\tau_{1}, \tau_{2}$ and $\tau_{3}$, respectively).

a non-linear system with two input signals, the feed concentration $u_{\mathrm{f}}$ and flow rate $Q_{\mathrm{f}}$ (or equivalently the feed flux $s=Q_{\mathrm{f}} u_{\mathrm{f}} / A$ ), and two output signals, the effluent and underflow concentrations $u_{\mathrm{e}}$ and $u_{\mathrm{u}}$, respectively. Since the process is governed by a partial differential equation, there is also an infinite number of internal state variables. The input-data space is conveniently represented by a concentration-flux operating chart, in which the central curve is the graph of the flux function $f(u)$ in the thickening zone. The location of the feed point $\left(u_{\mathrm{f}}, s\right)$ in such an operating chart (together with initial data) yields information on how the process behaves. It is such information that is presented in this and the previous paper [1] in this series.

Under normal and optimal operating conditions there is a distinct level within the thickening zone separating lower and higher concentrations. There is a natural way of defining optimal operation as a class of dynamic solutions of the governing PDE (Definition 3.1). Given that the system is in steady state with initial data corresponding to optimal operation, we have shown that there is a finite number of qualitatively different step responses. These are classified by means of the location of the feed point $\left(u_{\mathrm{f}}, s\right)$ in the operating chart in Figure 3, which is a refinement of the steady-state chart in Figure 2.

The analytically constructed and numerically demonstrated step responses reveal interesting, and perhaps not always expected, behaviour of the process. For example, if $u_{\mathrm{f}}$ varies, but the feed flux $s$ is constant ( $Q_{\mathrm{f}}$ varies), then the solution is unchanged as long as $u_{\mathrm{f}} \geq u_{\mathrm{m}}$ (Section 4.3). For a lower value of $u_{\mathrm{f}}$, the settler becomes overloaded (Section 4.5). During the transition to such an overloaded state, when $\left(u_{\mathrm{f}}, s\right) \in \mathcal{O}_{1}$ and $s>s_{0}$, the total mass increases initially and then decreases to a lower value than the initial one. During the other transitions to an overloaded settler the mass increases. For transitions to an underloaded settler the mass either increases or decreases monotonically depending on the location of the feed point.

It is well known, and confirmed in [1], that the local minimum point $u_{\mathrm{M}}$ of the flux function in the thickening zone has a great importance for the steady-state behaviour, particularly for the thickening zone. In the present paper it has been shown that the local maximum point $u^{\mathrm{M}}$ has a great importance for the dynamic behaviour, particularly in overloaded situations. This is expressed in the fact that $u^{\mathrm{M}}$ is crucial for the division into the 'dangerous' and 'safe' regions 
of the operating chart, see Figure 38. These two disjoint regions divide the step responses into two categories: either optimal operation is left immediately or at a later time. This fact is a part of Theorem 4.1, which collects all common properties of the step responses. Further detailed qualitative information on transitions to underloaded and overloaded steady states are presented in Theorems 4.2 and 4.3, respectively, which are connected to the refined operating charts of the underloaded and overloaded regions in Figures 39-43. Perhaps the most valuable information regards the region $\mathcal{O}_{2 \mathrm{a}} \cup \mathcal{O}_{3 \mathrm{a}}$, which is a part of the overflow region, but also a part of the 'safe' region. This means that the settler is going to be overloaded but stays in optimal operation for a while. The refined operating charts show when optimal operation is left as the particles reach the clarification zone, and when overflow occurs. Mathematically, these latter operating charts show contours of a quantity, for example, the time until overflow occurs, as a function of the feed point. There are at least two reasons for showing such information graphically in operating charts. Firstly, it is tedious to represent these functions. They have different representations, sometimes only implicit, in different non-rectangular regions of the chart. Secondly, operating charts give a good survey of the non-linear process and may supply direct information for an operator of a plant.

In the present paper the volume flow $Q_{\mathrm{u}}$ of the underflow is held constant. This can be used as the control parameter of the process and in the next paper we define control objectives and investigate possibilities of control of all step inputs.

Finally, we remark that the step responses in the cases $\mathcal{U}_{1}$ (Section 4.2) and $\mathcal{O}_{2 \mathrm{a}}$ (Section 4.7.1) are in qualitative agreement with the experimental ones presented by Maljian and Howell [48]: step decrease in feed concentration, see their Figures 4 and 5; step increase in feed rate $\left(Q_{\mathrm{f}}\right)$, see their Figures 6 and 7.

\section{Acknowledgement}

I am grateful to Dr Anders Holst, Centre for Mathematical Sciences, Lund University, for reading and commenting upon parts of the manuscript.

\section{References}

1. S. Diehl. Operating charts for continuous sedimentation I: Control of steady states. J. Eng. Math., 41:117144, 2001

2. G. J. Kynch. A theory of sedimentation. Trans. Faraday Soc., 48:166-176, 1952.

3. A. Jernqvist. Experimental and theoretical studies of thickeners. Part 2. Graphical calculation of thickener capacity. Svensk Papperstidning, 68:545-548, 1965.

4. Å. Jernqvist. Experimental and theoretical studies of thickeners. Part 3. Concentration distribution of the steady and unsteady state operation of thickeners. Svensk Papperstidning, 68:578-582, 1965.

5. T. M. Keinath, M. Ryckman, C. Dana, and D. Hofer. Activated sludge - unified system design and operation. J. Envir. Eng. Div., ASCE, 103(EE5):829-849, 1977.

6. V. D. Laquidara and T. M. Keinath. Mechanism of clarification failure. J. Water Pollut. Control Fed., 55(1):54-57, 1983.

7. H. Stehfest. An operational dynamic model of the final clarifier. Trans. Inst. Meas. Control, 6(3):160-164, 1984.

8. T. M. Keinath. Operational dynamics and control of secondary clarifiers. J. Water Pollut. Control Fed., 57(7):770-776, 1985.

9. B. F. Severin. Clarifier sludge-blanket behaviour at industrial activated-sludge plant. J. Environ. Eng., 117(6):718-730, 1991. 
10. N. G. Barton, C.-H. Li, and J. Spencer. Control of a surface of discontinuity in continuous thickeners. J. Austral. Math. Soc. Ser. B, 33:269-289, 1992.

11. R. Bürger and W. L. Wendland. Sedimentation and suspension flows: Historical perspective and some recent developments. J. Eng. Math., 41:101-116, 2001.

12. S. Hasselblad and S. L. Xu. Solids separation parameters for secondary clarifiers. Water Environ. Res., 70(7):1290-1294, 1998.

13. C. M. Bye and P. L. Dold. Evaluation of correlations for zone settling velocity parameters based on sludge volume index-type measures and consequences in settling tank design. Water Environ. Res., 71(7):1333$1344,1999$.

14. W. T. Manning, M. T. Garrett, and J. F. Malina. Sludge blanket response to storm surge in an activated-sludge clarifier. Water Environ. Res., 71:432-442, 1999.

15. G. Kaushik and Z. V. P. Murthy. Thickener design: The new method. Chemical Engineering World, 37:145$147,2002$.

16. B. Wett. A straight interpretation of the solids flux theory for a three-layer sedimentation model. Wat. Res., 36:2949-2958, 2002.

17. G. B. Wallis. One-dimensional Two-phase Flow. New York: McGraw-Hill, 1969. 281 pp.

18. C. A. Petty. Continuous sedimentation of a suspension with a nonconvex flux law. Chem. Eng. Sci., 30:1451$1458,1975$.

19. H. K. Rhee, R. Aris, and N. Amundson. First-Order Partial Differential Equations, volume 1. Englewood Cliffs: Prentice-Hall, 1986. 543 pp.

20. M. C. Bustos and F. Concha. On the construction of global weak solutions in the Kynch theory of sedimentation. Math. Methods Appl. Sci., 10:245-264, 1988.

21. M. C. Bustos, F. Concha, and W. Wendland. Global weak solutions to the problem of continuous sedimentation of an ideal suspension. Math. Methods Appl. Sci., 13:1-22, 1990.

22. M. C. Bustos, F. Paiva, and W. Wendland. Control of continuous sedimentation as an initial and boundary value problem. Math. Methods Appl. Sci., 12:533-548, 1990.

23. S. Diehl, G. Sparr, and G. Olsson. Analytical and numerical description of the settling process in the activated sludge operation. In R. Briggs, editor, Instrumentation, Control and Automation of Water and Wastewater Treatment and Transport Systems, pages 471-478. IAWPRC, Pergamon Press, 1990.

24. T. Gimse and N. H. Risebro. Riemann problems with a discontinuous flux function. In B. Engquist and B. Gustavsson, editors, Third International Conference on Hyperbolic Problems, Theory, Numerical Methods and Applications, volume I, pages 488-502, 1990.

25. S. Diehl. On scalar conservation laws with point source and discontinuous flux function. SIAM J. Math. Anal., 26(6):1425-1451, 1995.

26. S. Diehl. A conservation law with point source and discontinuous flux function modelling continuous sedimentation. SIAM J. Appl. Math., 56(2):388-419, 1996.

27. S. Diehl. On boundary conditions and solutions for ideal clarifier-thickener units. Chem. Eng. J., 80:119-133, 2000.

28. J.-Ph. Chancelier, M. Cohen de Lara, and F. Pacard. Analysis of a conservation PDE with discontinuous flux: A model of settler. SIAM J. Appl. Math., 54(4):954-995, 1994.

29. J.-Ph. Chancelier, M. Cohen de Lara, C. Joannis, and F. Pacard. New insight in dynamic modelling of a secondary settler - I. Flux theory and steady-states analysis. Wat. Res., 31(8):1847-1856, 1997.

30. J.-Ph. Chancelier, M. Cohen de Lara, C. Joannis, and F. Pacard. New insight in dynamic modelling of a secondary settler - II. Dynamical analysis. Wat. Res., 31(8):1857-1866, 1997.

31. R. Bürger, K. H. Karlsen, C. Klingenberg, and N. H. Risebro. A front tracking approach to a model of continuous sedimentation in ideal clarifier-thickener units. Nonl. Anal. Real World Appl., 4:457-481, 2003.

32. R. Bürger, K. H. Karlsen, N. H. Risebro, and J. D. Towers. Well-posedness in $B V_{t}$ and convergence of a difference scheme for continuous sedimentation in ideal clarifier-thickener units. Numerische Mathematik, 97:25-65, 2004.

33. K. H. Karlsen and J. D. Towers. Convergence of the lax-friedrichs scheme and stability for conservation laws with a discontinuous space-time dependent flux. Chinese Ann. Math. Ser. B., Vol. 25(3):287-318, 2004.

34. P. Garrido, R. Burgos, F. Concha, and R. Bürger. Software for the design and simulation of gravity thickeners. Miner. Eng., 16:85-92, 2003.

35. A. Zeidan, S. Rohani, and Z. Bassi. BioSys: Software for wastewater treatment simulation. Adv. Eng. Software, 34:539-549, 2003. 
36. R. Bürger, K. H. Karlsen, N. H. Risebro, and J. D. Towers. On a model for continuous sedimentation in vessels with discontinuously varying cross-sectional area. In T.Y. Hou and E. Tadmor, editors, Hyperbolic Problems: Theory, Numerics, Applications. Proceedings of the Ninth International Conference on Hyperbolic Problems Held in CalTech, Pasadena, March 25-29, 2002, pages 397-406. Springer Verlag Berlin, 2003.

37. R. Bürger, J. J. R. Damasceno, and K. H. Karlsen. A mathematical model for batch and continuous thickening of flocculated suspensions in vessels with varying cross-section. Int. J. Miner. Process., 73:183-208, 2004.

38. R. Bürger, K. H. Karlsen, N. H. Risebro, and J. D. Towers. Numerical methods for the simulation of continuous sedimentation in ideal clarifier-thickener units. Int. J. Mineral Process., 73:209-228, 2004.

39. R. Bürger, K. H. Karlsen, N. H. Risebro, and J. D. Towers. Monotone difference approximations for the simulation of clarifier-thickener units. Comput. Vis. Sci., 6:83-91, 2004.

40. S. Berres, R. Bürger, and K.H. Karlsen. Central schemes and systems of conservation laws with discontinuous coefficients modeling gravity separation of polydisperse suspensions. J. Comp. Appl. Math., 164-165:53-80, 2004.

41. R. Bürger, K. H. Karlsen, and N. H. Risebro. A relaxation scheme for continuous sedimentation in ideal clarifier-thickener units. To appear in Computers Math. Appl.

42. R. Bürger, K. H. Karlsen, and J. D. Towers. A model of continuous sedimentation of flocculated suspensions in clarifier-thickener units. To appear in SIAM. J. Appl. Math.

43. K. H. Karlsen, N. H. Risebro, and J. D. Towers. Upwind difference approximations for degenerate parabolic convection-diffusion equations with a discontinuous coefficient. IMA J. Numer. Anal., 22:623-664, 2002.

44. K. H. Karlsen, N. H. Risebro, and J. D. Towers. $L^{1}$ stability for entropy solutions of nonlinear degenerate parabolic convection-diffusion equations with discontinuous coefficients. Skr. K. Nor. Vidensk. Selsk., 3:49 pp, 2003.

45. S. Diehl. Scalar conservation laws with discontinuous flux function: I. The viscous profile condition. Comm. Math. Phys., 176:23-44, 1996.

46. S. Diehl and N.-O. Wallin. Scalar conservation laws with discontinuous flux function: II. On the stability of the viscous profiles. Comm. Math. Phys., 176:45-71, 1996.

47. S. Diehl and U. Jeppsson. A model of the settler coupled to the biological reactor. Wat. Res., 32(2):331-342, 1998.

48. M. V. Maljian and J. A. Howell. Dynamic response of a continuous thickener to overloading and underloading. Trans. Ind. Chem. Eng., 56:55-61, 1978.

49. O. A. Oleinik. Uniqueness and stability of the generalized solution of the Cauchy problem for a quasi-linear equation. Uspekhi Mat. Nauk, 14:165-170, 1959. Amer. Math. Soc. Trans. Ser. 2, 33, (1964), pp. 285-290.

50. D. P. Ballou. Solutions to nonlinear hyperbolic Cauchy problems without convexity conditions. Trans. Amer. Math. Soc., 152:441-460, 1970.

51. S. Diehl. Operating charts for continuous sedimentation III: Control of step inputs. To appear in J. Eng. Math.

52. S. K. Godunov. A finite difference method for the numerical computations of discontinuous solutions of the equations of fluid dynamics. Mat. Sb., 47:271-306, 1959. (In Russian). 